\title{
Plasma Torch Atomizer-Igniter for Supersonic Combustion of Liquid Hydrocarbon Fuels
}

\author{
Matthew Crockett Billingsley
}

Thesis submitted to the faculty of the Virginia Polytechnic Institute and State University in partial fulfillment of the requirements

for the degree of

Master of Science

In

Mechanical Engineering

Dr. Walter F. O'Brien, Chair

Dr. Joseph A. Schetz

Dr. Clint L. Dancey

December 16, 2005

Blacksburg, VA

Keywords: supersonic, combustion, atomization, liquid hydrocarbon 


\title{
Plasma Torch Atomizer-Igniter for Supersonic Combustion of Liquid Hydrocarbon Fuels
}

\author{
Matthew C. Billingsley
}

\begin{abstract}
To realize supersonic combustion of hydrocarbons, an effective atomizer-igniter combination with the capabilities of fuel preheating, atomization, penetration, mixing, ignition and flameholding is desired. An original design concept incorporating these capabilities was built and tested at Virginia Tech, and was found to provide good penetration, effective atomization, and robust ignition and flameholding. Quiescent testing with kerosene and JP-7 provided initial performance data. The atomizer-injector design was then modified for insertion into a supersonic wind tunnel, and tested with kerosene in an unheated Mach 2.4 flow with typical freestream conditions of $T_{o}=280 \mathrm{~K}$ and $P_{o}=360 \mathrm{kPa}$. Water injection was utilized in both cases for comparison and to analyze atomization behavior.

In the quiescent environment, the regeneratively cooled plasma torch igniter was found to significantly increase electrode life while heating, atomizing, and igniting the liquid fuel. Jet breakup length was measured and characterized, and mean droplet size was estimated using an existing correlation. Several qualitative observations regarding quiescent combustion were made, including torch power effects and the process of flame formation. In the supersonic environment, the effect of fuel injection direction was analyzed. Best results were obtained when fuel was injected with a velocity component opposite to the direction of main tunnel flow. Repeatable ignition occurred in the supersonic boundary layer at the fuel stagnation location near the plasma torch plume. Direct, filtered, shadowgraph, and schlieren photographs, temperature
\end{abstract}


measurements, and visible emission spectroscopy provided evidence of combustion and the details of the flame structure.

The new atomizer-igniter design provided robust and reliable ignition and flameholding of liquid hydrocarbon fuels in an unheated supersonic flow at $M=2.4$, with no ramp, step, or other physical penetration into the flowpath. 


\section{Acknowledgements}

Dr. O'Brien, I enjoyed the relaxed lab atmosphere, and am grateful for your unique ability to promote progress without being overbearing. Thank you for recognizing my circumstances, and being flexible as I managed my young family. Thank you for the enthusiasm you show for your research; it was a privilege and a joy working with you.

I appreciate the comments and suggestions given by Dr. Schetz throughout the project; he was motivating and taught me how to be excited about my research. Darius, thanks for all your help setting up and running. The Hypersonics Branch at NASA-Langley deserves credit for the financial support of this research; thanks to Technical Monitor Mr. David Reubush. I would also like to thank Dr. Gerald Pellett of NASA, Dr. Clint Dancey of Virginia Tech, and Dr. Uri Vandsburger of Virginia Tech for their insight and advice related to this work. Thanks to the rest of my turbolab colleagues. Thanks to the Mechanical Engineering machine shop: Bill, James, Timmy, and Johnny. Thanks to Steve Edwards for hours of experimental setup as well as testing; I value your friendship. Thanks to librarians John Cosgriff and Larry Thompson.

I thank my parents, brothers and sisters, extended family, friends, and the body of Harvest Baptist Church for their support and prayer. Micah and Jason, my two sons: thank you for providing me with a wonderful atmosphere to come home to at the end of a long day. Michelle, my wife: thank you for your love and encouragement, and your desire for my success as a graduate student, father, and husband. Thank you for making this an enjoyable experience as you modeled the excellent wife. Finally and most importantly, thanks and praise to God the Father and His Son Jesus Christ. As Creator, He gives us the ability to study physical processes and to experience temporary fulfillment from our efforts. But He has provided truly meaningful and eternal fulfillment only through His atoning work on the cross as Savior. 


\section{Table of Contents}

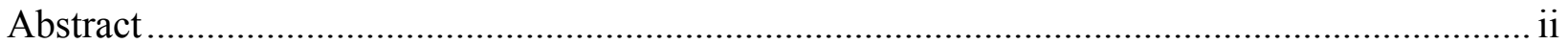

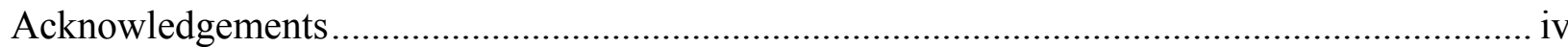

Table of Contents ...................................................................................................................

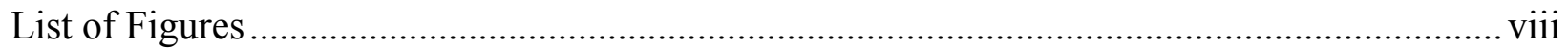

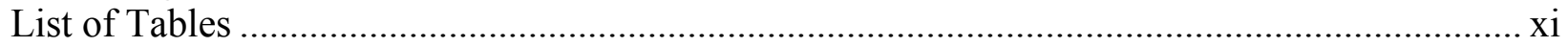

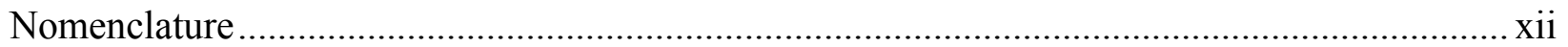

1 Introduction ............................................................................................................................ 1

1.1 Purpose and Scope of Research ........................................................................................... 1

1.2 Challenges to Supersonic Combustion …………….................................................... 1

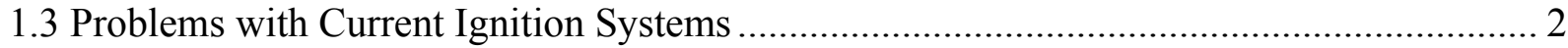

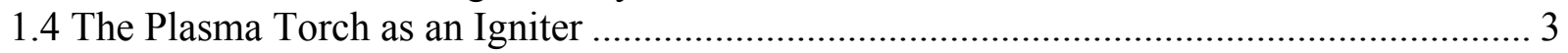

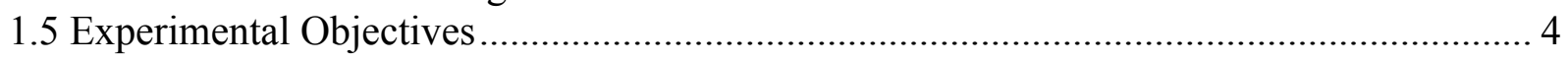

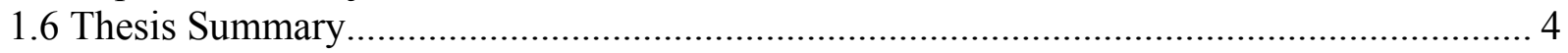

2 Background ............................................................................................................................................ 6

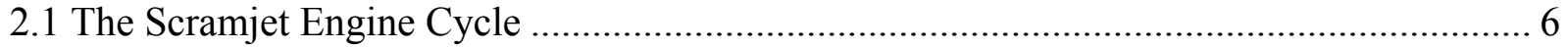

2.2 Current Trends in Hypersonic Research ......................................................................... 7

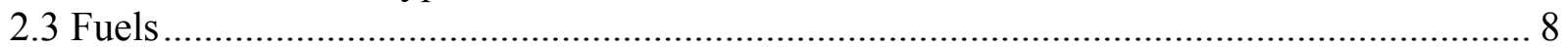

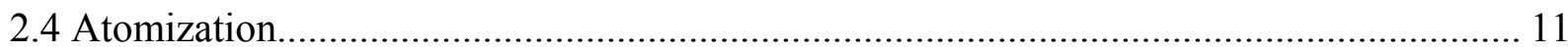

2.4.1 Liquid Jet Disintegration................................................................................. 12

2.4.2 Droplet Breakup............................................................................................ 13

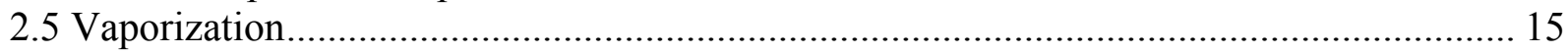

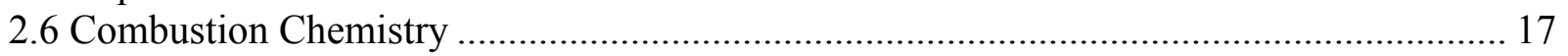

2.6.1 The Chain Reaction Mechanism........................................................................ 17

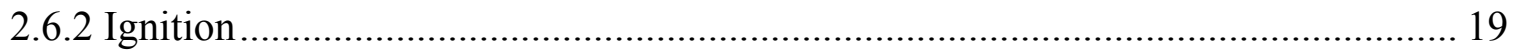

2.6.3 Steady State Combustion ................................................................................ 21

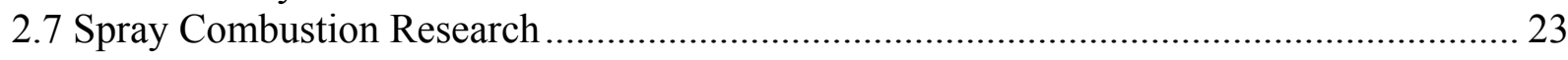

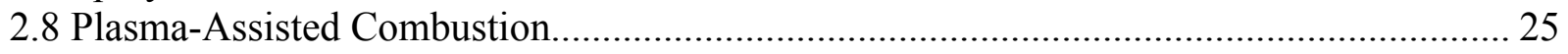

3 Experimental Equipment and Procedures ...................................................................................... 29

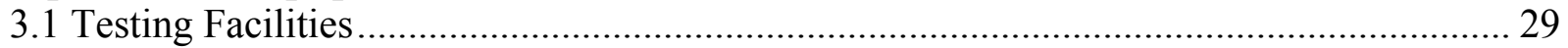

3.1.1 Quiescent Environment................................................................................ 29

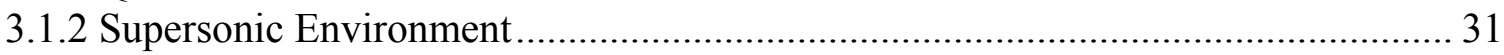

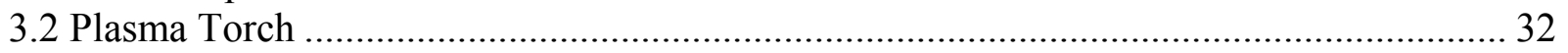

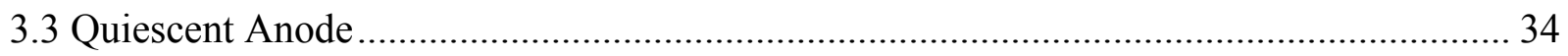

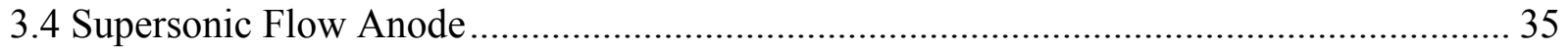

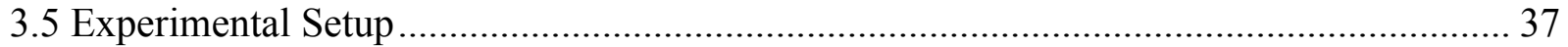

3.5.1 Plasma Torch Power Supply System ……………………………………….... 38

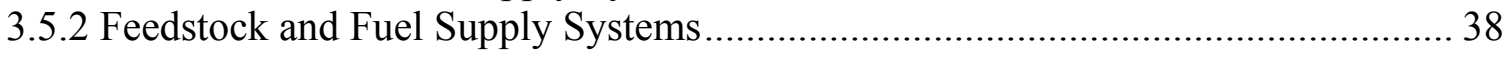

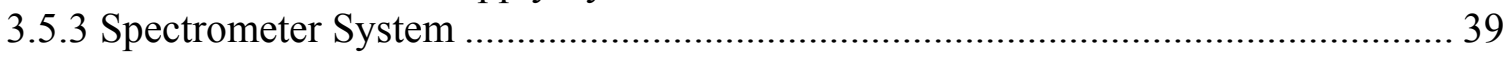

3.5.4 Data Acquisition and Instrumentation System ……………………………….... 39

4 Quiescent Results ........................................................................................................................... 42

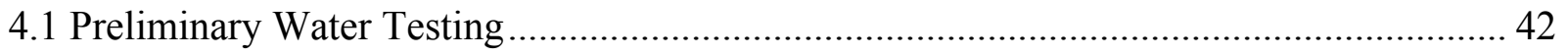




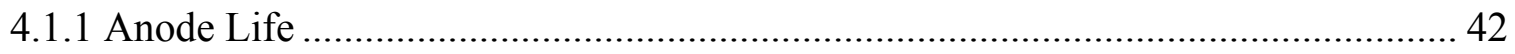

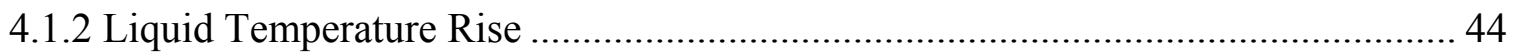

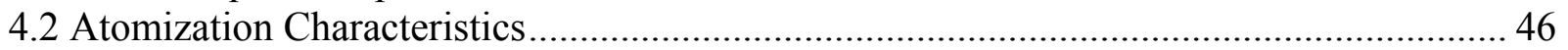

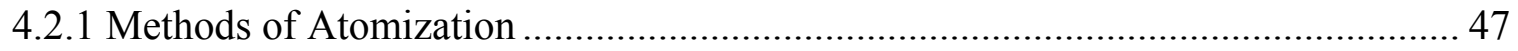

4.2.2 Qualitative Observations of Kerosene Injection Mechanics................................. 49

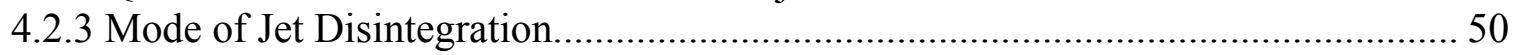

4.2.4 Droplet Breakup and Mean Drop Size ............................................................... 52

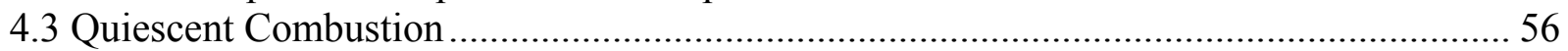

4.3.1 Qualitative Remarks on Combustion .................................................................... 56

4.3.2 Effect of Plasma Torch Power Level on Quiescent Combustion ............................. 57

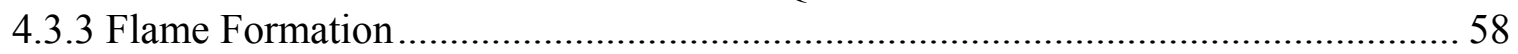

4.3.4 Flame Properties and Structure ............................................................................. 60

5 Supersonic Testing Results ................................................................................................62

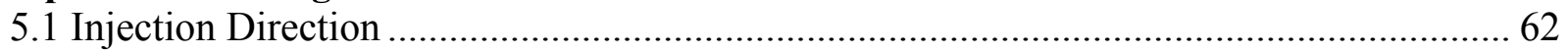

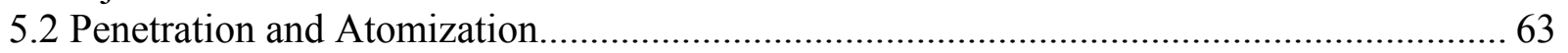

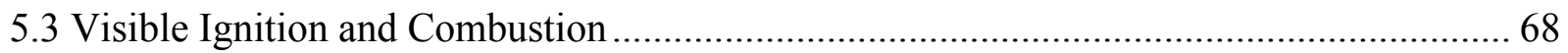

5.3.1 Water and Kerosene Combustion Comparison...................................................... 70

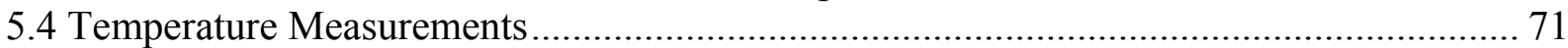

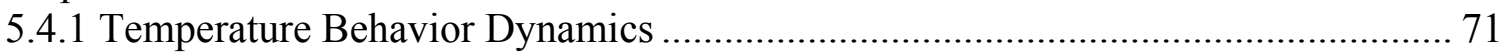

5.4.2 Time-Dependent Temperature Behavior ............................................................. 73

5.4.3 Total Temperature Profiles ............................................................................ 76

5.4.4 Effect of Injection Pressure on Total Temperature............................................... 79

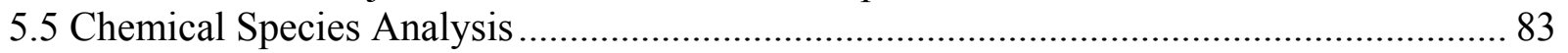

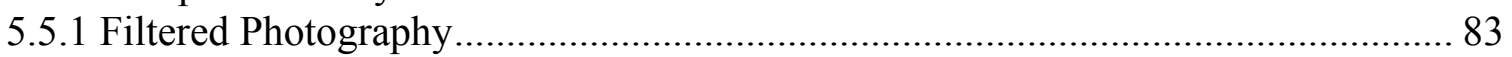

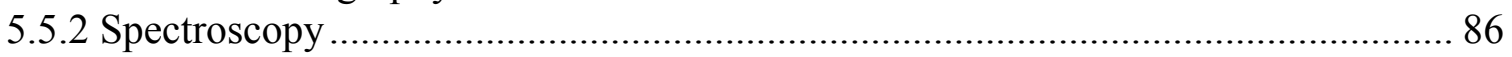

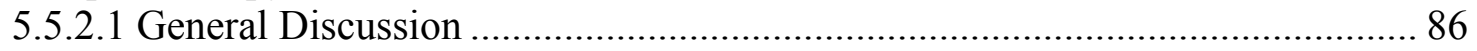

5.5.2.2 Emission Spectrum Characteristics............................................................. 87

5.5.2.3 Chemiluminescence Profiles......................................................................... 92

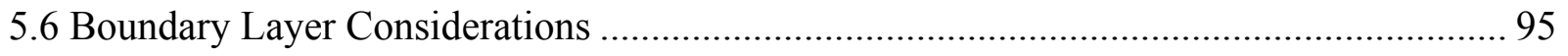

6 Conclusions and Recommendations........................................................................................ 98

6.1 Summary of Quiescent Testing Conclusions ................................................................ 98

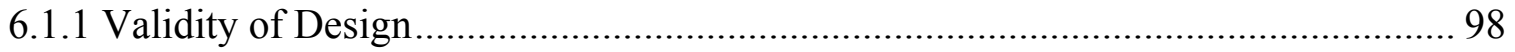

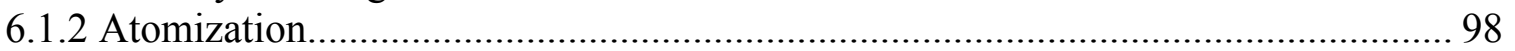

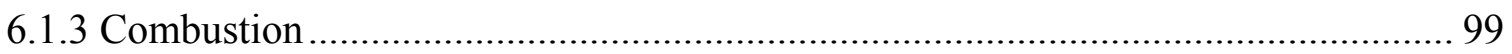

6.2 Summary of Supersonic Testing Conclusions ................................................................ 99

6.2.1 Injection, Penetration, and Atomization …………................................................ 99

6.2.2 Visible Evidence of Combustion ………………................................................... 99

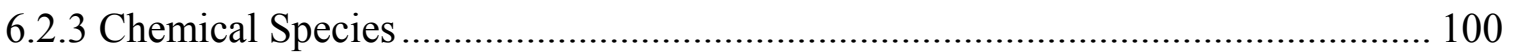

6.2.4 Temperature Measurements......................................................................... 100

6.3 Recommendations for Further Research...................................................................... 101

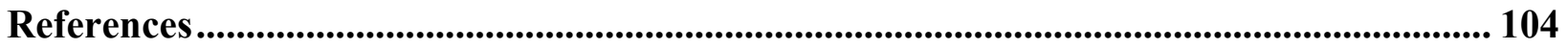

Appendix A: Photographic Techniques Used in Supersonic Testing....................................... 110

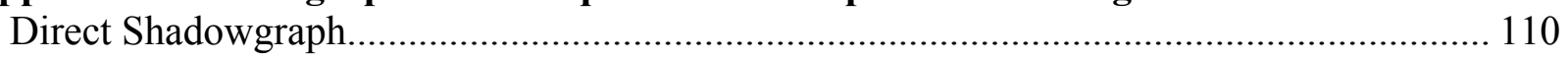


Focused Shadowgraph .......................................................................................... 111

Schlieren (with virtual image of plasma torch superimposed) ...................................... 112

Appendix B: Derivation of Conservation Equations for Plug-Flow Reactor (PFR) ......... 114

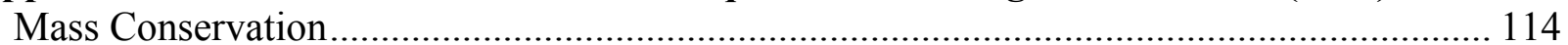

x-Momentum Conservation ....................................................................................... 115

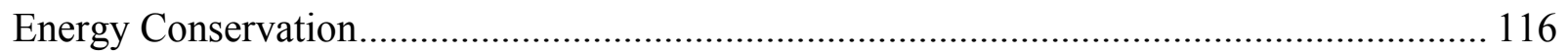

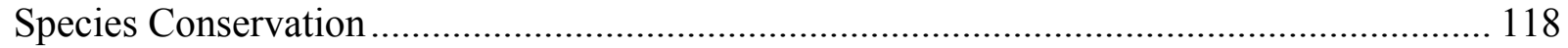

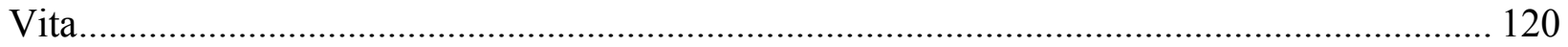




\section{List of Figures}

Figure 2.1: Force Balance on Droplet on Verge of Breakup .............................................. 14

Figure 2.2: Idealized and Actual $D^{2}$ Law for Droplet Evaporation ........................................ 15

Figure 2.3: Perfectly Stirred Reactor ............................................................................ 20

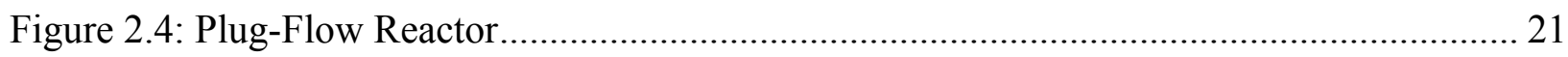

Figure 3.1: Testing Chamber of Quiescent Setup ........................................................... 29

Figure 3.2: Quiescent Testing Environment .................................................................. 30

Figure 3.3: Quiescent Ventilation System ................................................................. 31

Figure 3.4: Virginia Tech Unheated Blow-down Supersonic Wind Tunnel ............................. 32

Figure 3.5: Flush-Wall Supersonic Wind Tunnel Implementation........................................ 32

Figure 3.6: Plasma Torch Igniter: Component View ......................................................... 33

Figure 3.7: Plasma Torch Igniter: Assembled and Section Views ....................................... 34

Figure 3.8: Quiescent Injector-Igniter Anode Assembly Schematic ...................................... 35

Figure 3.9: Supersonic Anode: Assembly Schematic ...................................................... 36

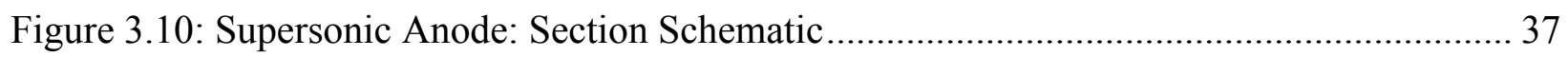

Figure 3.11: Experimental Setup (Supersonic Configuration) .......................................... 37

Figure 4.1: Anode Erosion Comparison Examining Effects of Regenerative Heat Exchange..... 43

Figure 4.2: Water Temperature Rise for First and Second Generation Quiescent Anodes ......... 45

Figure 4.3: Methods of Atomization with Inset Showing Pressure-Orifice Flow ..................... 48

Figure 4.4: Water and Kerosene Atomization Characteristics without Torch Ignition ............... 49

Figure 4.5: Pure Liquid and Effervescent Kerosene Injection without Torch Ignition ............... 50

Figure 4.6: Reitz Jet Breakup Regime Classification with Current Experiment ....................... 51

Figure 4.7: Magnification of Kerosene Jet Breakup with Arrows Indicating Instabilities .......... 52

Figure 4.8: Cross-Sectional View of Quiescent Injection Method ....................................... 53

Figure 4.9: Kerosene and JP-7 Quiescent Combustion at Similar Powers .............................. 57 
Figure 4.10: Kerosene Combustion Progression in Quiescent Test Configuration .................... 57

Figure 4.11: Kerosene and JP-7 Combustion at Varying Power Levels................................. 58

Figure 4.12: Kerosene Flame Formation Sequence with Visible Flame Kernel Marked............ 59

Figure 4.13: JP-7 Flame Formation Sequence with Visible Flame Kernel Marked................... 60

Figure 4.14: Regions of High and Low Soot Formation in Kerosene Flame .......................... 61

Figure 5.1: Schematic Representations of Co-Flow and Counter-Flow Fuel Injection............... 63

Figure 5.2: Shadowgraph Images of (a) Co-Flow and (b) Counter-Flow Kerosene Injection in

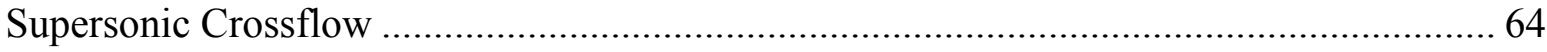

Figure 5.3: Image Processing Sequence for Penetration Height Measurements ....................... 65

Figure 5.4: Normalized Measured Penetration Height vs. Downstream Distance ..................... 66

Figure 5.5: Comparison of Measured and Predicted Penetration Heights................................ 67

Figure 5.6: Supersonic Kerosene Ignition for Pure Liquid and Effervescent Injection............... 68

Figure 5.7: Superimposed Schlieren and Direct Photographs of Supersonic Combustion.......... 69

Figure 5.8: Water and Kerosene Comparison: (a) and (b): Direct photographs; (c) and (d):

Schlieren-Direct Photographs .................................................................................... 71

Figure 5.9: Temperature Response to Fuel Flow for Co- and Counter-Flow Injection............... 72

Figure 5.10: Correlation Between Fuel Injection Pressure and Downstream Temperature ......... 73

Figure 5.11: Effects of Off-Center Arc Attachment and Combustion on Supersonic Anode ...... 74

Figure 5.12: Supersonic Total Temperature Measurements: Time-Dependent Behavior ............ 75

Figure 5.13: Water Injection Temperature Profile with Torch Ignited.................................. 76

Figure 5.14: Continuous Injection Total Temperatures for Normalized Locations.................... 78

Figure 5.15: Effervescent Injection Total Temperatures for Normalized Locations ................... 78

Figure 5.16: Water Injection with Torch: Total Temperature Profile ................................... 79

Figure 5.17: Total Temperature Profile Scale........................................................................... 79

Figure 5.18: Effect of Fuel Injection Pressure on Downstream Total Temperature................... 80

Figure 5.19: Normalized Total Temperature for 50 psi Injection Pressure ............................. 81 
Figure 5.20: Normalized Total Temperature for 70 psi Injection Pressure ............................. 82

Figure 5.21: Normalized Total Temperatures Obtained by Gallimore [43] and Cross [42]........ 82

Figure 5.22: OH Filtered Photographs: Torch Only; Continuous Fuel; Effervescent Fuel.......... 84

Figure 5.23: Effects of Feedstock Gas on $\mathrm{C}_{2} *$ Intensity for Typical Operating Conditions ........ 85

Figure 5.24: Comparison of Water and Kerosene Injection on $\mathrm{C}_{2}$ Emission Intensity ............... 86

Figure 5.25: Bunsen Burner Flame Chemiluminescence Emission Spectrum [60]................... 87

Figure 5.26: Plasma Torch Igniter (a) and Kerosene Combustion (b) Emission Spectra............ 88

Figure 5.27: CN Emission Bands in Kerosene Flame .......................................................... 89

Figure 5.28: $\mathrm{CH}$ and $\mathrm{C}_{2}$ Swan Emission Bands in Kerosene Flame....................................... 90

Figure 5.29: Comparison of $\mathrm{H}_{\alpha}$ Emission Intensities for Torch Only and Torch with Fuel........ 92

Figure 5.30: CN (415 nm) Emission Intensity for Igniter with and without Fuel Injection........ 93

Figure 5.31: $\mathrm{CH}^{*}(431 \mathrm{~nm})$ Emission Intensity for Igniter with and without Fuel Injection ....... 94

Figure 5.32: $\mathrm{C}_{2} *(513 \mathrm{~nm})$ Emission Intensity for Igniter with and without Fuel Injection........ 94

Figure 5.33: Supersonic Boundary Layer Measurements.................................................... 97 


\section{List of Tables}

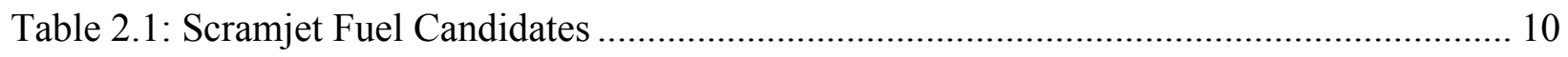

Table 2.2: Plasma Torch Research Conducted at Virginia Tech ............................................ 27

Table 4.1: Selected Properties of Experimental Liquids ................................................... 56 


\section{Nomenclature}

As

$B$

$C_{D}$

$C_{1}, C_{3}$

$d_{o}$

$D$

$D_{\max }$

$D_{\text {nom }}$

$\mathrm{D}_{32}$

$\mathrm{D}_{A B}$

$h$

$\bar{h}_{C}$

$\bar{h}$

$H_{L} \quad$ Height of liquid column in stand pipe

$l_{e}$

$k$

K

$\dot{m}$

M

$n$

$n_{o}$

$N_{R}$

Area of liquid surface in standpipe

Drag Coefficient

Fuel injection orifice diameter

Droplet diameter

Sauter Mean Diameter

Measured penetration height

Arbitrary constant

Evaporation constant

Mass flow rate

Mach number

Number of chain carriers

Initial number of chain carriers
Mass transfer number (Spalding number)

Experimentally determined drop size distribution constants

Maximum stable drop diameter for a given relative velocity

Nominal diameter of heat exchanger portion of anode body

Binary diffusivity between species $A$ and $B$

Correlated normalized penetration height

Measured normalized penetration height

Effective length of heat exchanger coil

Number of coil revolutions around heat exchanger 


\begin{tabular}{|c|c|}
\hline$O h$ & Ohnesorge number \\
\hline$P$ & Pressure \\
\hline$P_{o}$ & Total pressure \\
\hline $\bar{q}$ & Momentum flux ratio \\
\hline$R$ & Gas constant \\
\hline $\operatorname{Re}$ & Reynolds number \\
\hline$S$ & Flame speed \\
\hline$S_{L}$ & Laminar flame speed \\
\hline$S M D$ & Sauter Mean Diameter \\
\hline$t$ & Time \\
\hline$T$ & Temperature \\
\hline$V$ & Velocity \\
\hline$W e$ & Weber number \\
\hline $\mathrm{X}, \mathrm{Y}, \mathrm{Z}$ & Coordinate directions \\
\hline$x$ & Measured distance downstream \\
\hline $\bar{x}$ & Normalized measured distance downstream \\
\hline$\alpha$ & Thermal diffusivity \\
\hline$\gamma$ & Specific heat ratio \\
\hline$\varepsilon$ & Heat exchanger effectiveness \\
\hline$\theta$ & Injection angle relative to surface of orifice plane \\
\hline$\mu$ & Dynamic viscosity \\
\hline$\pi$ & Mathematical constant \\
\hline$\rho$ & Density \\
\hline
\end{tabular}


$\sigma$

$\Omega$

\section{Subscripts}

$\begin{array}{ll}A & \text { air } \\ \text { eff } & \text { critical } \\ f & \text { effective } \\ g & \text { fuel } \\ j & \text { gas } \\ L, l & \text { injectant } \\ o & \text { liquid } \\ R & \text { total } \\ s & \text { relative } \\ x & \text { liquid surface in stand pipe } \\ \infty & \text { Coordinate direction } \\ & \text { freestream }\end{array}$




\section{Introduction}

\subsection{Purpose and Scope of Research}

The primary goal of the current research was to achieve ignition and steady combustion of a conventional liquid hydrocarbon fuel in supersonic flow. This was achieved with regenerative fuel preheating, effective atomization, successful penetration and fuel-air mixing, and ignition using a design capable of providing favorable combustion conditions. Although the current work may be generically referred to as improved supersonic combustion by an integrated atomizer-igniter design, it involves a wide variety of subjects. These include compressible flow, turbulence, combustion chemistry, plasma kinetics, fuel injection, atomization and evaporation, mixing, droplet burning, ignition, and flameholding. Comments on some of these as they relate to the current work are found in Chapter 2. One area of hypersonic research which has received significant attention due to its difficulty is supersonic combustion.

\subsection{Challenges to Supersonic Combustion}

Investigations of supersonic combustion have been conducted for almost half a century. In 1958, Nicholls et al. [1] explored the possibility of using a stabilized detonation wave to achieve supersonic combustion for a high Mach number ramjet. Results showed that an underexpanded axisymmetric jet of supersonic gaseous hydrogen and air was ignited by a strong normal shock, or Mach disc, and an ignition delay time of about $25 \mu \mathrm{sec}$ was reported. Despite the longevity of scramjet research, turbojets and other propulsion methods have received more attention and developed more quickly. One reason for scramjet research proceeding at a slower pace than other aerospace propulsion technologies is the tremendous degree of complication involved with the combustion and other components. 
In the early years of supersonic combustion, Weber and Mackay [2] outlined some practical problems involved with employing such a process: fuel injection, uniform fuel-air mixing, and combustion in a short distance and in the absence of normal shocks. Almost fifty years later, the same problems pose challenges to scramjet designers. Williams et al. [3] expressed the magnitude of the task of supersonic combustion: airbreathing propulsion at hypersonic velocities "is subject to the stressing requirement that mixing, ignition, and combustion must take place on very rapid time scales since combustors feature millisecond residence times commensurate with combustion reaction times scales." Indeed, the complexity of supersonic combustion, coupled with the urgency of realizing heat release in a short distance, make it a difficult task to accomplish.

Hydrogen and hydrocarbons, each with respective advantages and disadvantages, are the two primary fuel candidates for scramjet propulsion based on desired mission parameters, e.g., cruise Mach number and range. Hydrocarbons in their liquid state add experimental complexity to the difficulties mentioned above. Namely, the fuel injection system, atomization process, droplet heat-up period and evaporation are compounded with the existing challenge of effective fuel-air mixing, and together these processes must be addressed appropriately.

\subsection{Problems with Current Ignition Systems}

Once the fuel has been injected and at least partially mixed with the air flowing through the engine, it must either autoignite or be ignited by another source. NASA's X-43A research vehicle [4] was a hydrogen-fueled vehicle incorporating silane as an ignition aid. Silane, although similar in chemical structure to alkane hydrocarbons, is unstable and burns when exposed to air. This reaction in turn ignites the hydrogen-air mixture, and combustion occurs. The hazard associated with cryogenic fuels and additives is offset by their effective combination 
as an igniter-fuel mixture: the X-43A recently demonstrated controlled accelerating flight at Mach 7 and Mach 10. However, to avoid the dangers of these and other pyrophoric additives, alternative ignition methods are sought. One supersonic ignition method which has received research attention over the years is the plasma torch.

\subsection{The Plasma Torch as an Igniter}

The operation of the plasma torch is quite simple. It relies on an electric arc discharge created by a voltage potential between two electrodes. The arc itself remains relatively stable provided that the distance between the electrodes, or gap distance, remains unchanged. As the arc attaches to the surface of each electrode, a gas passes through the annular space between the electrodes and discharges out a small orifice in the body of the positive electrode. This gas is referred to as the feedstock, and its flow through the orifice is choked at the location of minimum area. The plasma torch design is discussed in Chapter 3. The unique property of the plasma torch lies in the interaction of the feedstock gas with the electric arc. Energy transfer from the arc to the feedstock generates a high-temperature gaseous plasma. This partially ionized gas, which consists of ions, electrons, and neutral species, is expelled through the orifice directly into the combustion region. In this way, a constant, high-temperature, compact ignition source doubles as a source of electronically excited and ionized atoms and molecules which are directly related to the rate of the combustion reaction. A summary of research related to plasma-assisted combustion in supersonic flow is provided in Chapter 2. At Virginia Tech, numerical and experimental research has been conducted with various torch designs, injector-igniter configurations, feedstock gases, ambient flow conditions, and plasma torch operating characteristics. 


\subsection{Experimental Objectives}

The present work addresses a challenge yet to be met: a truly integrated injector-igniter combination capable of operating with liquid hydrocarbons. Prior to testing in a supersonic environment, baseline testing was conducted to determine feasibility of the concept, and quiescent testing allowed for design modifications before being implemented in the wind tunnel. Within these areas of experimentation, specific objectives included:

- Design a functioning regenerative heat exchanger anode capable of providing liquid fuel temperature rise

- Observe the effects of heat exchanger on anode erosion

- Study atomization characteristics in low crossflow environment

- Conduct combustion experiments to evaluate performance in low crossflow

- Modify design and experimental procedure for supersonic implementation

- Perform supersonic crossflow experiments, observing penetration, atomization, ignition, and combustion characteristics

- Draw conclusions based on the experimental testing, and suggest future courses of action

Desired outcomes in the supersonic regime include suitable atomization, penetration promoting fuel-air mixing, and ignition and steady state combustion evidenced by heat release.

\subsection{Thesis Summary}

Discussion of various topics of importance to the present work is the subject of Chapter 2. Attention is given first to scramjets, including engine cycles, fuel selection, and current research topics. Atomization of liquid jets and droplets and vaporization are discussed next, followed by some comments on combustion chemistry. Spray combustion is briefly addressed, 
then attention is given to plasma assisted combustion work, with emphasis placed on that conducted at Virginia Tech. The preceding subjects are discussed in terms of their applicability to the present work, and provide a framework for the remainder of the thesis.

Chapter 3 presents the experimental equipment used in the research. Specific components and their functions are included, as well as data acquisition and experimental procedure.

The experimental results are given in Chapters 4 and 5 for quiescent and supersonic sections, respectively, since the atomization, ignition, and combustion behavior varied greatly between the two cases. The results are discussed and conclusions are drawn from them.

Chapter 6 summarizes the conclusions of the experimental testing and includes recommendations for future work based on the results of Chapters 4 and 5 . 


\section{Background}

\subsection{The Scramjet Engine Cycle}

Due to the limitations involved with rotating turbomachinery, particularly the maximum allowable turbine inlet temperature, jet turbine engine flight speed reaches a maximum at around Mach 3. Rocket propulsion is a well-proven method for achieving hypersonic flight speeds, but has its drawbacks. By carrying its own oxidizer, rather than gathering air and utilizing the oxygen therein, the rocket vehicle size and weight increase.

To achieve hypersonic vehicle speeds without the use of rocket propulsion, airbreathing engines devoid of rotating turbomachinery have been proposed. These ramjets are capable of attaining flight Mach numbers up to approximately 5-6, at which speed a more efficient engine cycle may be implemented. To achieve high performance at hypersonic speeds (Mach number greater than 5) the fuel-air mixture remains supersonic while passing through the combustor. Such an engine is called a scramjet, or supersonic combustion ramjet.

A thorough but concise discussion of scramjet engine cycles and operation is given by Waltrup [5]. Anderson et al. [6] compared the fuel specific impulse of ramjets, scramjets, and rockets over a range of flight Mach numbers, showing that scramjet operation becomes advantageous at a Mach number of around 6-7. However, at lower supersonic Mach numbers, ramjets outperform scramjets. Ideally, an engine cycle would be implemented that utilizes both cycles during its operation, taking advantage of their respective strengths. This dual-mode engine operates as a ramjet at low Mach numbers, then transitions to a scramjet cycle as flight speed increases. Such an engine would simultaneously take advantage of the low combustion (Rayleigh) pressure losses during ramjet operation and the increased inlet total pressure recovery and lower internal static pressure during scramjet operation. 


\subsection{Current Trends in Hypersonic Research}

Although thermal management, engine/airframe integration, inlet and nozzle aerodynamics and other issues continue to be addressed, the majority of scramjet research to date has dealt with the scramjet combustor. In his review of scramjet combustion technology flight test efforts, Curran [7] discusses the historical and technological development of scramjet research on an international scope. The variety of technologies and research programs demonstrates the importance and value of research leading to the mastery of scramjet-powered flight. In the discussion of scramjets, the decisions of intended function and suitable fuel arise. The latter will be addressed subsequently. Many ideas have been proposed addressing the specific function of the scramjet during any given mission. Townend [8] highlights several options for scramjet implementation:

1. A commercial, horizontal takeoff single-stage-to-orbit (SSTO) plane;

2. A small-payload military SSTO aerospace plane; and

3. The second stage of a two-stage-to-orbit (TSTO) vehicle preceded by a first stage accelerating the vehicle to Mach 5 or 6 , and followed by a rocket.

Current research focuses mainly on these as well as implementation in rocket-based combined cycle (RBCC) engines and global presence, hydrocarbon-fueled missiles [9].

Marren et al. [10] discuss several "critical hypersonic technologies" that must be addressed to ensure successful hypersonic weapon and space access for the future. Stressing the importance of building on the infrastructure developed during the early years of space exploration, the areas of materials and structures and guidance navigation and control, among others, are recognized. Clearly, in order to realize successful hypersonic flight, technology from the past must be integrated with current research. Successfully meshing these innovations 
presents a formidable but necessary task, providing a multitude of research opportunities summarized by Waltrup [5]. With the intended application of scramjet-powered aircraft in mind, some discussion of supersonic combustion characteristics is in order.

\subsection{Fuels}

In achieving successful supersonic combustion, one of the first decisions made is what type of fuel to use. The type of fuel to use for scramjet operation is based on many factors, including cost, safety and handling, availability, energy, active cooling ability, and burning rate. At this time, the two main fuel candidates are hydrogen and hydrocarbons. Endothermic hydrocarbons are also being considered. Both hydrogen and liquid hydrocarbons have advantages and drawbacks. Their characteristics should be weighed depending on the desired mission, with one of the most prominent criteria being flight Mach number.

Hydrogen has been attractive as a fuel for scramjet propulsion for years, being selected as the fuel of choice for the National Aerospace Plane (NASP) [11], NASA's X-43A research vehicle mentioned above, and other scramjet operations. Lewis [12] points out that hydrogen has been attractive as a hypersonic airbreathing fuel of choice due to its rapid burning and high massspecific energy content. Furthermore, its heating ability based on constant-pressure specific heat is superior to conventional hydrocarbons. Hydrogen exhibits a greater specific impulse than hydrocarbon fuels, and it is understood that for transatmospheric airbreathing flight, hydrogen is the only likely fuel that might deliver net positive thrust up to near-orbital velocities. On the other hand, because of the very low density of hydrogen, its volume-specific energy content is much lower than typical hydrocarbons. This could result in aerodynamically unattractive vehicles. The nature of hydrogen causes safety, handling, and packaging complications. Finally, 
availability and cost considerations cause hydrogen to be more of a specialty fuel, and scramjet designers in the recent years have begun exploring alternative fuel options.

Unlike hydrogen, conventional hydrocarbon fuels are storable, and their handling is familiar. They are readily available, and cost less than hydrogen. Hydrocarbons are the fuel of choice for low-Mach hypersonic scramjet operations, such as the Air Force HyTech program [13]. Waltrup [14] has shown that a reasonable upper bound on flight Mach number for a hydrocarbon-fueled scramjet is between Mach 9 and 10, which is well within the flight speed range to be examined for practical applications in the near future. Lewis [12] has demonstrated that for a cruiser operating in the Mach 8-10 corridor, in which it is desired to maximize cruise range for a given total takeoff weight, the aerodynamic and volumetric advantages of storable hydrocarbons are about equivalent or superior to the specific impulse advantages of hydrogen in determining cruiser range. Additionally, Townend [8] has summarized that hydrocarbon would be the fuel of choice for a variety of scramjet operations, including both the airbreather and rocket modes of a small SSTO military use (cruise and space access) vehicle and the second stage of an even smaller, TSTO vehicle. Table 2.1 is a comparison of properties of potential scramjet fuels [15]. For the current investigation, liquid kerosene-class hydrocarbons were used. 
Table 2.1: Scramjet Fuel Candidates

\begin{tabular}{|l|l|l|l|l|l|l|l|}
\hline \multicolumn{1}{|c|}{ Fuel } & $\begin{array}{c}\text { Freeze } \\
\text { Point } \\
\left({ }^{\circ} \mathrm{C}\right)\end{array}$ & $\begin{array}{c}\text { Flash } \\
\text { Point } \\
\left({ }^{\circ} \mathrm{C}\right)\end{array}$ & $\begin{array}{c}\text { Net heating } \\
\text { value } \\
\left(\mathrm{kJ}^{\circ} / \mathrm{m}^{3}\right)\end{array}$ & $\begin{array}{c}\text { Viscosity } \\
\left(-40^{\circ} \mathrm{C}\right) \\
\mathrm{mm}^{2} / \mathrm{s}\end{array}$ & $\begin{array}{c}\text { Cost } \\
\$ / \text { liter }\end{array}$ & $\begin{array}{c}\text { Cost } \\
\$ / \mathrm{kJ}\end{array}$ & $\begin{array}{c}\text { Heat } \\
\text { Sink }\end{array}$ \\
\hline $\begin{array}{l}\text { Hydrogen } \\
\left(\mathrm{H}_{2}\right)\end{array}$ & -259.2 & Gas & 8,133 & $\begin{array}{l}0.0084 \\
\left(0^{\circ} \mathrm{C}\right)\end{array}$ & 16.33 & 2.01 & Highest \\
\hline $\begin{array}{l}\mathrm{JP}-7 \\
\left(\mathrm{C}_{12} \mathrm{H}_{24}\right)\end{array}$ & -44 & 63 & 34,423 & 17 & 0.80 & 0.02 & Lower \\
\hline $\begin{array}{l}\mathrm{JP}-8 \\
\left(\mathrm{C}_{12} \mathrm{H}_{22}\right)\end{array}$ & -50 & 38 & 34,674 & 10 & 0.24 & 0.01 & Lower \\
\hline $\begin{array}{l}\text { JP-10 } \\
\left(\mathrm{C}_{10} \mathrm{H}_{16}\right)\end{array}$ & -79 & 54 & 39,441 & 19 & 2.94 & 0.07 & Lowest \\
\hline
\end{tabular}

Although the experimental behavior of endothermic fuels was not part of this research, a discussion of scramjet fuel options would not be complete without their mention. As flight speed increases, effective cooling of aircraft surfaces, especially the combustor liner, becomes crucial. This thermal management must be accompanied by the subsequent heating of the cooling fluid. For hypersonic travel, regenerative heating, i.e. cooling engine surfaces while simultaneously heating the fuel in preparation for combustion, may be employed. The success of a fuel as an active coolant depends on its ability to absorb heat as its temperature is raised as well as its tendency to resist chemical decomposition. While hydrogen is a better candidate than keroseneclass jet fuels as far as specific heat is concerned, endothermic hydrocarbon fuels demonstrate that engine cooling may be achieved through chemical as well as sensible heat sink. The essence of endothermic fuels lies in their tendency to undergo heat-absorbing chemical reactions prior to ignition. This allows the fuel to absorb energy in addition to that energy absorbed through sensible heating, and can enable the use of airbreathing propulsion at hypersonic speeds utilizing hydrocarbons instead of cryogenics.

With the objective of liquid hydrocarbon supersonic combustion in mind, attention is now turned to some of the physical processes involved. Before combustion can occur, the 
injected liquid, in this case a stream of circular cross-section, must first be atomized, then vaporized and mixed with the air flowing through the combustor.

\subsection{Atomization}

Atomization can be described as the process of converting a bulk liquid into droplets. Many practical systems depend on effective atomization, employing various injectors to attain the spray characteristics desired, such as droplet size and distribution and spray pattern. For supersonic combustion applications, small droplets are desired due to the short residence time of the flow in the combustor. As the droplet evaporation time is directly related to the initial drop size, smaller drops will vaporize and be mixed with air more quickly. One method of atomization which has shown promise for supersonic combustion applications is the effervescent, or barbotage, method. Recently, Yu et al. [16] investigated the effects of hydrogen and air effervescent atomization on liquid-hydrocarbon supersonic combustion. They showed a $15-20$ $\%$ increase in combustion efficiency for barbotage injection over pure liquid injection, noting the more rapid atomization and better penetration accompanying barbotage injection. The general class of injector chosen for a given application is just one of many factors influencing the atomization. The properties of the atomized liquid as well as those of the ambient environment influence the spray characteristics. Additionally, subtleties in atomizer geometry cause changes in the resulting spray. Due to the tremendous variation of system characteristics on spray properties, as well as the countless flow situations encountered in practice, only the most basic principles of atomization are discussed here. For a more complete discussion, Lefebvre [17] has provided a summary of research in the field of atomization, including atomization methods, mechanics, and drop-sizing techniques. 


\subsubsection{Liquid Jet Disintegration}

The process of atomization in the present work begins as a jet with cylindrical crosssection injected through a plain orifice. Disturbances compete with the forces stabilizing the surface of the jet and eventually disrupt the jet enough to disintegrate it into droplets. This is referred to as primary atomization. Jet breakup research has received a tremendous amount of attention over the last century. Sirignano and Mehring [18] reviewed recent developments in the linear and nonlinear treatment of liquid stream instabilities. The magnitude of work devoted to this small but significant aspect of jet disintegration demonstrates the complexity involved. Many investigations have been conducted over the years, the results and conclusions of which vary slightly. For example, Weber [19] suggested a critical velocity at which the continuous length of the jet is maximized, but assumed a uniform velocity issuing from the orifice, thereby overestimating the aerodynamic effects on jet breakup. Sterling and Sleicher [20] later accounted for velocity profile relaxation and showed that Weber's analysis was qualitatively correct and that slight modifications showed good agreement with experimental results. Early work on the quantification of jet disintegration regimes was done by Ohnesorge [21], who proposed a measure of the ratio of the internal viscosity force to the surface tension force. The dimensionless expression is often referred to as the Ohnesorge number:

$$
O h=\frac{\mu_{L}}{\left(\rho_{L} \sigma d_{o}\right)^{1 / 2}}
$$

where $\mu_{L}, \rho_{L}$, and $\sigma$ are the liquid dynamic viscosity, density, and surface tension, respectively, and $d_{o}$ is the injection orifice diameter. The Reynolds number, a measure of the ratio of the inertial force on the liquid to the viscous force of the liquid, is calculated by

$$
R e_{L}=\frac{\rho_{L} V_{L} d_{o}}{\mu_{L}}
$$


where $V_{L}$ is the axial velocity of the jet. The Ohnesorge and Reynolds numbers for a given set of experiments are often plotted on logarithmic axes to describe the jet breakup regime. Reitz [22] , who studied jet breakup experimentally while varying nozzle geometry, injection pressure, injection liquid, ambient gas, and ambient gas pressure, focused primarily on the atomization regime, but first introduced the classification of jet breakup regimes in this way.

In most cases, strong dependence of jet disintegration on liquid viscosity, density, velocity, surface tension, and orifice diameter has been shown. Jet breakup regimes, discussed further in Section 4.2.3, refer to the method by which a jet breaks up into individual droplets. For a recent review of work focused on liquid jet breakup regimes, see Reference [23].

\subsubsection{Droplet Breakup}

Following the primary atomization of the liquid jet, the droplets formed often atomize further, resulting in a finer mist. This is called secondary atomization. Since all practical sprays exist as droplets prior to their vaporization, at least a fundamental discussion of droplet breakup is necessary. In general, droplet breakup occurs when the tension forces, a measure of molecular attraction, acting on the droplet surface are overcome by the external dynamic pressure forces acting on the entire droplet. These dynamic pressure forces are a direct measure of the relative velocity between the droplet and the surroundings. Therefore, any increase in the relative velocity will promote the onset of droplet breakup. Figure 2.1 is a free body diagram of the droplet when the surface tension force acting around its perimeter balances the dynamic pressure force acting on its cross-sectional area. 


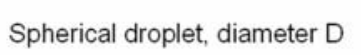

Free body diagram of unbalanced

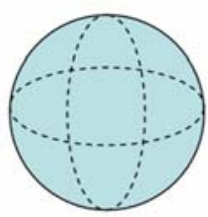

\section{Figure 2.1: Force Balance on Droplet on Verge of Breakup}

Expressing the net dynamic pressure force in terms of air density $\rho_{A}$, relative axial velocity $V_{R}$, drag coefficient $C_{D}$ and surface tension $\sigma$ :

$$
C_{D} \frac{\pi D^{2}}{4} \frac{1}{2} \rho_{A} V_{R}^{2}=\pi D \sigma
$$

Rearranging this expression, the dimensionless Weber number can be obtained:

$$
\mathrm{We}_{C}=\frac{\rho_{A} V_{R}^{2} D}{\sigma} c=\frac{8}{C_{D}}
$$

The subscript $c$ indicates that a critical condition has been reached, i.e. a further unbalanced increase in aerodynamic drag force will overcome the surface tension force and deform the droplet. The Weber number is a measure of the external pressure forces acting to deform the drop compared with the surface tension forces acting to maintain the spherical drop. Since the balance of forces on this drop at its critical state is related to the drop diameter $D$, it is clear that $D$ in the above expressions is the maximum stable drop diameter for a given relative velocity $V_{R}$ :

$$
D_{\max }=\frac{8 \sigma}{C_{D} \rho_{A} V_{R}^{2}}
$$

When the aerodynamic drag exceeds the critical value and the droplet deforms, smaller drops are formed, each with a smaller diameter $D^{\mathrm{I}}$. If $D^{\mathrm{I}}$ for this next generation of drops is less than $D_{\max }^{\mathrm{I}}$, the stable drop size has been reached and the drops will not break up any further. Note that as droplet breakup occurs and $D$ changes, $\sigma$ changes and therefore $D_{\max }$ changes. At the point where 
$D<D_{\max }$, no further breakup will occur for the relative velocity $V_{R}$. At this point, the newly formed droplets begin to vaporize due to heat transfer with the hot combustion environment.

\subsection{Vaporization}

The droplet size decreases as mass transfer occurs between the vaporized fuel on the surface of the droplet and the ambient gas. Similarly, the droplet velocity decreases due to the drag force as it moves through the ambient gas. Figure 2.2 shows the idealized and actual behavior of the square of the droplet diameter over the lifetime of the droplet. Clearly, the idealized droplet diameter decreases linearly as time progresses until the droplet diameter reaches zero at the droplet lifetime, $t_{d}$.

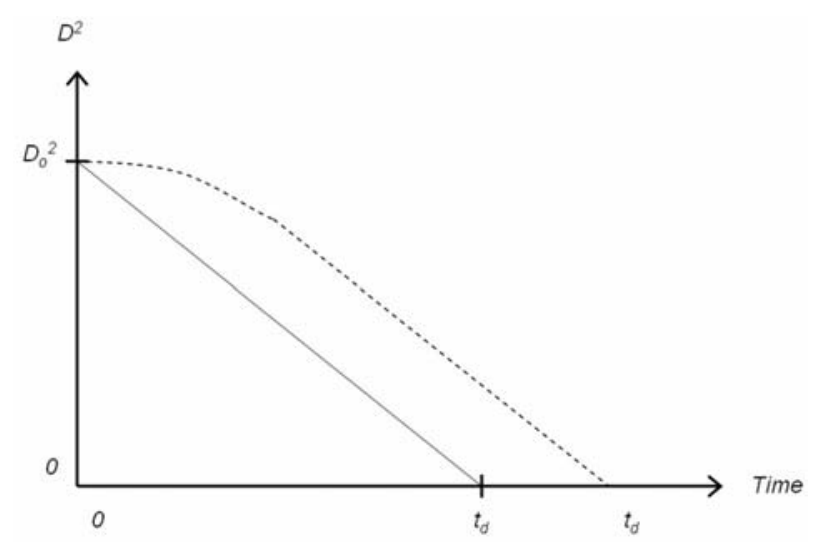

Figure 2.2: Idealized and Actual $D^{2}$ Law for Droplet Evaporation

It has been shown [24] that the slope of the path tracing the droplet progress is equal to the opposite of the evaporation constant, $K$ :

$$
K=\frac{8 \rho \mathrm{D}_{A B}}{\rho_{l}} \ln (1+B)
$$

where $\mathrm{D}_{A B}$ is the diffusivity, $\rho$ is the gas density, $\rho_{l}$ is the fuel density, and $B$ is a dimensionless transfer number. The well-known relationship between the square of the droplet diameter and time is known as the $\mathrm{D}^{2}$ law for droplet evaporation. In reality, the behavior is slightly different than the idealized situation, as shown on the graph. The actual droplet evaporation does not 
proceed until the completion of an initial droplet heat-up period. During this time, energy from the surroundings is employed in heating the fuel to its wet bulb temperature, and little heat contributes to the actual vaporization. Once the wet bulb temperature is reached, however, the heat transfer from the surroundings supplies the latent heat of vaporization, and a noticeable change in the sensible enthalpy is not observed. Chin and Lefebvre [25] found that the duration of the drop heat-up period increases with increasing pressure, and decreases with increasing temperature. Furthermore, relative velocity between the droplet(s) and surrounding gas, or forced convection, does not affect the duration of the heat-up period, though it will reduce the overall droplet lifetime. This result is important to supersonic combustion due to the tremendous relative velocity present between the injected fuel and the main air flow. Finally, fuel spray evaporation is enhanced through heating the fuel because a higher fuel temperature necessarily means less time is required to heat the droplet to its wet bulb temperature. This realization was made in the current experiment, and was the motivation for incorporating a regenerative heat exchanger design into the injector.

To summarize the mechanism of atomization and evaporation:

1. Liquid fuel is injected through a nozzle in the form of a circular jet.

2. Disturbances promote the disintegration of the jet into large droplets.

3. The large droplets are subdivided into smaller droplets until a point is reached where no further atomization will occur for the given relative velocity.

4. The small droplets are heated sensibly to the wet bulb temperature during the droplet heat-up period.

5. The small droplets at the wet bulb temperature evaporate in a linear fashion, with the fuel vapor diffusing into the surrounding medium. 
6. An ignitable fuel-air mixture is formed due to turbulent mixing.

With the physical processes necessary for combustion complete and a combustible mixture formed, attention is now directed to the chemical processes involved in the ignition and combustion of a hydrocarbon.

\subsection{Combustion Chemistry}

In many experimental investigations of supersonic hydrocarbon combustion, emphasis is placed on the inlet and outlet states, with little or no consideration given to the process inbetween. This treatment is often justified since ultimately, the temperature and pressure rise at the outlet determine the expansion of the flow and eventually the thrust. Despite this limited treatment of the chemical kinetics from an experimental point of view, an introductory understanding of the chemistry is necessary to appreciate supersonic combustion.

\subsubsection{The Chain Reaction Mechanism}

Combustion of a fuel is driven by chain reactions involving free radicals. A chain reaction may be thought of as a series of consecutive reaction steps, with intermediate products from one step reacting to produce new reactive intermediate products in the following step. These newly-formed reactive intermediates react in turn to produce yet another intermediate reactive product, and so on. This sequence of events continues until the chain sequence is broken due to the formation of a stable species by two free radicals. Free radicals are those chemical species in a reaction process which have unpaired electrons and can react very actively with other molecules [26].

In a global chain reaction mechanism, several types of elementary chain reactions are important. In a chain-initiation reaction, free radicals are formed from stable species. This occurs as stable propane decomposes into methyl and ethyl radicals: 


$$
\mathrm{C}_{3} \mathrm{H}_{8} \rightarrow \mathrm{CH}_{3}+\mathrm{C}_{2} \mathrm{H}_{5}
$$

Chain-propagation or chain-carrying reactions maintain the number of radical species. An example is the reaction of ethane with hydroxyl radicals, producing ethyl radicals:

$$
\mathrm{C}_{2} \mathrm{H}_{6}+\mathrm{OH} \rightarrow \mathrm{C}_{2} \mathrm{H}_{5}+\mathrm{H}_{2} \mathrm{O}
$$

Chain-termination reactions reduce the number of radicals, as seen in ethyl radical recombination producing stable butane:

$$
\mathrm{C}_{2} \mathrm{H}_{5}+\mathrm{C}_{2} \mathrm{H}_{5} \rightarrow \mathrm{C}_{4} \mathrm{H}_{10}
$$

Finally, chain-branching reactions increase the number of radicals. According to Westbrook [27], the most important high temperature chain-branching reaction consumes one $\mathrm{H}$ atom and produces two radicals:

$$
\mathrm{H}+\mathrm{O}_{2} \rightarrow \mathrm{O}+\mathrm{OH}
$$

Chain-branching reactions are an essential and important aspect of hydrocarbon combustion, enabling the rapid formation of product species and flame self-propagation [24]. The chain-branching reaction shown above is one of many elementary reactions involved in hydrogen combustion, represented globally as:

$$
2 \mathrm{H}_{2}+\mathrm{O}_{2} \rightarrow 2 \mathrm{H}_{2} \mathrm{O}
$$

In a time-limited system such as a scramjet combustor, where the combined processes of injection, atomization and evaporation, mixing, and combustion must occur within a short distance and therefore a short time, performance must take into account the degree of combustion. In other words, while steady-state combustion with full heat release may not be realized, the occurrence of an important chain-branching step, i.e. ignition, provides a reasonable estimate of the success of the combustor. Because of its significance for short time-scale experiments, ignition will now be discussed. 


\subsubsection{Ignition}

Westbrook [27] describes ignition as simply a means of starting a system on its way to steady state, possessing a great influence on system characteristics and performance. It may depend on physical, chemical, and mixing and transport features of a problem and in some cases on heterogeneous phenomena.

Referring to the chain reactions above and realizing the sequential progression of a global chain mechanism, it is apparent that a change in the number of chain carriers, or radical species, at a given time is dependent on the number of radical species available. That is, for a reacting system

$$
\frac{d n(t)}{d t}=k n(t)
$$

where $n(t)$ is the number of chain carriers, or free radicals, and $k$ is a constant. The solution of this first order differential equation leads to the relationship

$$
n(t)=n_{0} \mathrm{e}^{k t}
$$

where $n_{0}$ is the initial number of chain carriers. Now the exponential nature of chain branching combustion reactions becomes evident, with the number of free radicals at a given time dependent on the initial number of free radicals and a constant. The difference between ignition and steady state combustion lies in the value of the constant $k$. In a reacting system, $k$ is an average over initiation, propagation, branching, and termination reactions, so that for a system undergoing steady combustion, $k \approx 0$. Ignition, on the other hand, can be defined by requiring that $k>0$, i.e. the system experiences exponential growth in both temperature and number of chain carriers for a significant degree of fuel consumption. 
In numerical analyses of the relationship between detailed chemical kinetic mechanisms, reduced mechanisms, and reactor fluid mechanics, Mulholland et al. [28] provide results that may have implications for the modeling of ignition in supersonic flow reactors. First, reduced mechanism sets for methane, ethane, ethylene, and acetylene were generated by successively eliminating minor reaction pathways and observing changes in the global ignition kinetics. Second, and more importantly from a scramjet point of view, a surprising similarity in the global kinetics between a perfectly-stirred reactor (PSR) and a plug-flow reactor (PFR) indicates that the ignition kinetics have little dependence on the reactor environment. As Figure 2.3 shows, the PSR would be a poor choice for liquid hydrocarbon supersonic combustion, as it assumes perfect mixing in all directions, constant temperature, and constant pressure.

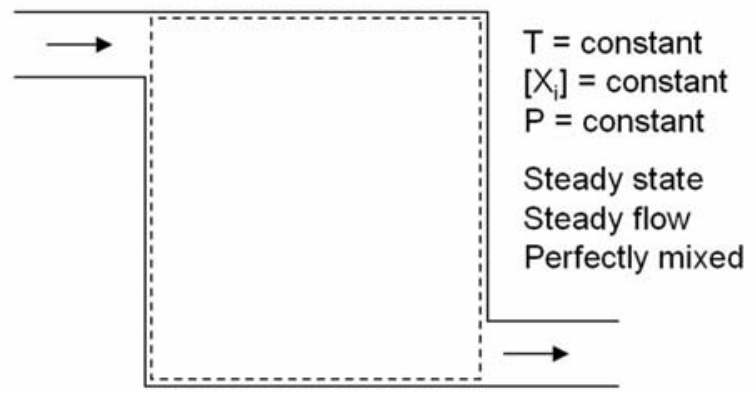

Figure 2.3: Perfectly Stirred Reactor

The PFR, shown in Figure 2.4, is also not ideal for modeling supersonic injection and combustion due to the assumptions of no axial mixing and uniform properties in the radial direction. However, an altered form of the PFR accounting for non-uniform flow and streamwise mixing would include temperature and pressure variation, and may be able to accurately simulate supersonic combustion. 


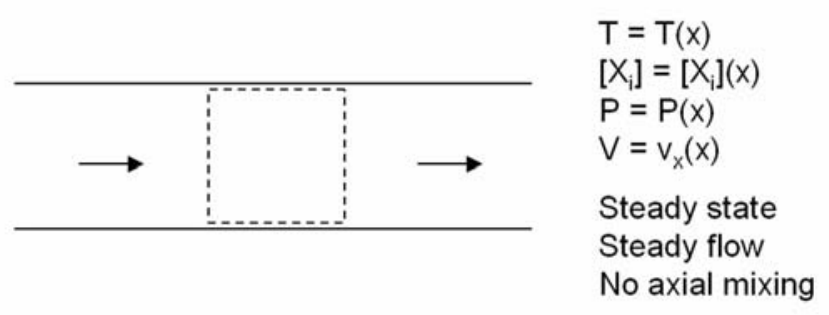

Figure 2.4: Plug-Flow Reactor

For this reason, the conclusions of Mulholland et al. are encouraging in that supersonic ignition with liquid hydrocarbon injection could be modeled using a global mechanism including just a few reactions. The derivation of the differential conservation equations for the PFR is given in Appendix B. Attention is now turned to some chemical kinetic aspects of steady state combustion.

\subsubsection{Steady State Combustion}

Although Equation (2.11) accurately describes the global hydrogen combustion reaction, the scope of the actual process is manifested by the numerous chain reactions occurring during ignition and steady-state combustion, and the process itself is much more than an immediate conversion of reactants to products. In reality, it consists of an interactive, continuous mechanism of elementary reactions. The well-known GRI Mech methane $\left(\mathrm{CH}_{4}\right)$ combustion kinetic mechanism (Version 2.11, 1998) considers 277 elementary reactions and 49 species [24]. Considering the relative simplicity of a methane molecule compared to heavier hydrocarbons, it is no surprise that hundreds of species and thousands of elementary reactions are involved in the complete combustion of a practical high hydrocarbon fuel. Lindstedt and Maurice [29] have validated a detailed chemical kinetic model for the gas-phase combustion of endothermic and conventional aviation fuels. Simmie [30] has provided a review of recent detailed reaction models for hydrocarbons in the gas phase. This thorough review covers alkanes up to decane, alkenes, alkynes, and aromatics. 
Despite the availability of detailed reaction models, even the most simplified droplet or diffusion combustion applications resort to smaller, reduced reaction mechanisms. These simplified mechanisms have been developed primarily for incorporation into multi-dimensional fluid dynamics codes, with present computational capabilities unable to handle the detailed kinetics mechanisms. Although their primary application is computational modeling, such reduced reaction mechanisms also offer insight to the most important, fundamental reactions and processes of hydrocarbon combustion.

In his work on reduced mechanisms, Warnatz [31] simplified the description of alkane combustion by realizing that the decomposition of large alkyl radicals following the initial attack on the parent hydrocarbon is not a rate-limiting process, and therefore may be represented with simplified decomposition paths. His results show good agreement with experiments and past research, but are developed for use with laminar, premixed flames.

Jones and Lindstedt [32] derived a global reaction mechanism for the combustion of alkane hydrocarbons up to butane, shown below:

$$
\begin{aligned}
& \mathrm{C}_{n} \mathrm{H}_{2 n+2}+\frac{n}{2} \mathrm{O}_{2} \rightarrow n \mathrm{CO}+(n+1) \mathrm{H}_{2} \\
& \mathrm{C}_{n} \mathrm{H}_{2 n+2}+n \mathrm{H}_{2} \mathrm{O} \rightarrow n \mathrm{CO}+(2 n+1) \mathrm{H}_{2} \\
& \mathrm{H}_{2}+\frac{1}{2} \mathrm{O}_{2} \leftrightarrow \mathrm{H}_{2} \mathrm{O} \\
& \mathrm{CO}+\mathrm{H}_{2} \mathrm{O} \leftrightarrow \mathrm{CO}_{2}+\mathrm{H}_{2}
\end{aligned}
$$

The predicted variations of burning velocity and mole fraction are in acceptable agreement with experimental values for both premixed and diffusion flames of methane and propane.

More recently, Held et al. [33] developed a 266-reaction, 41-species semi-empirical mechanism for $n$-heptane oxidation and pyrolysis to quantitatively capture transient phenomena 
and intermediate species distributions. The mechanism is compact enough to be used in combined fluid-mechanical/chemical kinetic computational studies, and has been validated against experimental results and existing literature. Although slightly modified to account for ignition phenomena, additional isomeric $n$-heptyl radicals, and updated oxidation submechanisms for small hydrocarbons, this model follows a similar approach to that of Warnatz [31]. Specifically, the primary route of fuel consumption is still considered to be H-atom abstraction from the parent fuel, and the $n$-heptyl radicals formed thereby are assumed to undergo rapid thermal decomposition. It is again noted that the important overall ratedetermining processes generally involve the small-molecule and radical chemistry. This important fact explains why alkanes, regardless of molecular size, exhibit similar flame properties.

Maurice [15] provides a description of the complete oxidation of a hydrocarbon fuel molecule RH, summarized in the sequence:

$$
\mathrm{RH} \rightarrow \mathrm{CH}_{2} \mathrm{O} \rightarrow \mathrm{CO} \rightarrow \mathrm{CO}_{2}
$$

This simplified expression neglects the underlying chemical kinetics, but highlights some important aspects of the combustion process: the presence of formaldehyde $\left(\mathrm{CH}_{2} \mathrm{O}\right)$, which is an intermediate in all hydrocarbon flames, and the final conversion to $\mathrm{CO}_{2}$ (as well as $\mathrm{H}_{2} \mathrm{O}$ ), which is the main source of heat release.

Finally, because of its significance to all systems of liquid fuel injection into a reacting environment, some attention will be given to spray combustion.

\subsection{Spray Combustion Research}

In his review of methods attempting to capture the simultaneous effects of turbulence and diffusion, Faeth [34] noted that the combined effects of turbulence and interphase transport make 
atomization a difficult process to define mathematically. Complete modeling therefore, becomes a difficult assignment. Furthermore, with the requirement that portions of the turbulent, multiphase mixture be evaporating and combusting, even the most advanced numerical analyses are oversimplified, and not intended to accurately or completely model the behavior of a real spray combustion application. Despite their deficiencies, however, these models examine the influence of flow characteristics on isolated droplets, and thereby provide insight to the entire system. Spray combustion research is limited on one hand by the inability to reproduce experimentally the physics of a practical system in a repeatable, organized manner, and on the other hand by the inability to model completely the processes occurring. For this reason, the majority of spray combustion research to date consists of creating a relatively simple, repeatable experiment, and comparing the results with a numerical model in an attempt to quantify mathematically the processes involved.

In their early fundamental study of flame propagation through heterogeneous fuel-air mixtures, Ballal and Lefebvre [35] obtained results applicable to quiescent combustible mixtures in which the fuel is present in the form of a multidroplet mist, or vapor, or both. They showed that the burning velocity, i.e. flame speed, of multidroplet fuel mists is enhanced by a reduction in drop size. Additionally, the presence of fuel vapor in a multidroplet mist causes an increase in flame speed, especially for larger drop sizes. This dependency of vapor concentration $\Omega$, which is the ratio of fuel vapor in the fresh mixture to total mass of fuel in the fresh mixture, on the pressure exponent $x$ in the flame speed expression

$$
S \propto P^{-x}
$$


was determined. The results show that for a given pressure $P$, an increase in $\Omega$ corresponds to a decrease in $x$, which results in a greater flame speed $S$. More importantly, they determined the following general equation for flame propagation through a quiescent fuel-air mist:

$$
S=\alpha_{g}\left[\frac{C_{3}^{3}(1-\Omega) \rho_{f} D_{32}^{2}}{8 C_{1} \rho_{g} \log (1+B)}+\frac{\alpha_{g}{ }^{2}}{S_{L}^{2}}\right]^{-0.5}
$$

This model predicts the behavior of the flame speed $S$ on the vapor concentration $\Omega$, and includes experimental drop size distribution constants $C_{1}$ and $C_{3}$, the mass transfer number $B$, the laminar flame speed $S_{L}$, the Sauter Mean Diameter $D_{32}$, and physical constants.

In the above, the physical and chemical processes of combustion as it pertains to supersonic combustion have been discussed. In the following section, emphasis will be placed on the efforts of ignition and combustion enhancement through the use of plasmas.

\subsection{Plasma-Assisted Combustion}

Experimental research on plasma-assisted combustion gained attention in the early 1960's. Harrison and Weinberg [36] demonstrated the success of imparting electrical energy in high concentrations to a species which is capable of subsequently producing radicals important in flame propagation, noting jet propulsion as a practical application. Kimura et al. [37] were the first to study the effects of adding plasma, generated with a relatively small amount of electrical power, to reacting supersonic flow. Their results showed the effectiveness of this method for flame stabilization and the promotion of combustion, and prompted interest from other researchers. Virginia Tech's involvement in the field began when Northam et al. [38] successfully demonstrated the advantages of plasma-assisted combustion of hydrogen. The wide variety of research at Virginia Tech has contributed to the development of plasma-assisted 
ignition and combustion in high-speed flows over the years. A summary of plasma-assisted combustion research conducted at Virginia Tech [39-48] is shown in Table 2.2.

In other plasma-assisted supersonic combustion research, Jacobsen et al. [49] investigated the operating conditions and gaseous fuel ignition behavior for two torch designs: one a direct current (DC) constricted-arc design and the other an alternating current (AC) unconstricted-arc design. Computational analysis assists the design of the experiments, and results show regions of high radical activity and temperatures up to $5000 \mathrm{~K}$. Kitigawa et al. [50] achieved supersonic ignition of gaseous hydrogen and methane by the use of a plasma torch, reporting that methane ignition was only confirmed for fuel injection upstream of the torch. Their results conclusively demonstrate temperature increase associated with combustion, particularly in the case of gaseous hydrogen. A temperature increase of approximately $50 \mathrm{~K}$, relative to the torch-only operating condition, was witnessed as high as $27 \mathrm{~mm}$ above the injection surface for the gaseous hydrogen case. Recently, Takita et al. [51] implemented plasma torch igniters in a more realistic configuration, an array of igniters in the flow direction. Although only two were used, the idea of augmenting the benefits of plasma ignition by arranging multiple torches may show a significant increase in overall combustor performance. 
Table 2.2: Plasma Torch Research Conducted at Virginia Tech

\begin{tabular}{|c|c|c|c|}
\hline Year & Investigator & Description & Summary of Conclusions \\
\hline 1986 & Barbi & $\begin{array}{l}\text { Experimental testing of } \\
\text { uncooled, choked torch with } \\
\text { hydrogen/argon feedstock }\end{array}$ & $\begin{array}{l}\text { Stable operation over wide } \\
\text { range of conditions; thermal } \\
\text { efficiency } \eta \approx 88 \%\end{array}$ \\
\hline 1987 & Wagner & $\begin{array}{l}\text { Analytical and experimental } \\
\text { investigation of radical } \\
\text { effects on ignition }\end{array}$ & $\begin{array}{l}\text { Hydrogen atoms provide } \\
\text { effective ignition, } \\
\text { flameholding source at low } \\
\mathrm{T}_{\circ}\end{array}$ \\
\hline 1989 & Stouffer & $\begin{array}{l}\text { Redesign of torch to } \\
\text { decrease anode erosion; } \\
\text { study of operational } \\
\text { characteristics }\end{array}$ & $\begin{array}{l}\text { Stable operation with pure } \\
\text { nitrogen; anode lifetime } \\
\text { increased to over } 20 \text { hours }\end{array}$ \\
\hline 2001 & Gallimore & $\begin{array}{l}\text { Investigation, design, and } \\
\text { testing of torch with } \\
\text { hydrocarbon fuel injection }\end{array}$ & $\begin{array}{l}\text { Material, geometric, and } \\
\text { spectroscopic analysis of } \\
\text { torch-injector design }\end{array}$ \\
\hline 2001 & Jacobsen & $\begin{array}{c}\text { Experimental torch } \\
\text { operation with gaseous } \\
\text { hydrocarbon aeroramp fuel } \\
\text { injection }\end{array}$ & $\begin{array}{c}\text { Successful mixing and } \\
\text { sustained ignition of gaseous } \\
\text { hydrocarbons }\end{array}$ \\
\hline 2003 & Mozingo & $\begin{array}{l}\text { Experimental examination } \\
\text { of strut-torch combination } \\
\text { as injector-igniter }\end{array}$ & $\begin{array}{l}\text { Heat release, at times well } \\
\text { above torch exit plane, } \\
\text { largely independent of torch } \\
\text { power }\end{array}$ \\
\hline 2004 & Anderson & $\begin{array}{c}\text { Experimental torch } \\
\text { operation with liquid } \\
\text { hydrocarbon aeroramp fuel } \\
\text { injection }\end{array}$ & $\begin{array}{l}\text { Documented interaction of } \\
\text { torch and injector; ignition } \\
\text { not immediately evident }\end{array}$ \\
\hline 2004 & Cross & $\begin{array}{l}\text { Operational characteristics } \\
\text { of torch and gaseous, } \\
\text { thermally cracked } \\
\text { hydrocarbon }\end{array}$ & $\begin{array}{l}\text { Successful operation over } \\
\text { range of powers; temperature } \\
\text { and spectra results presented }\end{array}$ \\
\hline 2005 & Bonanos & $\begin{array}{l}\text { Experimental and numerical } \\
\text { heated flow investigation of } \\
\text { injector-igniter combination }\end{array}$ & $\begin{array}{l}\text { Supersonic and dual-mode } \\
\text { combustion achieved; high } \\
\text { combustion efficiency }\end{array}$ \\
\hline 2005 & Sanders & $\begin{array}{l}\text { Modeling and testing of } \\
\text { unsteady torch operational } \\
\text { characteristics }\end{array}$ & $\begin{array}{l}\text { Improved fuel-air mixing for } \\
\text { a wide range of frequencies } \\
\text { and various waveforms }\end{array}$ \\
\hline
\end{tabular}

In addition to the direct application of supersonic combustion, more fundamental research is being conducted to closely examine the chemical and physical effects of ionized gases on combustion. Arnold et al. [52], studying the role of primary atmospheric cations $\mathrm{N}_{2}^{+}, \mathrm{O}_{2}^{+}, \mathrm{N}^{+}$, $\mathrm{O}^{+}$, and $\mathrm{NO}^{+}$in large alkane reactions, point out the fundamental purpose of the plasma torch: "The oxidation of hydrocarbons is a chain reaction process involving free radicals; the most 
difficult step is thought to be chain initiation, formation of the first radicals, because this involves either thermal decomposition of, or reaction between, relatively stable molecules. Once radical formation is initiated, the remaining steps in the process proceed with little to no activation energy." They conducted similar work with the atomic oxygen anion $\mathrm{O}^{-}$, mentioning that ion-molecule reactions may significantly affect combustion or ignition rates since they are typically 100 times faster than neutral species reactions [53]. They note that this could be accomplished through breaking chemical bonds, creating radicals, and speeding up the first and slowest step in the combustion reaction. Williams et al. [54] conclude that the reactions between air plasma ions and typical aviation fuel constituents are typically much faster than reactions between neutral species involved in hydrocarbon combustion initiation. Furthermore, they find that due to radical recombination, ionization levels for a plasma generating source external to the combustion would be too low to significantly affect combustion. For this reason, the source of ions must be located internal to the combustor in order to significantly reduce ignition delay time. This important conclusion summarizes the function and purpose of the Virginia Tech plasma torch used in the current investigation. 


\section{Experimental Equipment and Procedures}

\subsection{Testing Facilities}

\subsubsection{Quiescent Environment}

Quiescent testing was conducted in a chamber which was fabricated from a section of steel pipe. The chamber itself was located on the outside of the building, and a large hole in the wall enabled access to the chamber from the inside test area. The pipe is shown Figure 3.1; on the right is a heavy canvas tarp which was used to protect the test section from the weather. Visible on the left is a large rectangular hole which was cut in the pipe and allows for the experimental apparatus to be enclosed by the pipe.

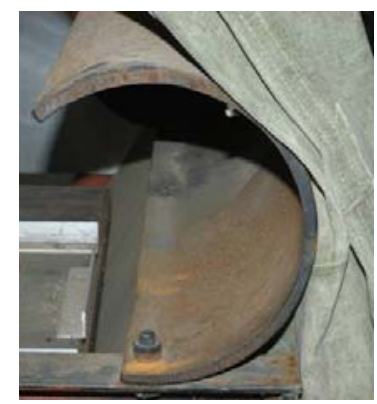

Figure 3.1: Testing Chamber of Quiescent Setup

A piece of Lexan was fitted over the opening and secured during testing as a safety measure. For optical access, cameras were focused through small openings in the thermoplastic barrier. An optical table housed the electrically isolated plasma torch bracket and the fuel delivery system. Cameras were mounted to the table, which was positioned on rails so it could be easily moved into and out of the combustion chamber. During tests, the plasma torch was secured in the bracket, and the assembly was slid into the chamber, as seen in Figure 3.2. The fuel delivery and control system was very similar to that used in the supersonic tests, and can be seen in Figure 3.11 . 


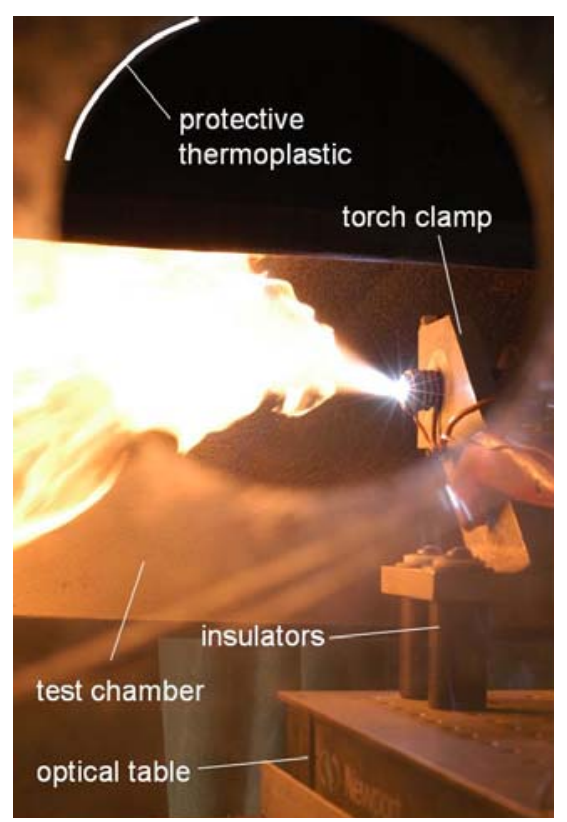

\section{Figure 3.2: Quiescent Testing Environment}

Designing and building an adequate ventilation system for the combustion reaction was necessary for safety reasons. Its functions included containment of the combustion reaction, removal of combustion products and unburned reactants from the experimental area, and control of the air flow supplied to the combustion zone. Air flow was achieved by a constant speed induced-draft blower. The blower was capable of drawing air through the experimental area at a rate of 1050 CFM. Control of the flow rate of air was achieved with an adjustable damper mounted on the upper leg of the tee which connected the blower to the experimental area. Closing the damper resulted in greater flow rates through the experimental area. Fully opening the damper allowed air to be drawn from the atmosphere. A partially-open damper produced a flow rate in-between the maximum and minimum. For the experimental results shown, the damper was fully open. This ventilation system is shown in Figure 3.3. 


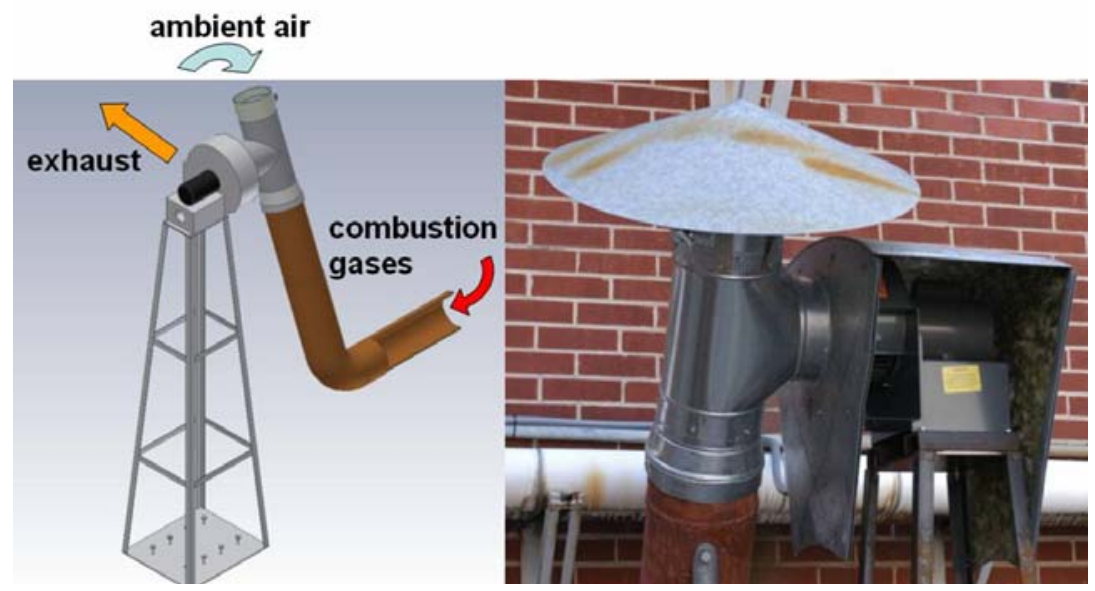

Figure 3.3: Quiescent Ventilation System

\subsubsection{Supersonic Environment}

Supersonic testing was conducted in the Virginia Tech unheated, blow-down wind tunnel with a Mach 2.4 nozzle. A compressor pressurizes a supply tank, which feeds air through a main valve and a control valve into the wind tunnel plenum. The valves were controlled with a computer, the plenum pressure adjusted by a proportional integral derivative (PID) controller. Tunnel operation was conducted by at least two people. One operator monitored the feedback from the tunnel control computer, which was located a safe distance away from the tunnel window. This operator initiated the LabVIEW sequence which automated the tunnel run. The other operator operated the main valve, safety horn, and supply tank load and unload switches from a control panel. Typical freestream conditions were $\mathrm{T}_{\mathrm{o}, \infty}=280 \mathrm{~K}$ and $\mathrm{P}_{\mathrm{o}, \infty}=360 \mathrm{kPa}$, with run duration lasting approximately $10-12 \mathrm{sec}$. Key features of the supersonic wind tunnel are noted in Figure 3.4. 


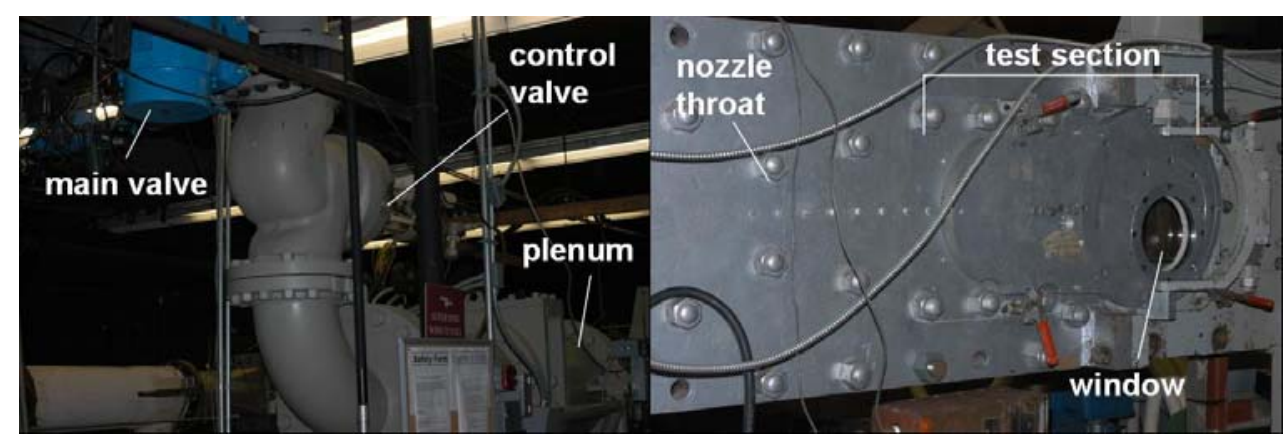

Figure 3.4: Virginia Tech Unheated Blow-down Supersonic Wind Tunnel

The igniter-injector was installed in the floor of the test section as seen in Figure 3.5. Precise tolerancing allowed for nearly-flush implementation. The inserts shown were necessary to avoid modifying the geometry of the floor plate, which was being used by another tunnel operator in subsequent tests. A single thermocouple is seen exposed in the flow; this was used as an initial temperature rise indicator. The total temperature rake, described in Section 3.5.4, entered the test section through the long slot seen near the back end of the floor plate.

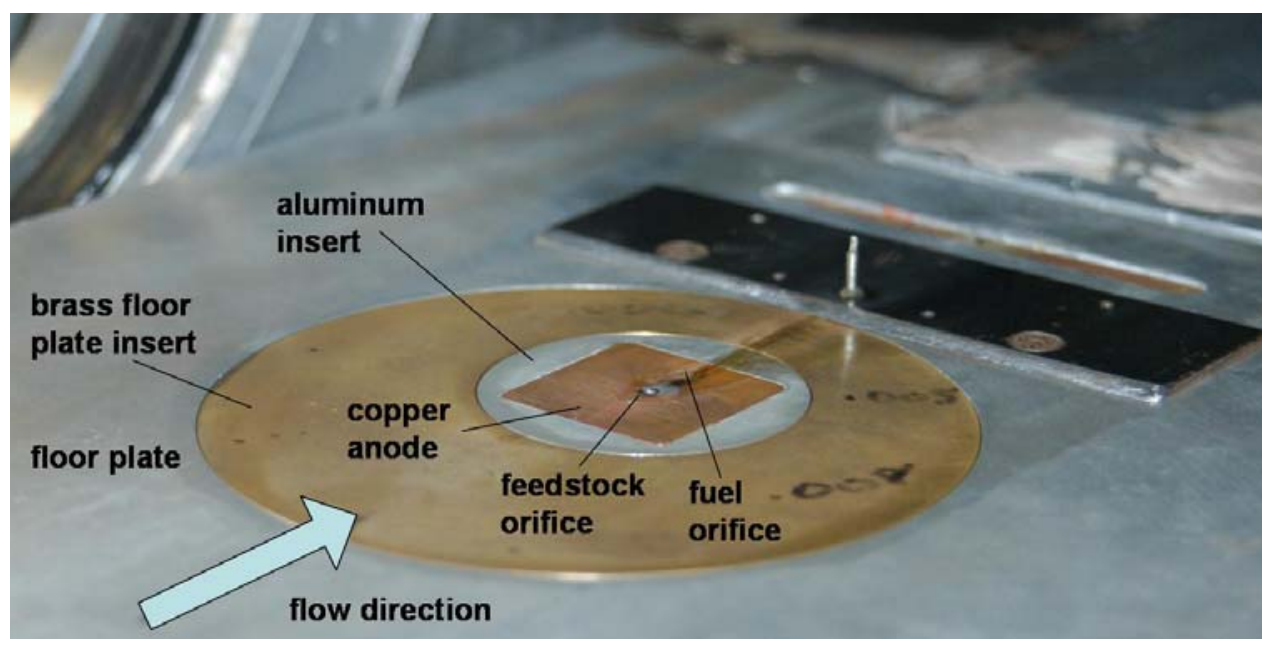

Figure 3.5: Flush-Wall Supersonic Wind Tunnel Implementation

\subsection{Plasma Torch}

Individual components of the plasma torch igniter are identified in Figure 3.6. The anode, which threads on the left end, is discussed later. The cathode extends the length of the torch body, passing through bored holes in each piece. The flow swirler is design to impart tangential 
velocity to the feedstock gas. The insulator rod is meant to provide perfect alignment of the cathode so that it remains concentric with the anode when assembled. The two connections are a pressure tap and the feedstock supply line. Insulators on the assembly screws and the torch body maintain adequate space between the positive and negative electrodes to prevent arcing. The micrometer drive provides an easy method of gap adjustment, and can be used as the contact point for the positive electrode.

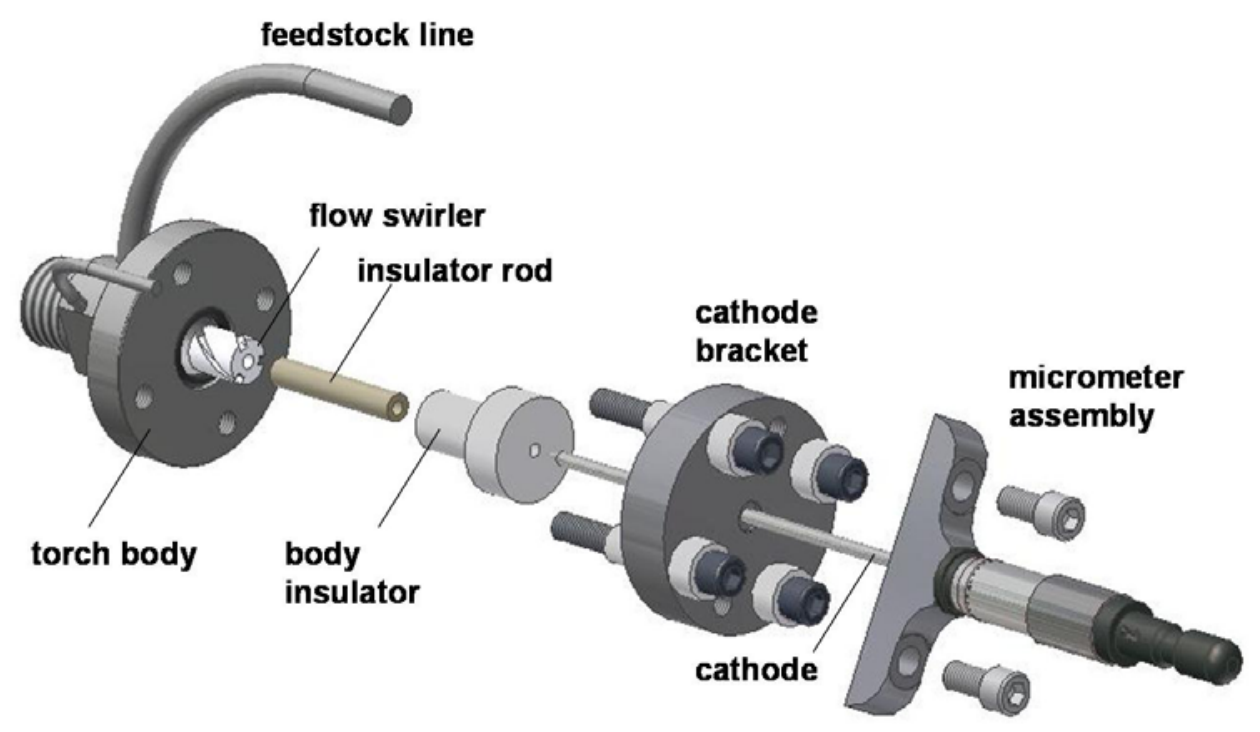

Figure 3.6: Plasma Torch Igniter: Component View

The assembled plasma torch is shown in Figure 3.7, along with the indicated section view. Again, the anode is not shown here. The section view illustrates the assembled relationships between individual components. 

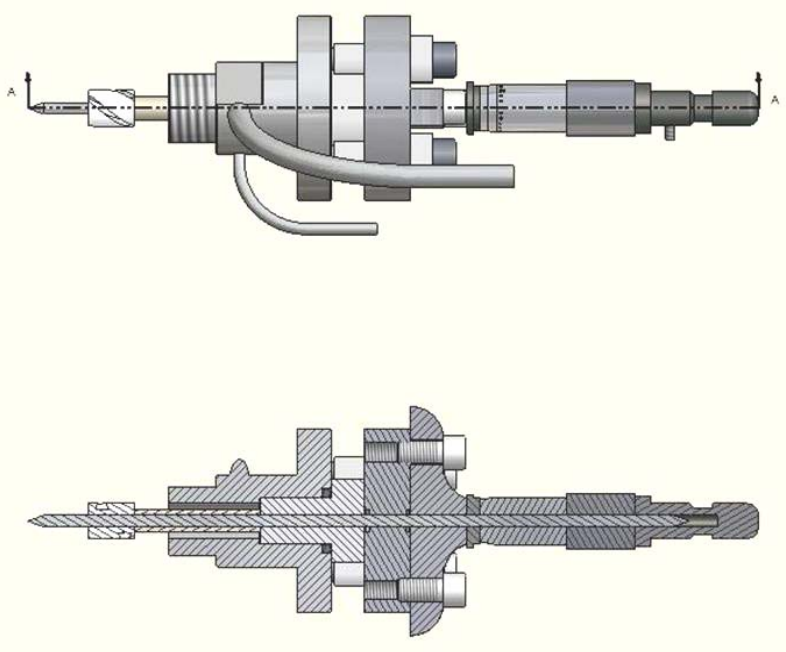

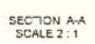

Figure 3.7: Plasma Torch Igniter: Assembled and Section Views

\subsection{Quiescent Anode}

The plasma torch igniter shown in Figure 3.7 has repeatedly been proven as a capable ignition source (see Table 2.2) which produces a high temperature, partially ionized mixture with relatively low power consumption. Because of the effectiveness it has demonstrated, it was decided to use the currently available igniter described previously rather than alter the design. However, with the need for regenerative fuel heating and operation with liquid hydrocarbons, the anode was redesigned. The majority of the internal geometry remained essentially unchanged, as did certain external dimensions which were necessary for mounting in the current test setup (Figure 3.2). However, modifications were made to allow the anode to function as a regenerative heat exchanger which simultaneously cooled the anode and heated the fuel. Additionally, it was chosen to implement anode inserts, which were relatively easy to fabricate. An anode insert was removed when it was too eroded to function properly, and replaced with a new one. By doing this, the complicated geometry of the main anode body was only machined once. Figure 3.8 shows schematics of the anode body including insert and heat exchanger coil. A cylindrical channel was machined in a spiral pattern along the length of the copper anode body to provide a 
seat for the heat exchanger coil. The tubing was silver-soldered into the channel to maximize surface contact area. The effectiveness of this modification on heat transfer is discussed in Section 4.1.2. The near end of the heat exchanger tubing was plugged with silver solder, and the fuel injection orifice was drilled from the anode face through a portion of the anode and into the tubing. The fuel injection orifice was drilled with a $0.020^{\prime \prime}$ bit at an angle of between $37^{\circ}$ and $40^{\circ}$ with respect to the anode face.

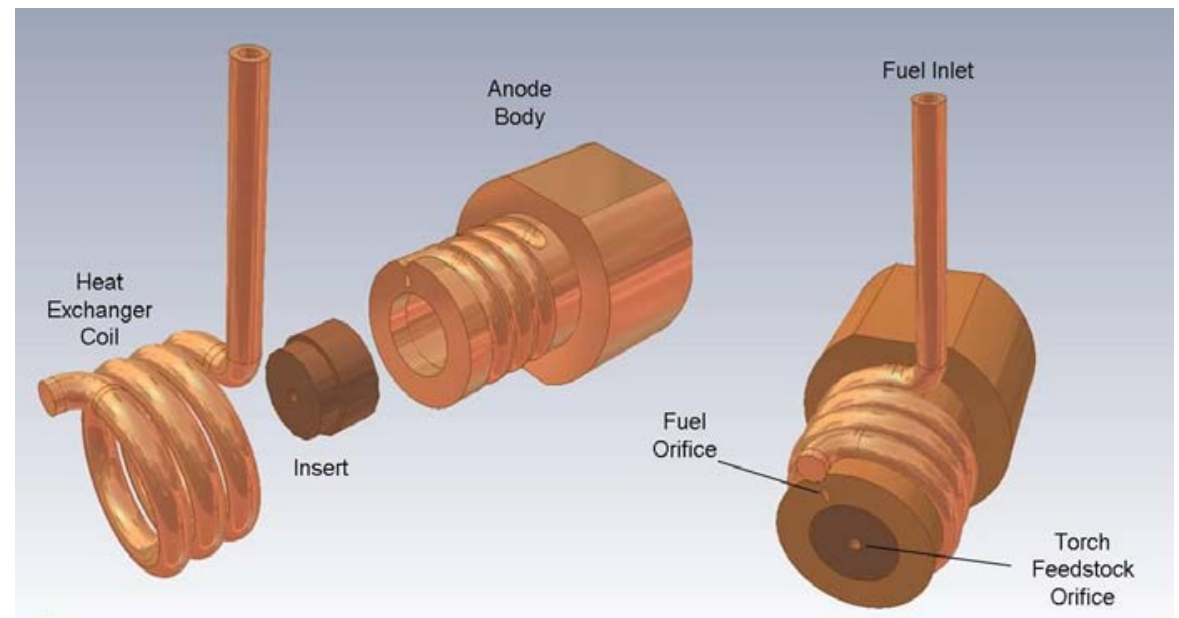

Figure 3.8: Quiescent Injector-Igniter Anode Assembly Schematic

\subsection{Supersonic Flow Anode}

For supersonic testing, it was realized that the anode would need to be altered due to the noticeable gap between the end of the coil and the anode face (see Figure 4.1). Even if this gap could be filled with wax or resin, there was not a suitable way to secure the quiescent anode design in a tunnel floor plate, mainly due to its circular geometry and the heat exchanger coil. Several designs were considered. Ultimately, the anode shown in Figure 3.9 was designed and constructed. While this uniquely-shaped heat exchanger anode posed some fabrication difficulties, it has the benefits of internal cooling passages which maximize heat transfer, a smooth external surface so it can be snugly fit and fastened into the aluminum insert shown, and the ability to change the fuel injection direction by $90^{\circ}$ or $180^{\circ}$ due to its square shape. The 
aluminum insert was secured into a brass insert, which was in turn fit into the aluminum floor plate, as shown in Figure 3.5. The most difficult task in constructing the anode was forming the internal cooling passages. This was a complex and time-consuming process, but the skill of the machinists resulted in a leak-free anode with internal cooling passages and a 0.020 " fuel injection orifice.

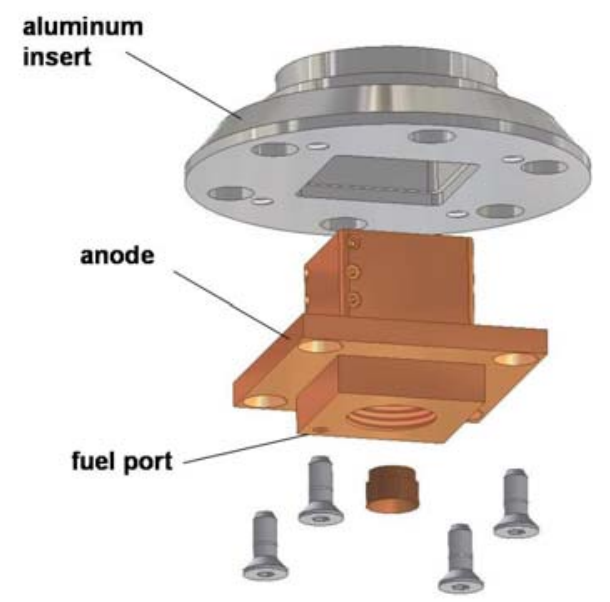

Figure 3.9: Supersonic Anode: Assembly Schematic

Another perspective of the anode is provided in Figure 3.10. In this view, the anode is shown inserted into the aluminum insert. The anode insert has been press-fit into the anode, and the internal cooling (fuel heating) passages are shown. The figure on the left shows two diagonally-drilled passages, which were necessary to connect a level of passages with the level above or below it. The plasma torch was threaded into the anode as indicated, with the flow swirler in-between the anode insert and the torch body. Fuel entered through the bottom, and moved through the hot anode body until it reached the fuel injection passage, which was drilled at $40^{\circ}$ to the horizontal anode face. At this point it was injected through the orifice at a location close to the plasma torch feedstock orifice. The proper operation of the heat exchanger-injectorigniter was impressive given its complexity and small scale (the anode measures 1.125 " on its sides). 


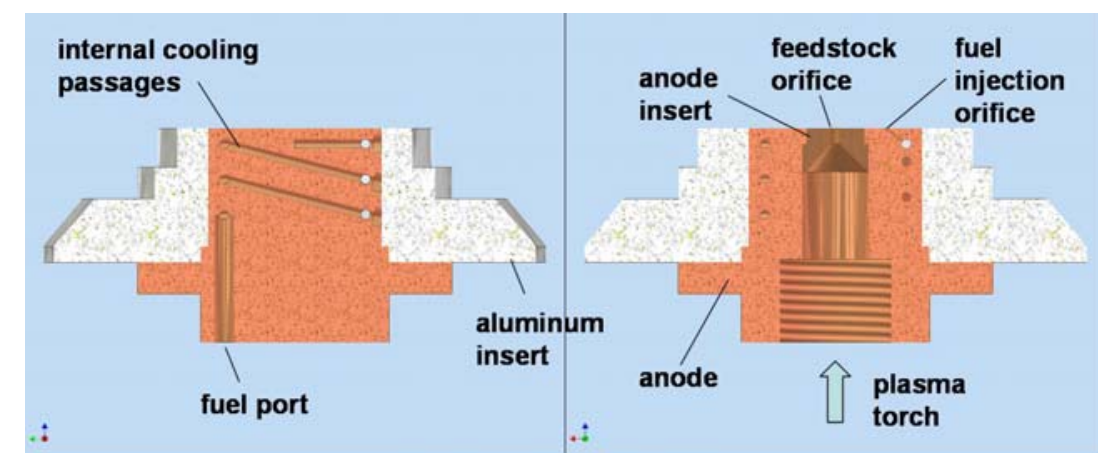

Figure 3.10: Supersonic Anode: Section Schematic

\subsection{Experimental Setup}

The experimental setup for the supersonic configuration is shown in Figure 3.11. Five primary systems are shown, indicated by color according to the legend. The supersonic setup was understandably more complex than the quiescent, given the additional wind tunnel operation data. Important features of each system will be discussed individually.

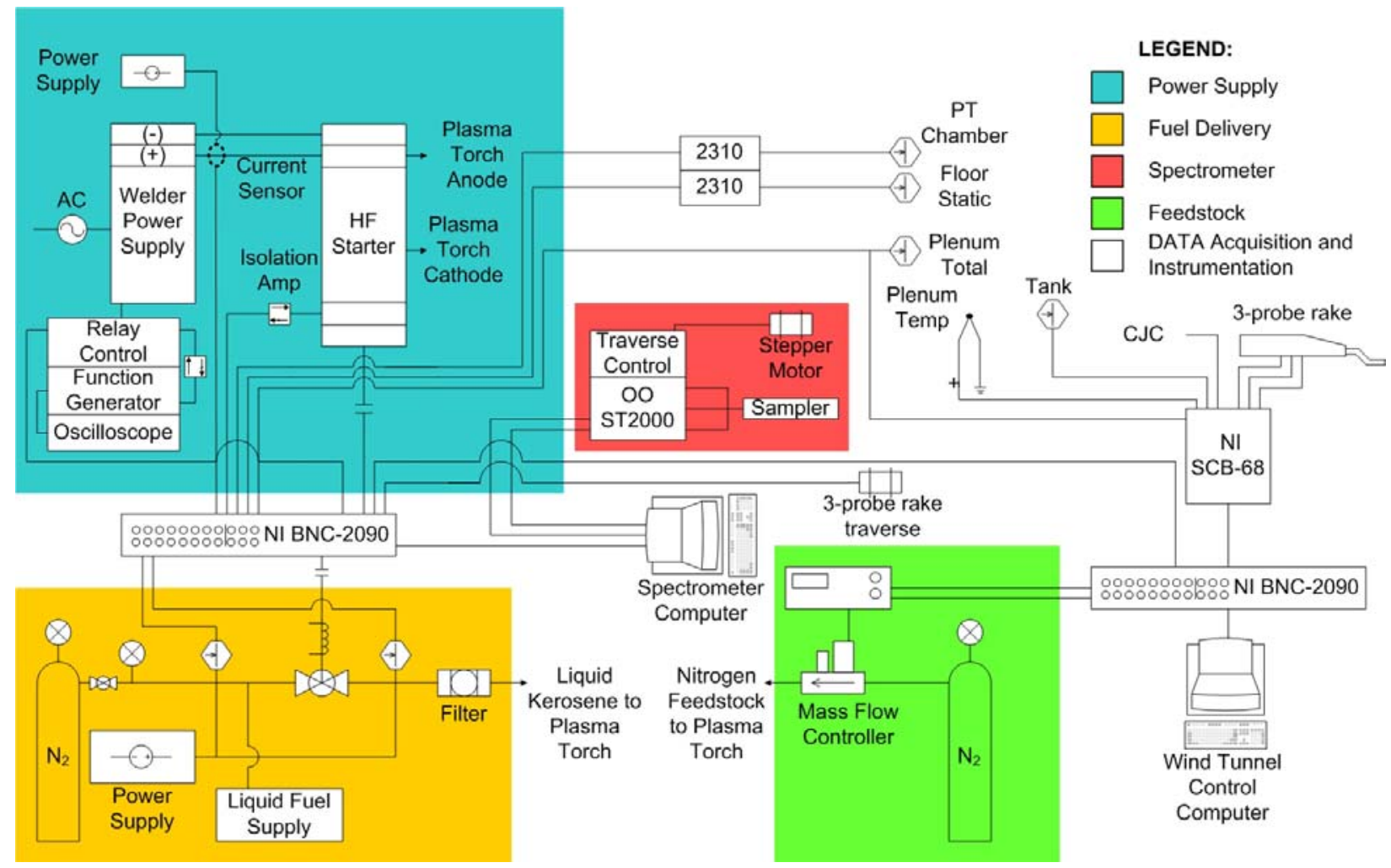

Figure 3.11: Experimental Setup (Supersonic Configuration) 


\subsubsection{Plasma Torch Power Supply System}

The power required to initiate and maintain the arc was provided by a Thermal Dynamics PakMaster 100XL Plus Plasma Cutting Power Supply and a Miller HF-251D-1 High Frequency Starter. The starter provided a short burst (between 0.1-0.25 sec.) of high frequency current to initiate the arc, although in some cases, the welder alone provided the potential necessary to draw an arc. Both the welder and the starter were remotely controlled through individual relays by the computer. The welder provided an open circuit voltage of $260 \mathrm{~V}$, with an adjustable current level of 15 - 80 A. The plasma torch current level was controlled by a G5100 Sensotek programmable function generator, which sent a voltage signal to the welder relay control box. This signal was monitored by a Beckman Industrial 9020 oscilloscope. When the computer activated the relay, the remote voltage signal modulated the welder current and the plasma torch. This allows the plasma torch power level to be adjusted or modulated over a wide range of frequencies and waveforms [46]. For the current tests, pure DC voltage was used. Analog Devices isolation amplifiers were used to protect sensitive equipment from high transient voltages and a Hall Effect current sensor measured the plasma torch current.

\subsubsection{Feedstock and Fuel Supply Systems}

Nitrogen feedstock was controlled by a Sierra Instruments $840 \mathrm{M}$ mass flow controller. The nitrogen supplies for the feedstock and the fuel driver were ordinary gas cylinders. A liquid fuel delivery system was designed to allow for convenient testing with any liquid fuel compatible with the materials of construction, although water, kerosene, and JP-7 were the fluids tested, with water being a baseline case to test system performance. It was decided to avoid a large fuel supply tank, and instead test small amounts of fuel, refueling the system after each run. This was accomplished using a vertical standpipe, which was filled with between 10 and $20 \mathrm{~mL}$ of liquid 
fuel, depending on the desired injection duration. This design proved to be safer, less complicated, and more efficient, and allowed for comparison runs between fuels using the same torch and ambient operating conditions. The pipe was then capped, and the system was pressurized to the desired injection pressure. Nitrogen was chosen as the pressurizing gas for safety and availability. When the plasma torch was remotely ignited, a trademark luminous plume of excited species was visible at the feedstock discharge orifice. Shortly after the torch operation began, the automated solenoid valve in the fuel delivery system was opened, and fuel injection started about $0.5-1$ second later. Typical supply pressures of between 20-70 psi were tested, with most tests using approximately $50 \mathrm{psi}$. The liquid fuel injection consisted of between 3-5 seconds of pure liquid fuel flow, followed by a period of intermittent fuel and gas flow as the pressurizing gas purged the system of fuel, and finally a short period of pressurizing gas flow to cool the anode.

\subsubsection{Spectrometer System}

An Ocean Optics ST2000 three-channel spectrometer was used for spectral emission investigations. The light was collimated and focused at the end of a fiber optic line, which was then split into three individual channels. These channels were processed by a charged-coupled device (CCD) and processed with the LabVIEW programs provided by Ocean Optics. The spectrometer was traversed automatically with a Velmex NF-90 2-axis stepper motor controller.

\subsubsection{Data Acquisition and Instrumentation System}

All data was acquired with National Instruments cards and processed with LabVIEW. As shown in Figure 3.11, each NI BNC-2090 interface board utilizes 8 analog input channels, as well as DIO channels and analog out channels. Additionally, the spectrometer computer processed spectral data with through a separate port. Because the tunnel control computer was 
not equipped with cold junction compensation (CJC), an NI SCB-68 (with CJC) box was used to interface between the instruments and the card. Since high frequencies were not expected during the steady-state torch operation, a low sampling frequency of $500 \mathrm{~Hz}$ was used. A multiplexer was not used because previous testing complications led to the conclusion that the plasma torch operation interfered with the MUX processing to the extent that the tunnel control program itself was not behaving properly. For this reason, a two-card DAQ method was implemented. In addition to DAQ, the computers worked simultaneously to provide control of the experiment through the use of digital lines. For a typical run, the spectrometer waited for a handshake signal from the tunnel computer, which was sent after the tunnel computer started the feedstock and the wind tunnel. After receiving the handshake, the spectrometer computer sent a busy signal back to the tunnel computer on another DIO line, then started the welder and high frequency starter. The program allows for spectral snapshots to be taken at various locations throughout the run. For the spectrometer tests, a snapshot was taken with the torch on but without the fuel on. The fuel solenoid was then opened, and fuel entered through the injector about a second later. After a brief time, another spectral snapshot was taken. All this time, the tunnel computer waited for a finished signal from the spectrometer computer, which it eventually received, and then closed the wind tunnel valves.

Various types of data were collected, but two important sources of information from a combustion standpoint were the spectral data (Section 3.5.3) and the total temperature data. The total temperature was measured using a three-probe traversing rake. The exposed thermocouple junctions inside the individual probes were located approximately 0.9375 in. downstream of the torch feedstock orifice (See Figure 5.11). The rake had the capability of traversing vertically into 
the flow, but due to the unsteady behavior of the temperature vs. time, it was decided to move the traverse manually between tests. 


\section{Quiescent Results}

The quiescent testing served as the proving ground for the design, so the results presented here are important from an operational standpoint. In the current discussion, the term quiescent is used to designate conditions very close to atmospheric, with relatively no velocity. Although for the combustion experiments a significant velocity was introduced by the induced-draft blower, the direction of airflow was in approximately the same direction as the fuel injection, and therefore had little crossflow effect on the combustion reaction. Velocity is also present in the fuel mist as the atomized droplets evaporate and burn, although their velocity is relatively low assuming thorough atomization. These approximations are sufficient in this case to treat the experimental conditions as close to quiescent.

\subsection{Preliminary Water Testing}

\subsubsection{Anode Life}

Any practical ignition system must be able to operate without failure in extreme conditions. In particular, the electrode materials are subject to high temperatures as the electric arc attaches directly to their surfaces. The detrimental effects of this arc attachment can be seen immediately, as the anode develops a blackened region on its surface. Eventually, the anode body itself melts in the region of arc attachment, and globules of molten metal have been observed separating from the anode body and being carried downstream [42]. In fact, Stouffer [47] devoted significant time and effort to eliminate anode erosion by redesigning the igniter itself. Due to the fact that anode erosion is a limiting factor in the operational time of the igniter, substantial effort was made to partially eliminate anode erosion.

The term regenerative indicates that the atomizer-igniter design uses otherwise wasted energy in a constructive way. In this case, energy transfer to the anode body from the electric arc 
is otherwise wasted energy. Therefore, a method of useful heat transfer was implemented that effectively cooled a portion of the anode body. This cooling caused the anode body to act as a heat sink for the extremely high-temperature arc attachment region. The utilized energy was manifested in the heating of the working fluid, in this case water or kerosene. In the study of anode life, water was used as a working fluid due to safety concerns that were subsequently addressed.

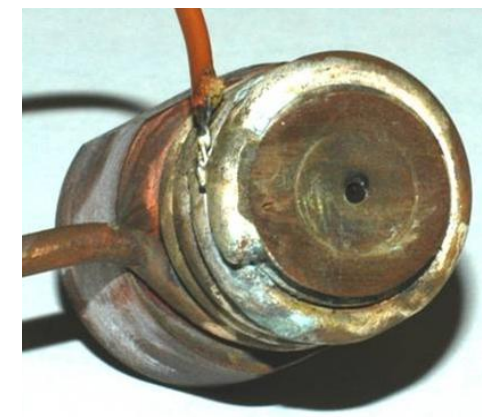

(a)

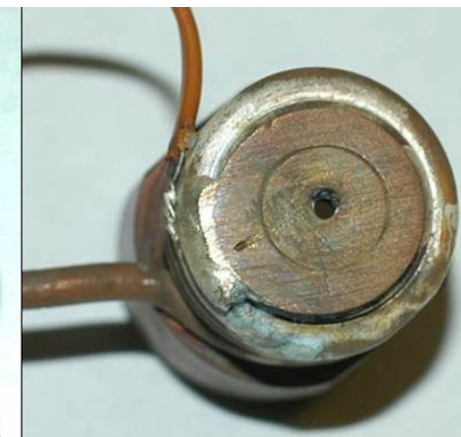

Figure 4.1: Anode Erosion Com

Figure 4.1 is a comparison of photographs taken of the anode after various run durations, with and without water cooling. In (a), the anode is shown after approximately $10 \mathrm{~min}$. total run time, using water as a cooling fluid. No critical erosion has occurred, although as expected a small blackened area is visible along the upper rim of the feedstock discharge orifice. This burnt portion has increased slightly in area in (b), taken after about $15 \mathrm{~min}$. total run time. At this point, the torch was operated at the same power level and ambient conditions for another $10 \mathrm{~min}$. without using water as a heat sink, and the results are shown in (c). A large semicircular cavity has formed, with its blackened perimeter proceeding even until the edge of the anode insert. To summarize, little noticeable anode erosion is seen after continuous operation for $15 \mathrm{~min}$. with heat exchange. However, operation for an additional $10 \mathrm{~min}$. without heat exchange caused drastic anode erosion, evidenced by the large pit on the anode surface. Based upon these observations, it is concluded that torch operation with regenerative heat exchange is far more 
effective than torch operation without anode cooling, causing a significant increase in anode life. These anode erosion comparison tests justified the design of the heat exchanger, and were an important part of the preliminary testing.

\subsubsection{Liquid Temperature Rise}

In addition to addressing a possible solution to anode erosion, the preliminary tests served the purpose of studying the temperature rise in the cooling fluid. As described above, regenerative cooling utilizes wasted energy effectively. Not only did the heat exchanger design prolong anode life, but it also acted as a convenient method of fuel preheating. Tests were run to examine the degree of temperature rise associated with the heat exchanger design, to give an indication of atomization and combustion benefits. It was realized that preheating a liquid fuel prior to atomization and ignition would have a positive effect on combustion, namely a decrease in the time required from injection to ignition. Fuel preheating is a practical way to reduce the evaporation time. Furthermore, an increase in fuel temperature results in lower viscosity and surface tension, leading to better atomization, i.e. reduced initial mean drop sizes, and therefore a further decrease in evaporation time [25]. Again, for the series of tests conducted in this discussion, water rather than kerosene was used. Figure 4.2 shows water temperature behavior over time for several mass flow rates. 

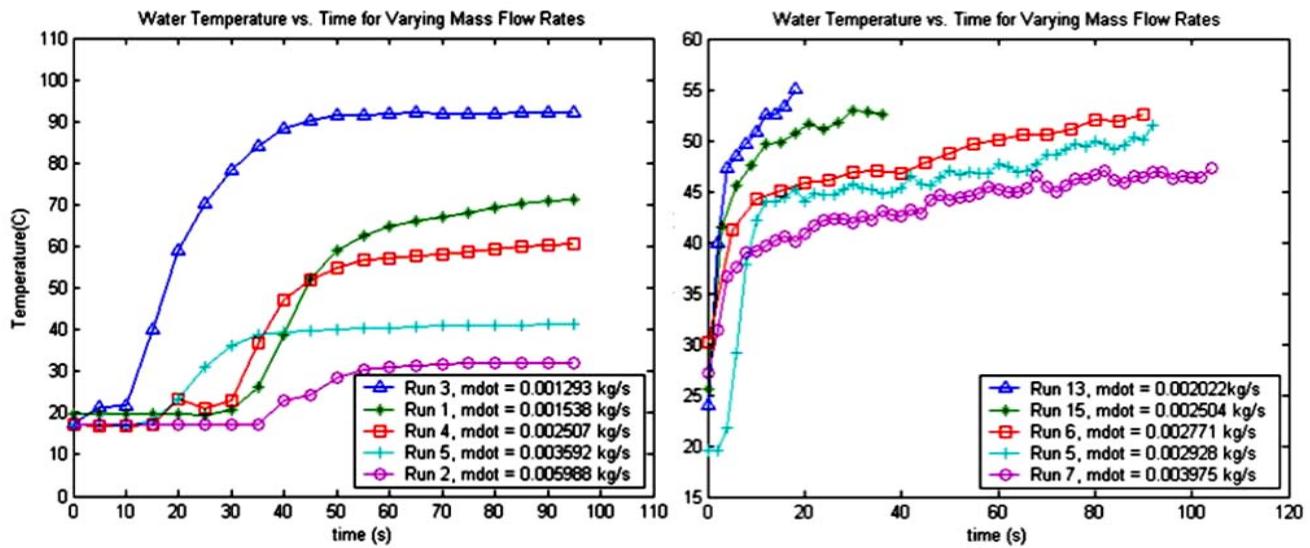

\section{Figure 4.2: Water Temperature Rise for First and Second Generation Quiescent Anodes}

As expected, a reduction in flow rate corresponds to a greater increase in temperature.

The water temperature rise shown in (a) was measured with the first stage heat exchanger anode, which returned the heated water to a collection container instead of injecting it. The anode was then redesigned, resulting in the second stage configuration, which injected the heated water through the fuel injection orifice after it passed through the heating coil. The second stage results are shown in (b). Note that the legends on each figure do not correspond to equal flow rates. Note also that in (b), the initial period of inactivity, i.e. constant temperature, is not shown in order to directly compare the transient temperature rise behavior. As the figure shows, the first and second stage heat exchanger anodes produce similar temperature rises for a given flow rate, such as approximately $0.002 \mathrm{~kg} / \mathrm{s}$. This would seem to indicate that the first stage anode performed as well as the second stage anode, and therefore no improvements in heat exchange were witnessed by redesigning the anode. However, it should be noted that the first stage anode coil made 5.5 revolutions around the 3/4-in. cylinder, while the second generation anode made only 4 passes around the smaller 5/8-in. cylinder. To quantify, the heat exchanger effectiveness, $\varepsilon$, is defined: 


$$
\varepsilon=\frac{\Delta T}{l_{e}}
$$

where $\Delta T$ is the increase in temperature, and $l_{e}$ is the effective length, in this case found in terms of the number of revolutions $N_{R}$ and the nominal diameter $D_{\text {nom }}$ :

$$
l_{e}=\pi D_{\text {nоm }} N_{R}
$$

For equal temperature rise for the two heat exchanger designs, the increase in heat exchanger effectiveness is a function of the ratio of effective lengths. Based on this calculation for the current heat exchanger designs, it was found that the second stage anode was $65 \%$ more effective than first stage anode. In addition to its greater heat exchanger effectiveness, the second stage anode is smaller and therefore weighs less than the first stage, and this consideration is important to any scramjet designer, particularly when an array of igniters would be used.

\subsection{Atomization Characteristics}

Due to its impact on the combustion process, the atomization characteristics of the injector design were given special consideration. It was decided to examine this behavior in the quiescent environment, understanding that incorporating the injector in the supersonic flow environment would surely result in a different spray pattern as well as a different mean drop size. Theoretically, however, the atomization resulting from supersonic injection would occur more quickly and result in smaller drops than the quiescent atomization due to the extremely high relative velocity between the injected liquid and the surrounding medium. For this reason, studying the atomization of the design in its quiescent setup serves as a worst case scenario, and finer and more immediate atomization would be expected for supersonic injection. 


\subsubsection{Methods of Atomization}

In choosing an atomizer design, it was necessary to consider not only the design that would produce the smallest drop size and a uniform drop distribution, but also to consider physical parameters that were presently available. Already incorporated in the system were a high-temperature sonic flow of plasma torch feedstock gas and ultimately a supersonic stream of air. With both of these high-velocity gas sources available, it seemed sensible to employ a type of fluid-blast or fluid-assist atomizing mechanism, taking advantage of the relative velocity between the atomizing gas and the liquid to be atomized. However, restrictions on the type of atomization, including the existing fixed geometry of the anode body, the size of the experimental apparatus and test area, and the operation of the plasma torch igniter, caused difficulty in employing a well-known atomizer.

Ultimately, the atomizer consisted of a single pressure orifice with no internal mixing. This design could be considered an external-mixing fluid-assist atomizer, as the high-velocity feedstock gas impinges on the liquid fuel stream at a point external to the fuel injection orifice. However, upon examination of the atomizer, it would be more accurately described as a plain orifice pressure atomizer acting in combination with an external-mixing fluid-assist atomizer, yielding a type of hybrid atomizer with two separate methods of atomization. In the first method, the pressure difference across the orifice acts to impart kinetic energy to the liquid stream. This effect is pictured in the inset of Figure 4.3. The small arrows within the confined region indicate that no radial velocity component is present: the flow is confined by the walls of the orifice. Upon injection into the ambient gas, this confinement is no longer present, and the pressure difference between the liquid inside the orifice and the ambient gas is manifested in a radial velocity component, the magnitude of which is proportional to the pressure drop across the 
orifice. In the second method, the kinetic energy of the atomizing gas is used to shatter the stream or droplets of fuel.

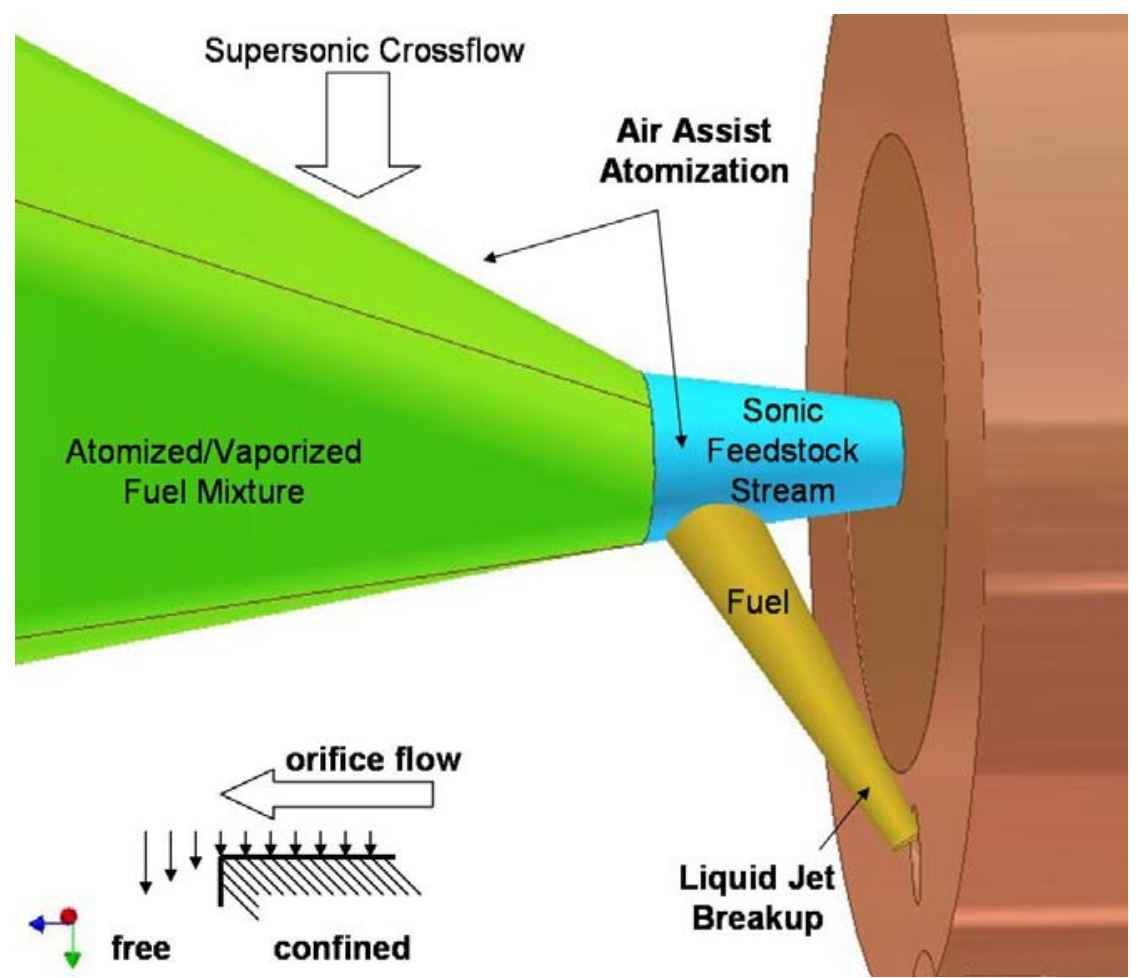

Figure 4.3: Methods of Atomization with Inset Showing Pressure-Orifice Flow

In addition, the implementation of this design into the supersonic crossflow resulted in a third method as the supersonic airstream impinges on the liquid jet, promoting instabilities that immediately cause the circular stream to disintegrate into droplets. The quiescent injector operation with water and kerosene is compared in Figure 4.4. The photographs were taken with an equal strobe time of $3 \mu \mathrm{sec}$ and equal feedstock (atomizer) gas flow rates. It is clearly seen that the atomizer breaks the liquid jet into a cone-shaped polydisperse spray, with the water spray possessing a greater number of large droplets, and the kerosene spray a greater number of small droplets. This difference in drop size between the atomized liquids is primarily due to their difference in surface tension, which influences atomization as discussed in Chapter 2. With the surface tension of water more than two times that of kerosene, the difference in spray shape and 
drop size distribution is not surprising. Both sprays possess regions of fine atomization as well as regions of droplets, large and small, that are not yet vaporized.

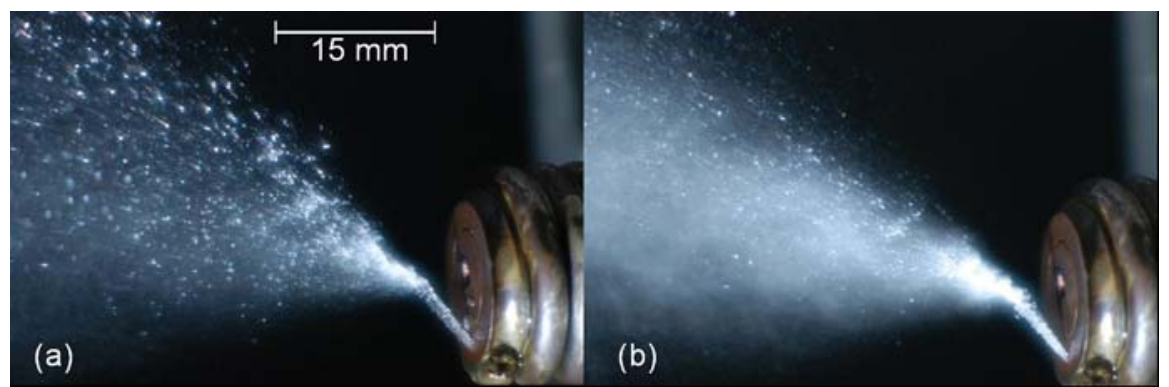

Figure 4.4: Water and Kerosene Atomization Characteristics without Torch Ignition

\subsubsection{Qualitative Observations of Kerosene Injection Mechanics}

Figure 4.5 compares two strobe photographs of kerosene injection and atomization, with insets showing a magnified view of the injection. Several interesting observations can be made about these pictures. The torch is not ignited for these pictures; the feedstock gas discharges at close to sonic velocity from the orifice on the right side to the left, impinging on the liquid kerosene jet. A continuous liquid stream of injected fuel is shown in (a), while (b) shows liquid fuel mixed with nitrogen driver gas being discharged in small quantities as the injection system purged fuel traces remaining in the system. The mode of atomization in (b) can be considered effervescent, as the turbulent flow within the injection system promotes mixing of the driver gas (nitrogen) with the remaining liquid fuel. Although the current experimental setup wasn't designed with barbotage in mind, this type of aerated injection occurred naturally due to turbulent mixing within the injection system. The difference between the photographs in Figure 4.5 is immediately apparent. The continuous fuel injection results in a polydisperse spray including larger droplets as well as fine mist. The kerosene-nitrogen mixture is injected as a spray of droplets rather than a solid stream, and is quickly vaporized and appears as a cloudy mist. The overall spray structure between the two types of injection is also different. The effervescent injection appears to have a narrower, uniform shape, while the continuous fuel 
injection is a wider, cone-shaped spray of droplets. The inset of Figure 4.5(a) shows the beginning of jet disintegration, with the wavelike protrusions growing larger as the jet prepares to breakup. Droplet formation due to jet breakup is not evidenced in this picture, as the jet reached the path of the sonic feedstock stream, and was quickly pulverized and scattered. Droplet formation due to jet disintegration was witnessed in other cases, however.

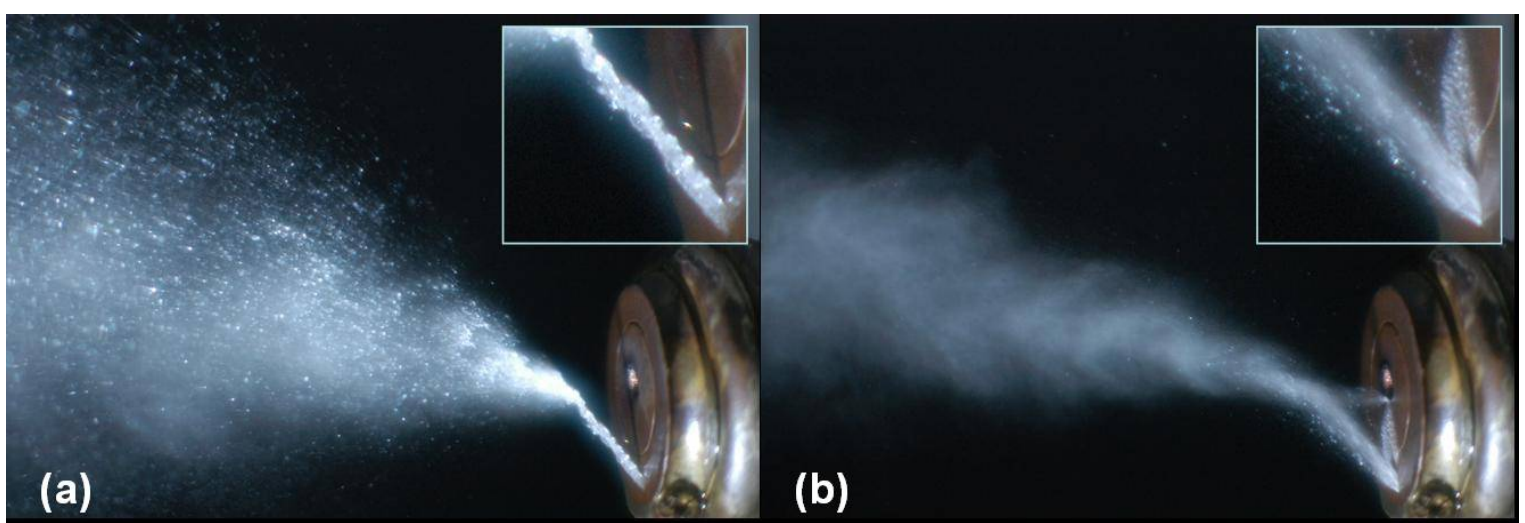

Figure 4.5: Pure Liquid and Effervescent Kerosene Injection without Torch Ignition

\subsubsection{Mode of Jet Disintegration}

To provide a qualitative indication of the jet breakup portion of the injection, the Ohnesorge number for kerosene in the current configuration was calculated according to Equation (2.1): $O h=0.016$.

The Reynolds number was then calculated by Equation (2.2). In the current work, the axial jet velocity in the Reynolds number expression was taken as the discharge velocity, estimated by conservation of momentum for incompressible flow between two points:

$$
V_{L}=\frac{4 A_{s}}{\pi d_{o}{ }^{2}} \cdot V_{s}
$$

where the subscript $s$ refers to the surface of the fuel in the standpipe. The velocity of the fuel in the standpipe, $V_{S}$, was determined based on the height of the standing liquid column, $H_{L}$, and the run duration, $t$ : 


$$
V_{s}=\frac{H_{L}}{t}
$$

For a typical run, the fuel column changed by an average of $2 \mathrm{~cm} / \mathrm{sec}$, which was calculated from the average volumetric flow rate for the run, the area of the vessel, and the average run time. The average mass flow rate of fuel was calculated to be about $0.002 \mathrm{~kg} / \mathrm{sec}$. This results in a Reynolds number $R e=3175$.

The Ohnesorge and Reynolds numbers were plotted on a logarithmic scale to give an indication of the method of jet disintegration. This is shown in Figure 4.6, with the current experiment represented with a darkened square. The classification of regimes shown follows the work of Reitz. As seen in the figure, the jet disintegration of the current work falls in the second wind-induced regime.

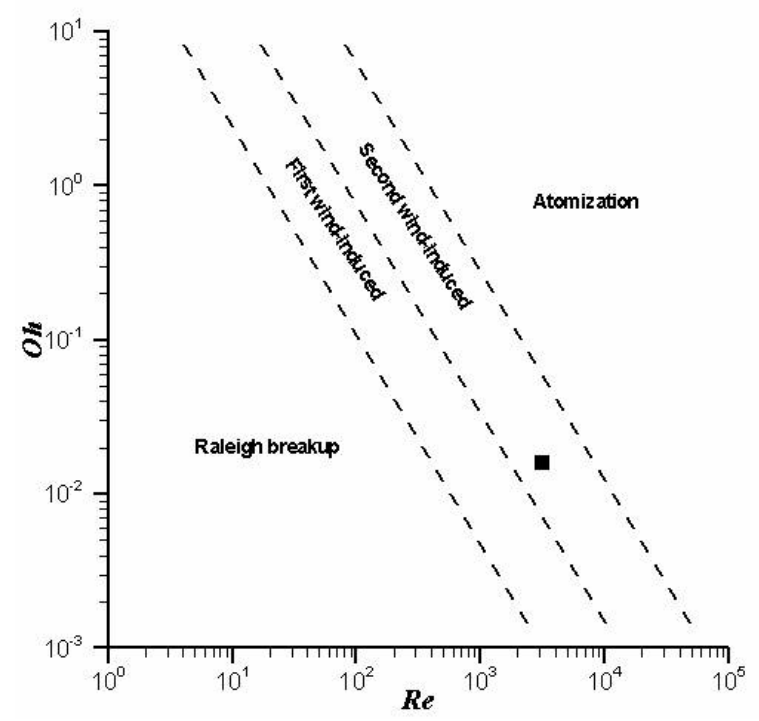

Figure 4.6: Reitz Jet Breakup Regime Classification with Current Experiment

In the wind-induced regime, short-wavelength instabilities on the outer surface of the jet, caused by the relative motion between the jet and the ambient gas, promote breakup into drops. Breakup is opposed by surface tension, drop formation occurs several jet diameters downstream of the orifice exit plane, and drop diameter is much less than jet diameter. This result is in good 
agreement with the magnified kerosene injection photographs shown in Figure 4.7. The photographs clearly show the instabilities, indicated by arrows, forming on the surface of the jet. In accordance with theory, droplets have not formed by the time the stream reaches the sonic feedstock flow.

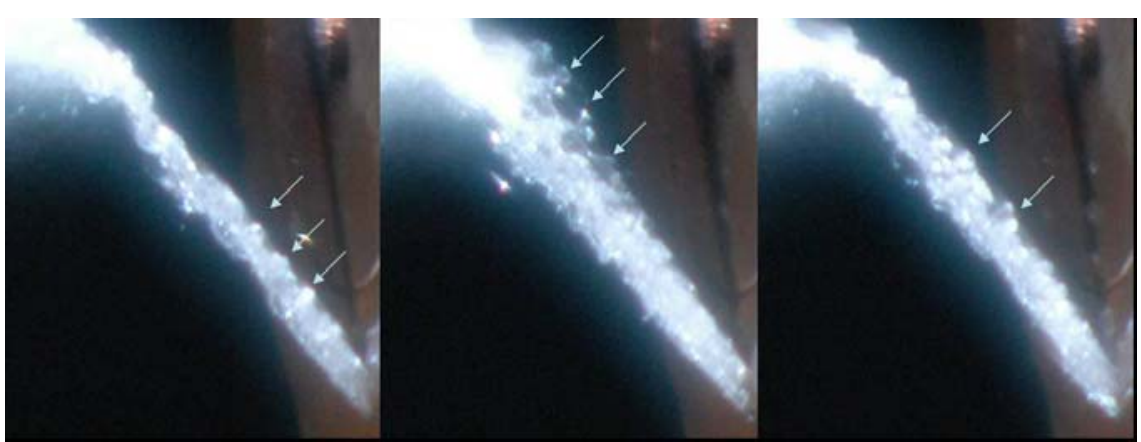

Figure 4.7: Magnification of Kerosene Jet Breakup with Arrows Indicating Instabilities

\subsubsection{Droplet Breakup and Mean Drop Size}

For combustion applications, a spray with small mean drop size is desired for various reasons. One reason is the obviously shorter droplet lifetime associated with smaller drops. The drop size was not experimentally measured in this experiment. Instead, it was estimated from various correlations available in the literature. It was noted above that the design in its quiescent and supersonic configurations depends on fluid-assist atomization to achieve the desired spray properties. Although the fluid used as the high-velocity gas was nitrogen rather than air, the similarities between the two gases allow this difference to be neglected. The current concept, therefore, may be compared directly with existing external-mixing air-assist atomizers, since the high velocity gas interacts with the liquid fuel at a location external to the fuel injection orifice. Experimental studies have achieved drop size correlations for such atomizers with a high degree of accuracy. These have been adapted for the current study to give an approximation of the mean drop size in the resulting spray. This estimate is reasonable given the similarities between the current design and common external-mixing air-assist atomizers, such as the design used by 
Suyari and Lefebvre [55]. Both designs incorporate a cylindrical liquid fuel jet being impinged upon by a high-velocity gas stream at a point external to the liquid injection. A cross-sectional view of the current design is provided in Figure 4.8.

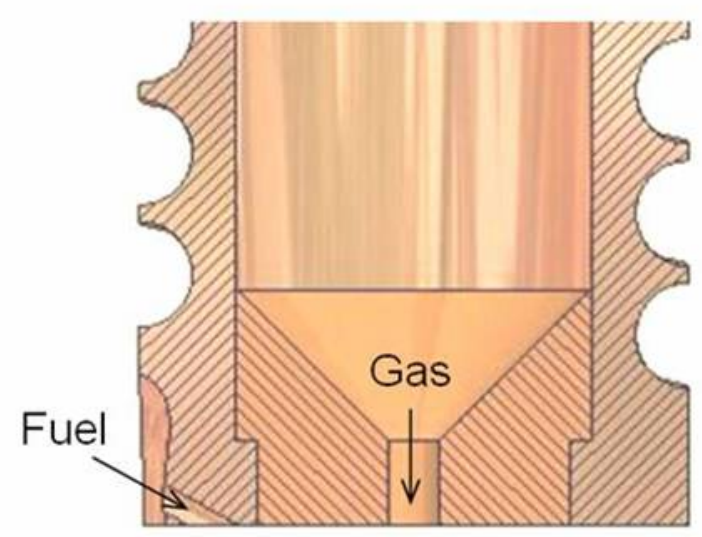

Figure 4.8: Cross-Sectional View of Quiescent Injection Method

Elkotb et al. [56] correlated experimental data for drop size distribution and mean drop size using forty atomizers. Their correlation was later modified by Lefebvre [17] to the following dimensionless form:

$$
S M D=51 d_{o} R e^{-0.39} W e^{-0.18}\left(\frac{\dot{m}_{L}}{\dot{m}_{A}}\right)^{0.29}
$$

where $\dot{m}_{A}$ is the air mass flow rate and $\dot{m}_{L}$ is the liquid mass flow rate. $S M D$, Sauter Mean Diameter, is a commonly used designation for the mean drop size in a mist. It is the diameter of the drop whose ratio of volume to surface area is the same as that of the entire spray. Its other representation is $\mathrm{D}_{32}$, with subscripts 3 and 2 referring to the order of dimension used for volume and surface area, respectively. The Weber number $W e$ was defined for a single droplet deforming in airflow in Equation (2.4), and represents the ratio of aerodynamic forces to surface tension forces. In this correlation, it takes on a slightly modified form: 


$$
W e=\frac{\rho_{L} d_{o} V_{R}{ }^{2}}{\sigma_{L}}
$$

The jet velocity term in the Reynolds number, which was defined in Equation (2.2), is replaced by the relative velocity between the atomizing air and the injected liquid, $V_{R}$ :

$$
R e=\frac{\rho_{L} V_{R} d_{o}}{\mu_{L}}
$$

The first challenge in applying this correlation to the current experiment is determining a reasonable estimate for the relative velocity, $V_{R}$. This can be done by first assuming that little diffusion between the nitrogen feedstock and the surrounding air has occurred. This is reasonable given that the distance from the feedstock orifice to the point where atomization begins is short (approximately $0.19 \mathrm{in}$, or $5 \mathrm{~mm}$.) compared with the overall scale. Therefore, the velocity of the atomizing gas, $V_{A}$, is assumed to be completely in the direction of the discharge orifice. Obtaining this velocity component of the liquid jet is done as follows:

$$
V_{L_{x}}=V_{L} \sin \theta
$$

where $\theta$ is the injection angle relative to the surface and $V_{L}$ is the jet velocity as calculated in Equation (4.3). For the current experiments, $V_{L} \approx 12.5 \mathrm{~m} / \mathrm{s}$ and $\theta=29^{\circ}$. This results in $V_{L_{x}}=6.06$ $\mathrm{m} / \mathrm{s}$. The atomizing gas velocity is found by

$$
V_{A}=M \sqrt{\gamma R T}
$$

For choked flow at the feedstock orifice, $V_{A}=353 \mathrm{~m} / \mathrm{s}$. Clearly, the liquid jet x-direction velocity component has little effect on reducing the relative velocity and therefore the atomization. Now $V_{R}$ can be found:

$$
V_{R}=\left|V_{A}-V_{L_{x}}\right|
$$


For this experiment, $V_{R}=347 \mathrm{~m} / \mathrm{s}$. The next step is determining the liquid and gas mass flow rates. The kerosene flow rate has been calculated as $\dot{m}_{L}=0.002 \mathrm{~kg} / \mathrm{s}$. The volumetric flow rate of the feedstock gas was controlled during experimental testing and was measured in units of standard liters per minute (SLPM). Typical experimental feedstock volume flow rates were around 25 SLPM. Therefore, the mass flow rate of atomizer gas can be found by multiplying by nitrogen density at standard temperature and pressure, and was calculated $\dot{m}_{A}=0.000475 \mathrm{~kg} / \mathrm{s}$. The remaining parameters needed for $\mathrm{D}_{32}$ are either physical properties, geometric constants, or have been solved for. Table 4.1 shows some physical properties important to atomization for the liquids injected in the current work. Finally, Equation (4.5) is used to calculate the $S M D\left(\mathrm{D}_{32}\right)$ for the current external-mixing air-assist atomizer, resulting in a mean drop size $S M D=35.7 \mu \mathrm{m}$. This may be compared with the results reported by Anderson [39], who used an aeroramp injector in supersonic crossflow and measured mean drop sizes between $21-37 \mu \mathrm{m}$. Given the conclusion of Suyari and Lefebvre [55] that atomization quality is promoted by relative velocity between the liquid and gas phases and dynamic pressure of the atomizing air, it is expected that the implementation of the current design in supersonic flow, i.e. a greater relative velocity, will produce atomization comparable or superior to that obtained by the aeroramp configuration used by Anderson. It is likely that the actual $S M D$ for the present work is less than that predicted by Equation (4.5) due to the fact that partial jet disruption has occurred by the time of air-assist atomization.

Finally, it should be noted that rigorous analysis of the injection jet and resulting spray was not conducted, as the focus of the experiment dealt with studying the reacting flow in the presence of a proven igniter. The quantifications discussed here, namely the OhnesorgeReynolds relationship leading to the specific jet disintegration regime and the SMD calculation 
based on the cited empirical correlation provide a good overall indicator of the mechanics of atomization produced by the design.

Table 4.1: Selected Properties of Experimental Liquids

\begin{tabular}{|l|c|c|c|l|}
\hline \multicolumn{1}{|c|}{ Liquid } & \multicolumn{1}{|c|}{$\begin{array}{c}\text { Density } \\
\left(\mathrm{kg} / \mathrm{m}^{3}\right)\end{array}$} & $\begin{array}{c}\text { Viscosity } \\
(\mathrm{kg} / \mathrm{m} / \mathrm{s})\end{array}$ & $\begin{array}{c}\text { Surface Tension } \\
\left(\mathrm{kg} / \mathrm{s}^{2}\right)\end{array}$ & $\begin{array}{c}\text { Tested } \\
(\mathrm{Q}) \text { uiescent; (S)upersonic }\end{array}$ \\
\hline Water & $1000(278 \mathrm{~K})$ & $0.001519(278 \mathrm{~K})$ & $0.0749(278 \mathrm{~K})$ & $\mathrm{Q}, \mathrm{S}$ \\
\hline Kerosene & $800(298 \mathrm{~K})$ & $0.0016(293 \mathrm{~K})$ & $0.032(298 \mathrm{~K})$ & $\mathrm{Q}, \mathrm{S}$ \\
\hline JP-7 & $800(298 \mathrm{~K})$ & N/A & N/A & Q \\
\hline
\end{tabular}

\subsection{Quiescent Combustion}

\subsubsection{Qualitative Remarks on Combustion}

Figure 4.9 shows photographs of the plasma torch igniter operating in conjunction with the injector-atomizer to produce combustion of (a) kerosene and (b) JP-7 for similar power levels. A noticeable difference between the combustion behavior of kerosene and of JP-7 was not immediately realized. A luminous flame was clearly visible the entire duration of the injection of both fuels, and the combustion was accompanied by a loud roar. The pictures were taken at an angle perpendicular to the direction of feedstock gas flow and liquid fuel injection. The fuel is visible as a luminous stream, with injection occurring below the plasma plume and proceeding up and to the left. Shortly after the fuel is injected, the sonic gas stream impinges upon the fuel jet, scattering it into a droplet spray. This region of interaction is visible as the bright bulbous portion on the right side of the images. The light scattering and reflection due to the droplets is an indicator of the region of atomization, not the area of the torch plume. Although in these images the flames appear different in size, shape, and color, it should be noted that the flame properties fluctuated throughout the course of each test, and therefore these images are not necessarily representative of the entire duration of combustion. 


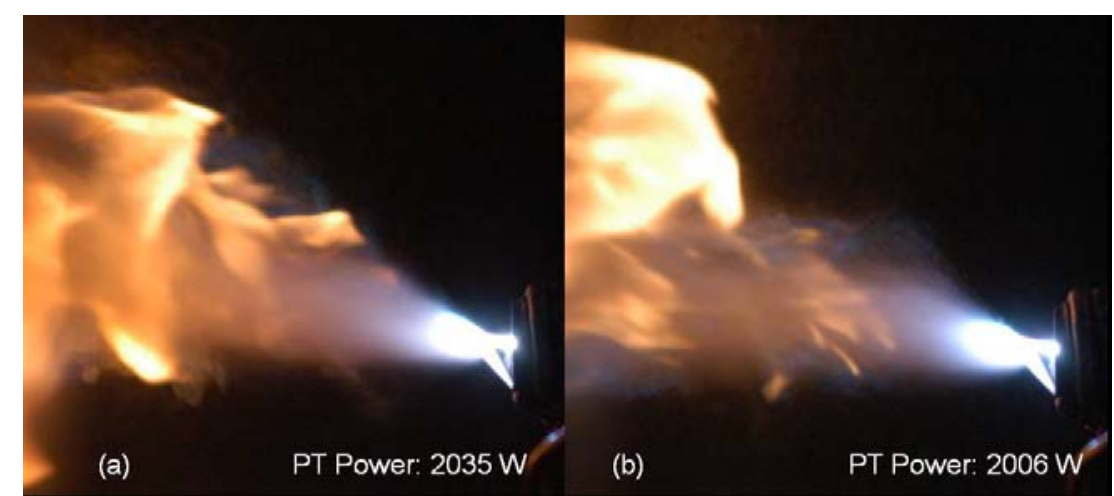

Figure 4.9: Kerosene and JP-7 Quiescent Combustion at Similar Powers

The sequence of frames in Figure 4.10 shows the progression of a typical kerosene combustion test. Frame (a) shows the luminous plume of the plasma torch igniter operating in the absence of fuel. (b) and (c) were taken during the injection period of the pure fuel. A puff of vaporized fuel is shown in (d) as the purge nitrogen flushes the system of fuel. (e) shows a small sliver of blue luminescence, indicating hydrocarbon combustion even though at this point most of the liquid fuel has been flushed.

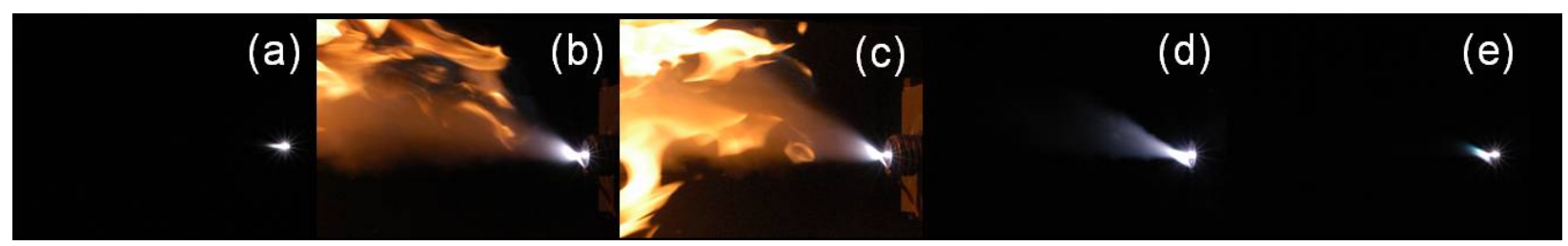

Figure 4.10: Kerosene Combustion Progression in Quiescent Test Configuration

\subsubsection{Effect of Plasma Torch Power Level on Quiescent Combustion}

The plasma torch igniter power level was adjusted over a wide range of settings, and did not appear to significantly affect the degree of combustion. Figure 4.11 shows representative views of the combustion reaction for varying plasma torch power levels for each hydrocarbon used. Kerosene is pictured in frames (a), (b), and (c), with power levels 1558W, 1367W, and $883 \mathrm{~W}$, respectively. JP-7 combustion is shown in (d), (e), and (f), with torch operating powers $1571 \mathrm{~W}, 1338 \mathrm{~W}$, and $844 \mathrm{~W}$, respectively. The bright white portion near the point of fuel injection is the luminous nitrogen plasma plume, and is shown to decrease in area with power 
level decrease. As the figure indicates, plasma torch powers as low as around $850 \mathrm{~W}$ ignite the fuel-air and droplet mixture, producing an equal flame luminosity and area compared with the higher igniter power level tests. Although the power was not decreased to the point of no visible evidence of combustion, the tests at low power levels did seem to produce sporadic combustion in some instances. It is possible that the equivalence ratio was too low for ignition of the fuel droplets and the fuel-air mixture at these low power settings.

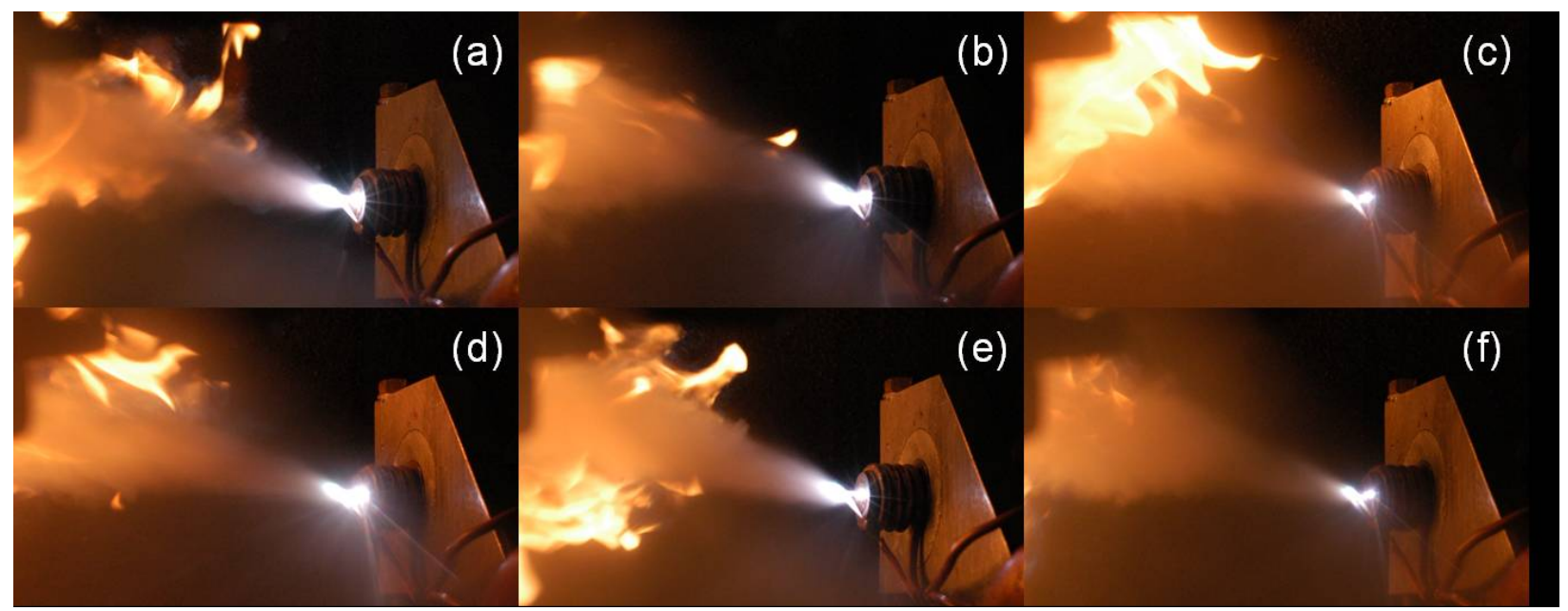

Figure 4.11: Kerosene and JP-7 Combustion at Varying Power Levels

\subsubsection{Flame Formation}

High speed digital video photography was used to measure the time from the beginning of visible fuel injection to the formation of a visible flame in the combustion region. It is important to realize that this study was not a direct measure of ignition delay, which refers to a time period in the chemical regime during which intermediate reactive species form prior to ignition. This discussion includes physical processes, such as atomization and diffusion, and is more appropriately a measure of flame formation. Figure 4.12 and Figure 4.13 show the flame development sequence for kerosene and JP-7, respectively. Both figures are sequences of frames, with the frame in the upper-left of the frame matrix being the first frame, and the frame sequence increasing from left to right for each row of frames. The dark object visible on the left of the 
images is blockage from part of the experimental apparatus and should be disregarded. An orange box on each figure indicates the instant that a luminous flame kernel, indicating the onset of ignition, became visible. With each frame representing $2 \mathrm{~ms}$, it is apparent that the flame formation time for JP-7 is approximately $36 \mathrm{~ms}$ longer than that of kerosene. A possible reason for the difference in flame formation is explained by the discrepancies in evaporation behavior between kerosene (Jet A) and JP-7 [57]. Another possibility for these results is simply coincidence, especially considering the degrees of uncertainty involved with the injection process, i.e., minute changes in injection pressure, torch behavior, etc. In any case, both fuels ignite and develop luminous flames in less than one-tenth of a second following injection, hinting at the promising behavior of this igniter-atomizer design in high-velocity crossflow.

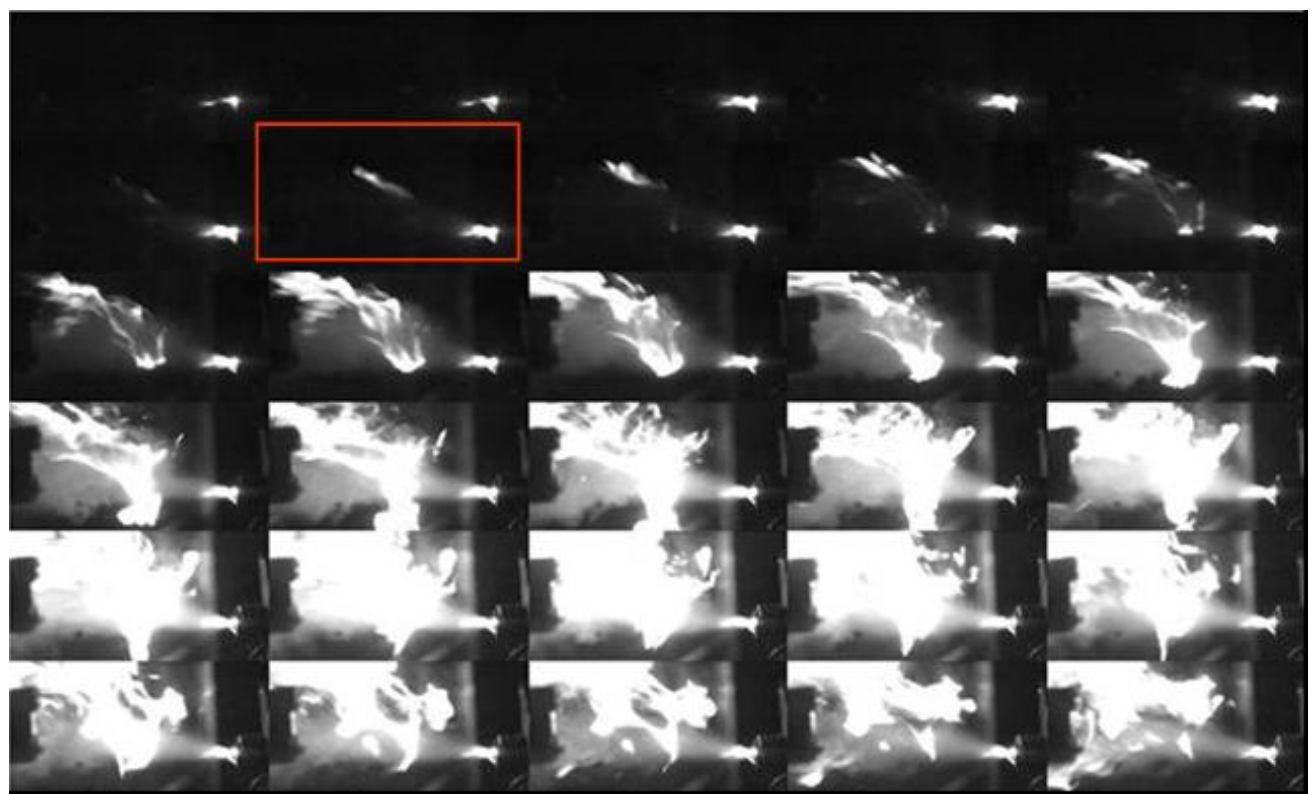

Figure 4.12: Kerosene Flame Formation Sequence with Visible Flame Kernel Marked 


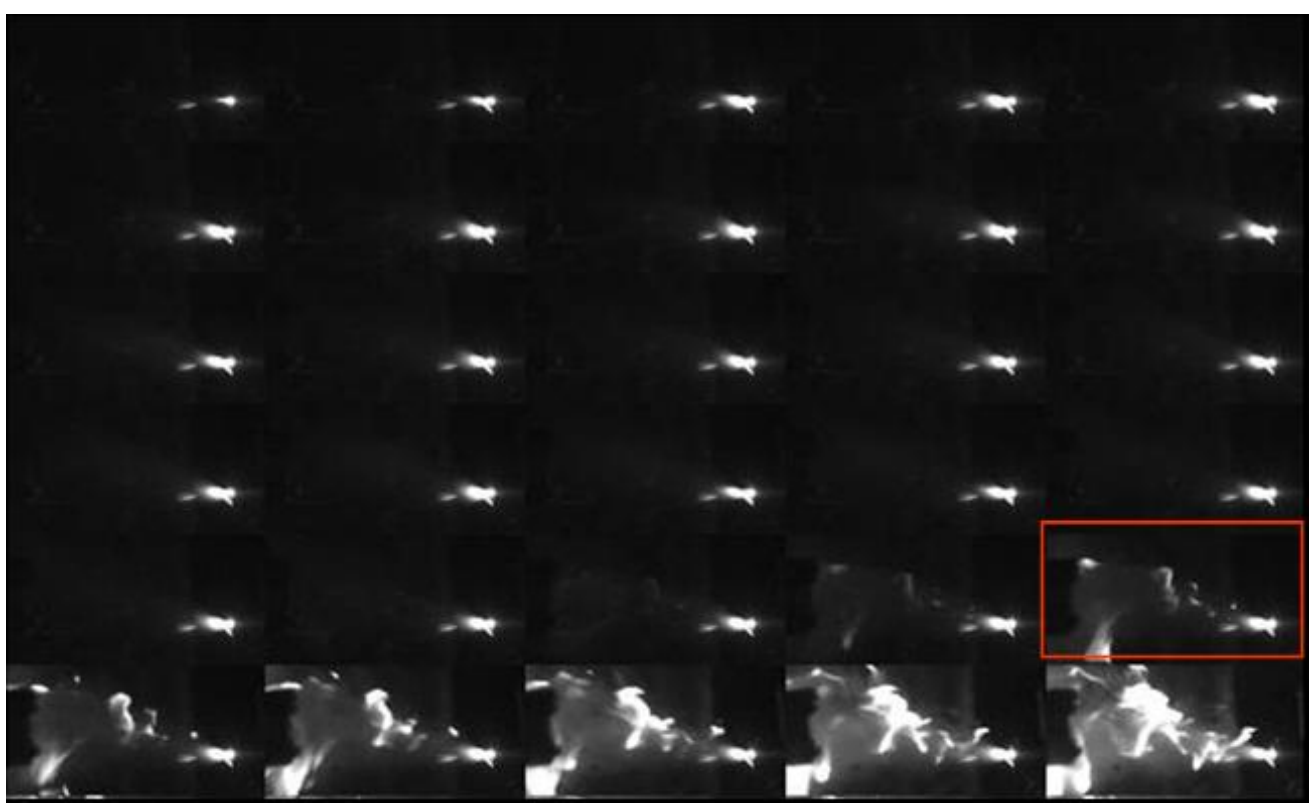

Figure 4.13: JP-7 Flame Formation Sequence with Visible Flame Kernel Marked

\subsubsection{Flame Properties and Structure}

Due to the nature of the fuel injection-atomization process with respect to the igniter location, it is difficult to quantitatively characterize this flame. While in form it is closely-related to the turbulent diffusion flames studied by Hawthorne [58], the visible fuel vapor coupled with rapid fuel-air mixing indicate that there is partial premixing occurring, resulting in a complicated heterogeneous flame structure, including turbulent diffusion flame burning of evaporating fuel droplets in combination with a premixed turbulent flame. This situation is even more likely when considering that the atomization pictures discussed in Figure 4.4 do not include ambient air heating by the plasma torch igniter. Studies on the effect of ambient temperature on quality of atomization have shown that an increase in ambient temperature significantly decreases the droplet heat-up period, leading to speedier evaporation [25]. With this in mind, it is likely that heterogeneous burning of the fuel in air is occurring. A typical flame from a kerosene test is pictured in Figure 4.14. This luminous, brushy-edged flame is characteristic of a turbulent nonpremixed jet flame. The bright-yellow appearance in the upper-left corner is most likely due to 
the considerable quantity of soot existing. On the other hand, the region directly below it is relatively soot-free, indicated by its low luminosity and bluish hue. Although blue, low-soot regions are often seen in turbulent diffusion jet flames, it is uncharacteristic to see such regions far from the base of the flame. For these reasons, it is probable that the flame structure is comprised of both a turbulent diffusion (non-premixed) flame and a turbulent premixed flame.

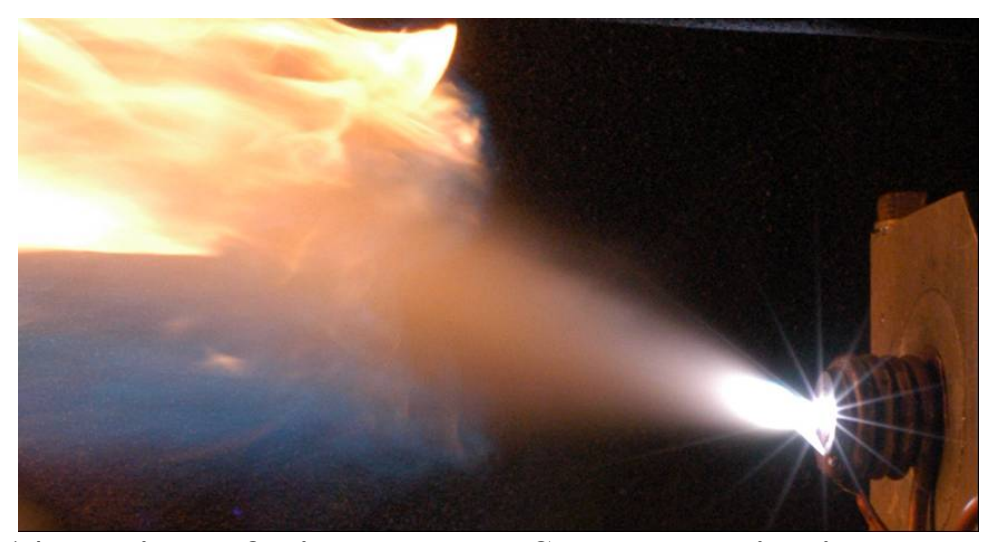

Figure 4.14: Regions of High and Low Soot Formation in Kerosene Flame 


\section{Supersonic Testing Results}

Since the primary consideration was the effectiveness of the atomizer-igniter on supersonic ignition and combustion, efforts were made to obtain data indicative of the success or failure thereof. Hydrocarbon combustion is almost always accompanied by two aspects: a luminous flame and heat release. Additionally, the chemical species associated with the elementary reaction steps are present in varying amounts, depending on the reaction temperature, ambient environment, parent fuel type and method of decomposition, i.e., the path of chemical reactance. These three characteristics were primarily observed using photography, total temperature probes, and spectroscopy. Boundary layer measurements were made to determine the interaction between the combustion region and the wall. Finally, since the atomization method was quite different than the quiescent configuration, the relationships between injector orientation, penetration, atomization, and ignition were observed.

\subsection{Injection Direction}

The most immediate observation made during supersonic testing was the effect of the fuel injection direction with respect to the main tunnel flow. As described in Section 3.4, the supersonic anode was designed to provide fuel injection in $90^{\circ}$ increments due to its square shape. The two schemes tested were fuel injection in the direction of the main tunnel flow (referred to as co-flow injection), and fuel injection in the opposite direction of the main tunnel flow (referred to as counter-flow injection). These types of fuel injection are shown in Figure 5.1. Qualitative results indicated that in the current experimental setup, counter-flow fuel injection produced a luminous flame and temperature rise downstream, while co-flow fuel injection was accompanied by little luminosity other than the bright torch plume and little downstream temperature rise (see Section 5.4.1). With this initial observation made, the 
remaining testing was performed with counter-flow injection, as this study was not to compare injection direction, but rather to implement the design in a way that would maximize combustion. Results in this report, therefore, are those of the counter-flow fuel injection setup; where co-flow fuel injection was implemented, it is indicated on the figure.

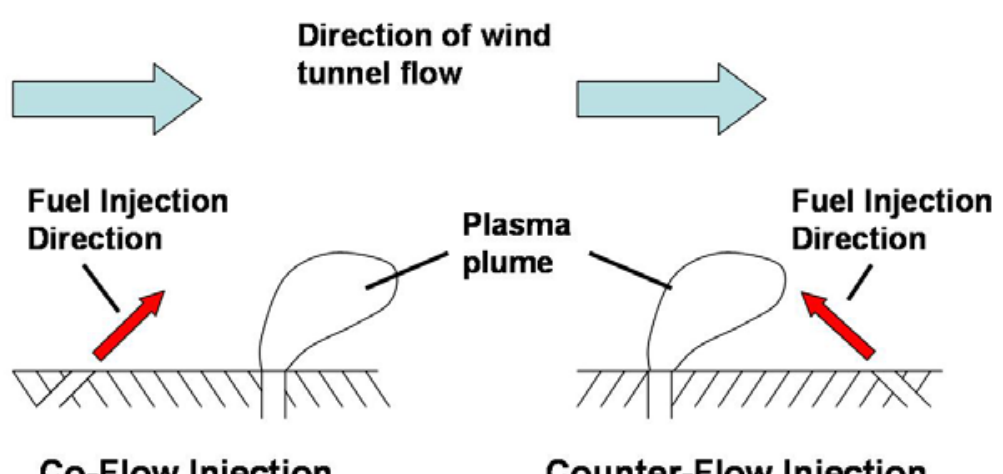

Figure 5.1: Schematic Representations of Co-Flow and Counter-Flow Fuel Injection

\subsection{Penetration and Atomization}

Focused shadowgraph pictures of co-flow and counter-flow fuel injection are shown in Figure 5.2(a) and (b), respectively. Nitrogen feedstock is flowing but the torch is not ignited. Shocks due to the incoming fuel and feedstock are seen in the counter-flow case. The most immediate observation from these photographs is the penetration achieved by the counter-flow fuel injection case. The fuel injected in the co-flow case appears to initially penetrate into the flow, then gradually approach the floor as it is carried downstream. This behavior was repeatedly observed during experiments. However, in the counter-flow case, there is a visible space between the vaporized fuel and the floor for the duration of the photograph. That is, enhanced penetration is experienced for the counter-flow injection case. 


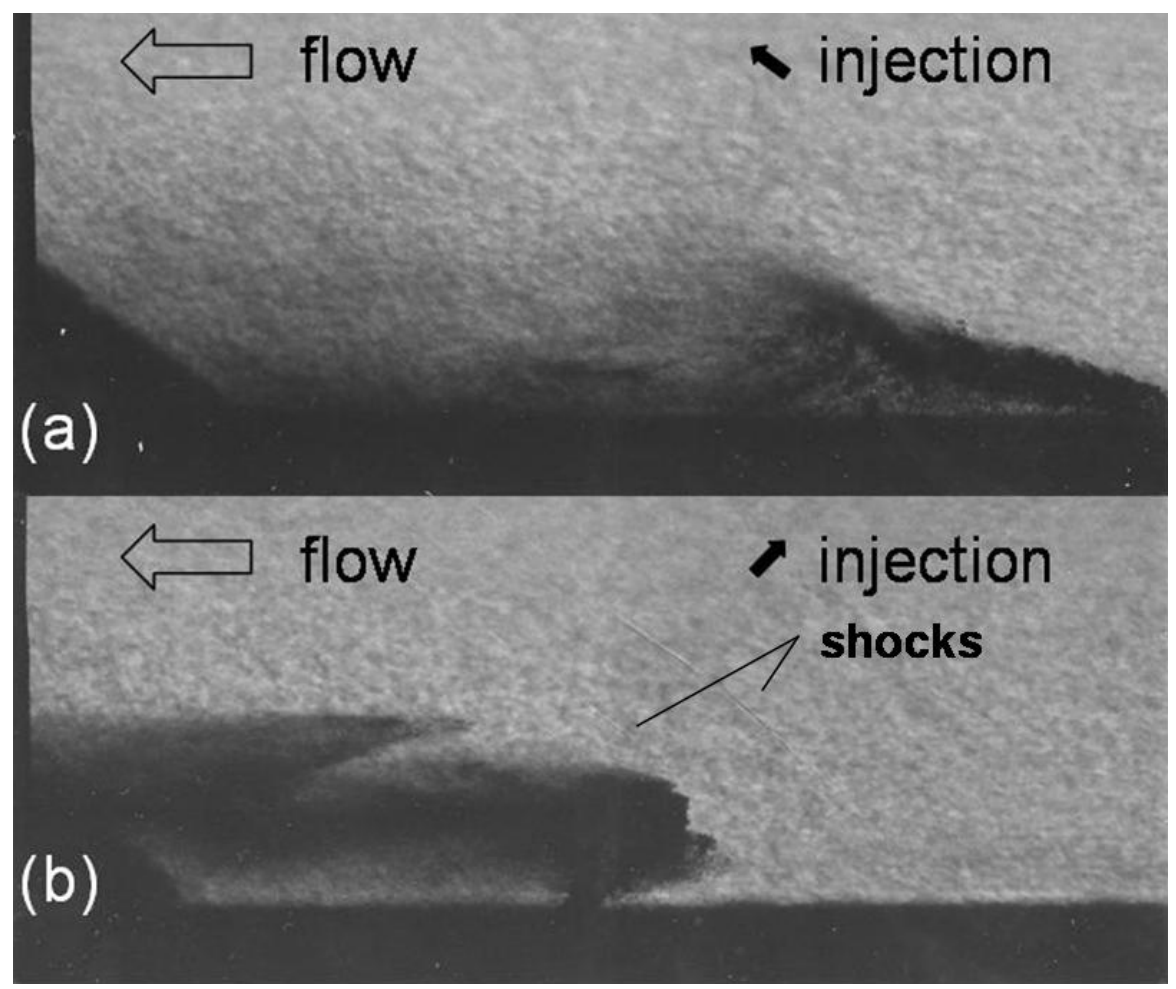

Figure 5.2: Shadowgraph Images of (a) Co-Flow and (b) Counter-Flow

Kerosene Injection in Supersonic Crossflow

To quantify the penetration of fuel into the main flow, a series of digital time-averaged shadowgraph pictures was taken during fuel injection. The torch feedstock gas was flowing because it is thought to have a significant effect on the mixing and penetration mechanics. The torch was not ignited, however, in order to obtain detailed information at the injection point. The photographs were processed as shown in Figure 5.3. The original digital RGB images were converted to grayscale, then resized to magnify the region of interest. Finally, intensity adjustments were made to increase the contrast and make the droplets more visible. 

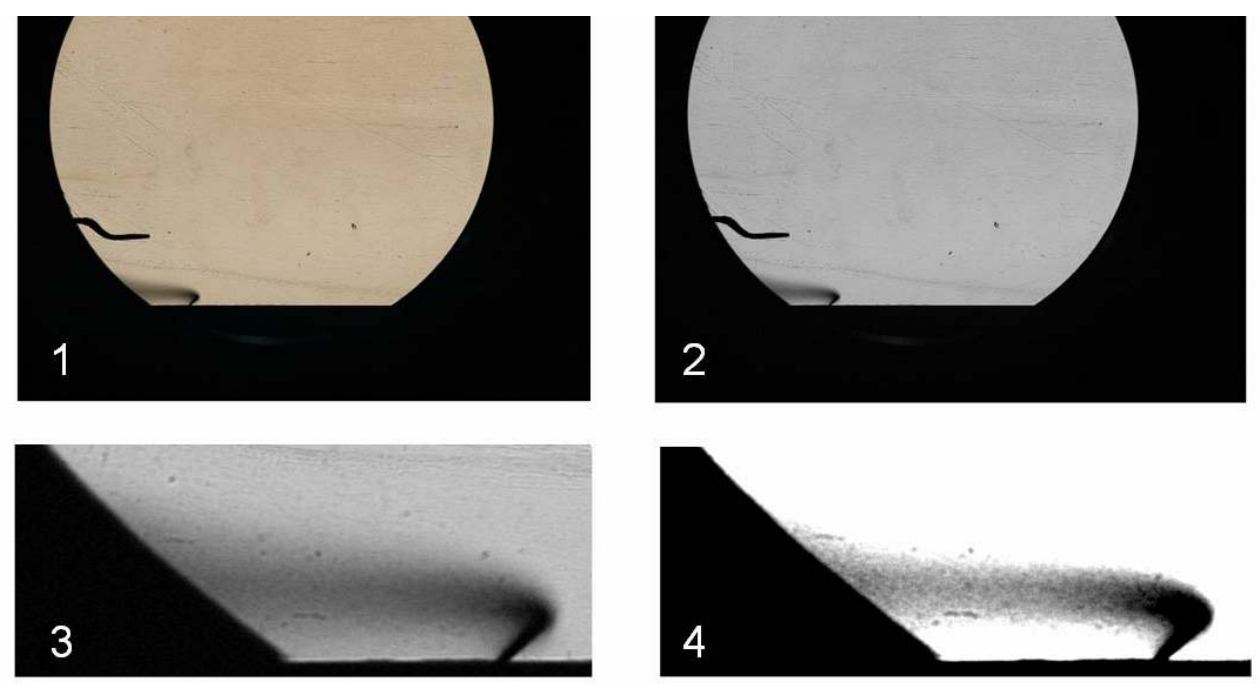

Figure 5.3: Image Processing Sequence for Penetration Height Measurements

With the resolution of the images and a physical reference, the tunnel window diameter, the actual penetration height was measured for various downstream locations, beginning with the maximum penetration directly above the injection hole. The actual penetration height and downstream distance were then normalized by the injection orifice diameter, which was 0.020 in. These results are plotted in Figure 5.4. The curves show the dimensionless penetrations against the dimensionless streamwise distances, defined by

$$
\bar{h}=\frac{h}{d_{o}}
$$

and

$$
\bar{x}=\frac{x}{d_{o}}
$$

where the measured penetration height is $h$ and the measured axial streamwise distance is $x$. The data displays a definite third-degree polynomial shape, as indicated by the $\mathrm{R}^{2}$ values in the figure. There is a significant offset in penetration height in all instances. This is due to the initial penetration which occurred in the upstream direction. After being injected into the oncoming flow, the fluid stagnates then proceeds downstream. The penetration height continues to increase 
gradually. At $\bar{x} \approx 20$, the slope of the line increases, indicating strong penetration into the main flow. The penetration height is continuing to increase as the fluid moves out of the observable area. The general shape of the penetration for these cases is similar. Differences in absolute penetration height are most likely due to fuel injection dynamics, which were unavoidable with this type of fuel injection system.

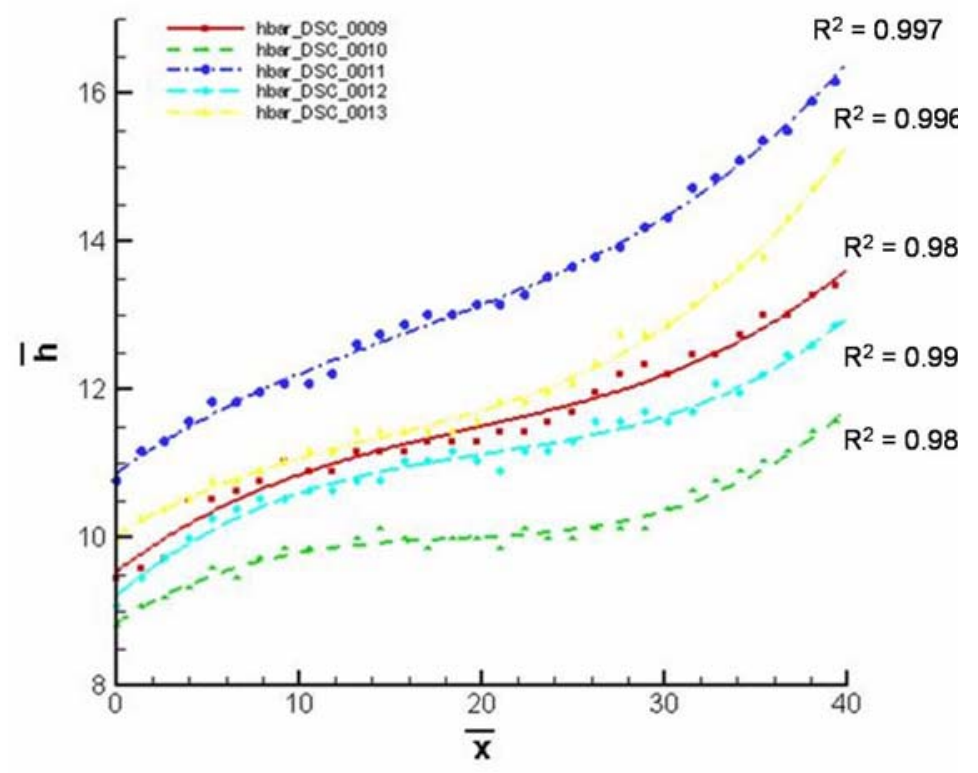

Figure 5.4: Normalized Measured Penetration Height vs. Downstream Distance

The measured penetration height of the current injection scheme may be compared with an empirical correlation such as that developed by Baranovsky and Schetz [59]. The correlation takes into account injection angle $\theta$, initial jet diameter $d_{o}$, jet density $\rho j$, jet initial velocity $V j$, and freestream conditions, and is given by

$$
\bar{h}_{C}=\frac{\bar{q}^{1 / 2}\left[1.32 d_{o} \sin \left(\frac{2}{3} \theta\right) \ln (1+6 \bar{x})\right]}{d_{o}}
$$

where

$$
\bar{q}=\frac{\rho_{j} V_{j}^{2}}{\rho_{\infty} V_{\infty}^{2}}
$$


The subscripts $C, o, j$, and $\infty$ denote correlation, orifice, jet, and freestream. For these tests, $\bar{q}$ was calculated as 0.658 , based on freestream total pressure and temperature measurements of $345 \mathrm{kPa}$ and $292 \mathrm{~K}$, respectively, in Mach 2.4 flow, and liquid injection conditions. The experimental parameters used in the current tests were input into Equation (5.3), and the results are compared with the measured penetration for a representative run in Figure 5.5. As shown, the current injector penetrates further into the freestream flow than the design used by Baranovsky \& Schetz. This is not surprising given the blockage caused by the feedstock injection just upstream of the fuel injection. The low-velocity region behind the feedstock injection enables the fuel jet to penetrate further into the flow before stagnating and moving downstream. No direct conclusion regarding the quality of atomization can be drawn from these comparisons, but theoretically the injector with the greatest penetration into the high-velocity flow will yield smaller drop sizes and shorter droplet lifetime.

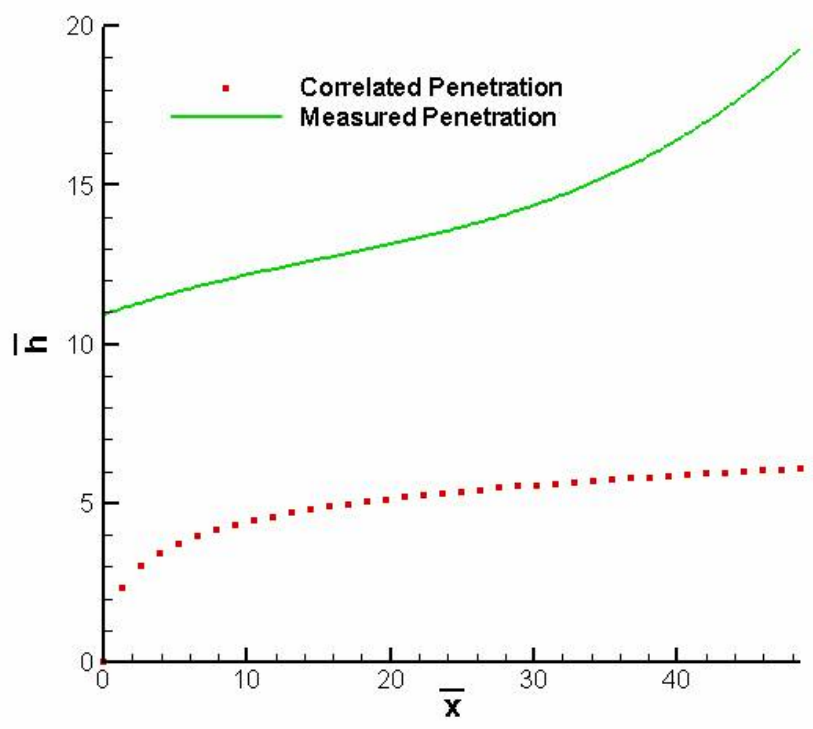

Figure 5.5: Comparison of Measured and Predicted Penetration Heights 


\subsection{Visible Ignition and Combustion}

Co-flow fuel injection was accompanied with minimal luminosity. The counter-flow case, on the other hand ignited the fuel vapor and air mixture effectively for two primary reasons:

1. The recirculation zone downstream of the feedstock injection orifice provides a turbulent mixing region for the vaporized fuel, nitrogen radicals, and main air;

2. High-temperature ignition gases from the plasma torch are readily available, and flow into the recirculation zone.

Direct photographs of kerosene ignition are shown in Figure 5.6. Both were taken with an exposure time of $1 / 500 \mathrm{sec}$. It appears from (a) that a small region of fuel vapor is combusting, but the main fuel stream is intact. However, in (b), fuel is ignited close to the stagnation point of the jet, demonstrated by the very luminous area.

(a)

(b)

Figure 5.6: Supersonic Kerosene Ignition for Pure Liquid and Effervescent Injection

These pictures demonstrate the advantages of effervescent atomization, which is the case in (b). Effervescent atomization, discussed in Section 4.2.2, produces a finer mist of droplets, and enables rapid evaporation and mixing followed by ignition in the stagnation region, as witnessed here. Rather than relying on mass diffusion from the solid jet to the surrounding medium, the nitrogen-pressurized fuel was dispersed quickly, forming mixtures with proper equivalence ratio for combustion. Effervescent injection occurred as the last of the fuel was being injected. Injection was no longer in the form of a steady stream, but a nitrogen-fuel mixture, with the fuel 
often already vaporized by the time the mixture reached the ignition area. The luminous combustion region in case (b) also has a greater area and extends further downstream that case (a). Further effects of effervescent atomization on other combustion characteristics are discussed later.

To observe the interaction between chemical activity and fluid and gasdynamic behavior, Schlieren images were taken with the torch operating. Figure 5.7 shows the four typical stages of the experiment. In (a), the feedstock gas is flowing. The torch is ignited at full power in (b), and (c) was taken during injection of the steady liquid stream. Finally, (d) captures the fuel injection as the remaining fuel left in the system is purged by the nitrogen feedstock.

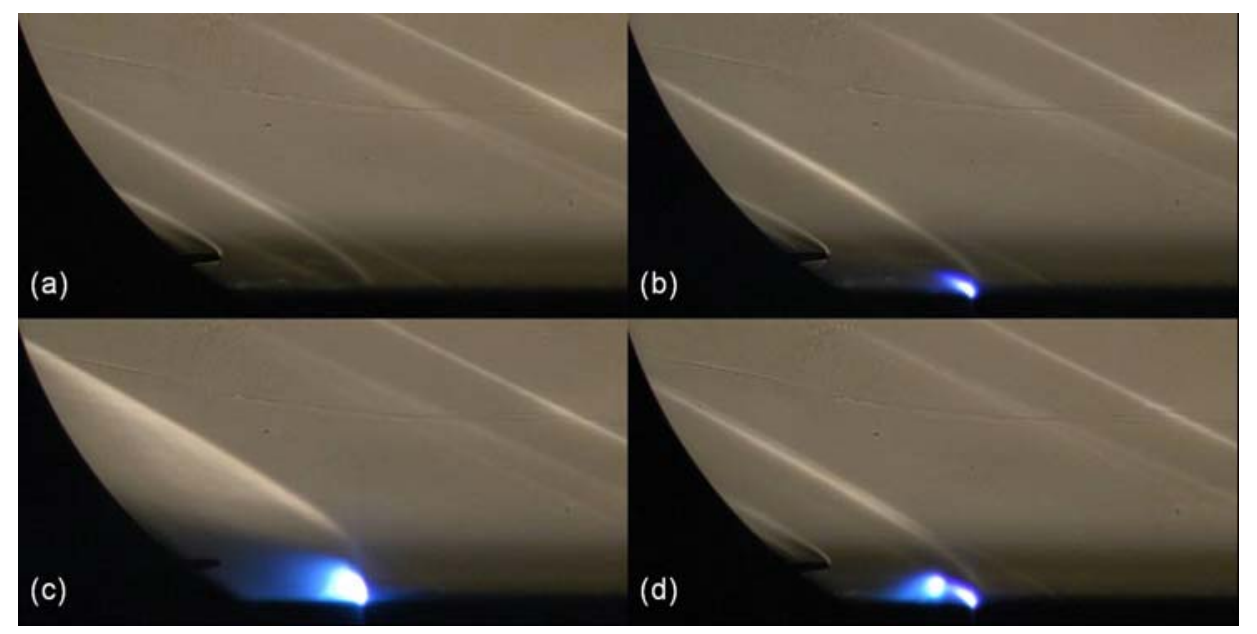

Figure 5.7: Superimposed Schlieren and Direct Photographs of Supersonic Combustion Observations regarding these figures are:

1. As the torch is ignited (a), the oblique shock strength increases slightly.

2. As the fuel is injected and ignited, a significant increase in shock strength is observed.

3. No shock is seen in front of the three-probe rake for case (c).

4. The luminous flame in (d), with effervescent atomization, proceeds farther downstream than for pure liquid injection (c). 
5. The boundary layer is visible in all photographs.

Gallimore [43] had difficulty obtaining shadowgraph and Schlieren images with the torch operating due to the plasma torch washing out the light source. These problems were overcome to produce images such as those in Figure 5.7 using the optical setup shown in Figure A.4 Of Appendix A, which describes schematically the photographic techniques implemented during supersonic testing.

\subsubsection{Water and Kerosene Combustion Comparison}

Efforts were made to compare water and kerosene injection for similar torch powers and experimental settings. This was done to ensure that the results from the kerosene tests, particularly the luminous combustion flame, were not associated with factors such as droplet light scattering. Figure 5.8 compares direct and Schlieren photographs of water (b) and (c) and kerosene (a) and (d). Pictures (a) and (b) are direct photographs with flow from left to right and shutter speed indicated. Pictures (c) and (d) are Schlieren-direct photographs with flow from right to left and shutter speeds indicated. These photographs conclusively show the difference between water and kerosene injection with the torch ignited. In particular, the long green-blue flame extending downstream in (a) has no counterpart in picture (b). Similar results are seen for pictures (d) and (c), respectively. The luminous region seen in pictures (a) and (d), therefore, is certainly light emitted from the combusting mixture. 


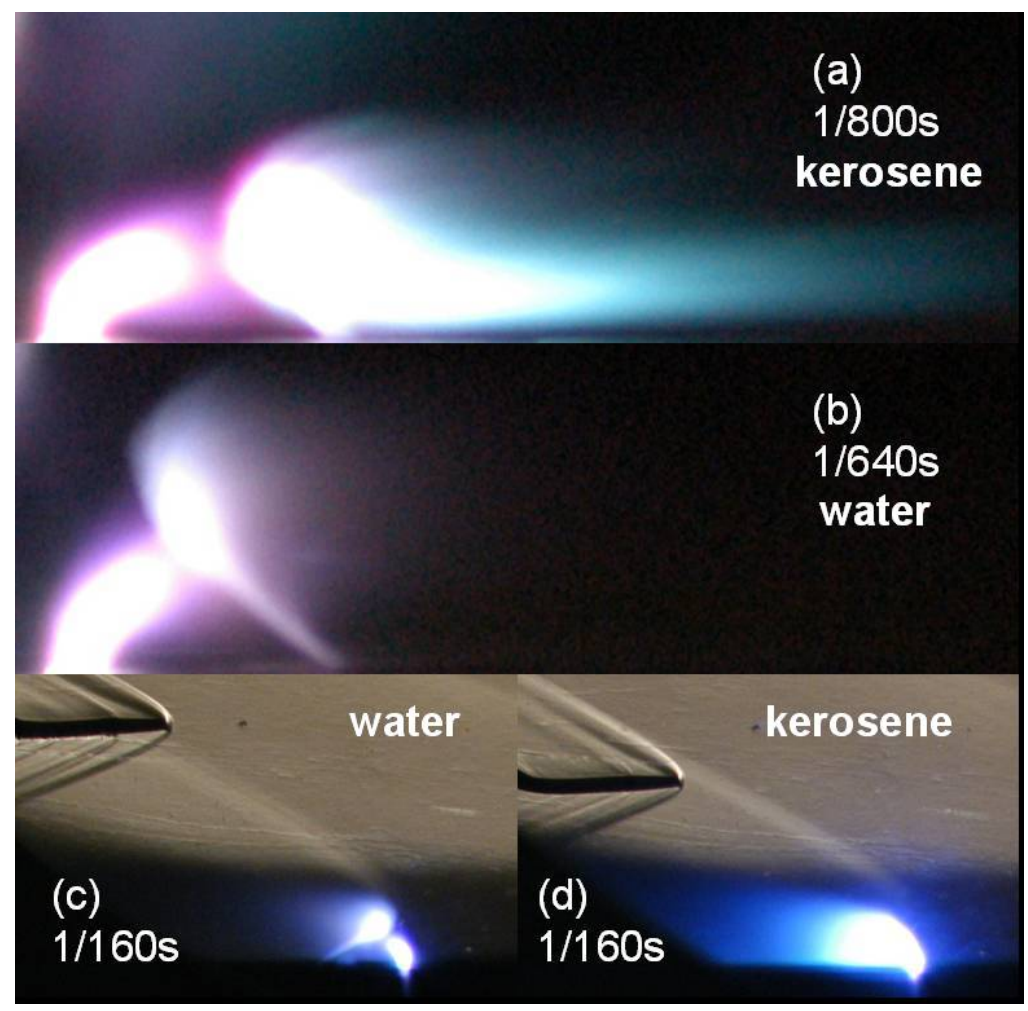

Figure 5.8: Water and Kerosene Comparison:

(a) and (b): Direct photographs; (c) and (d): Schlieren-Direct Photographs

\subsection{Temperature Measurements}

\subsubsection{Temperature Behavior Dynamics}

Figure 5.9 compares the temperature histories for co-flow and counter-flow fuel injection. The same torch power and fuel pressure were used. Certain key events in the progression are marked. In particular, both temperatures decrease as the cold tunnel flow cools the thermocouple. As the torch is ignited, the co-flow temperature seen by the thermocouple continues to decrease gradually. The counter-flow temperature, however, increases rapidly due to the warm mixture of feedstock gas and air. As the fuel is injected, a slight dip in temperature is observed. As the fuel is ignited, heat is released and the temperature continues to rise gradually until the fuel and torch are shut off. 


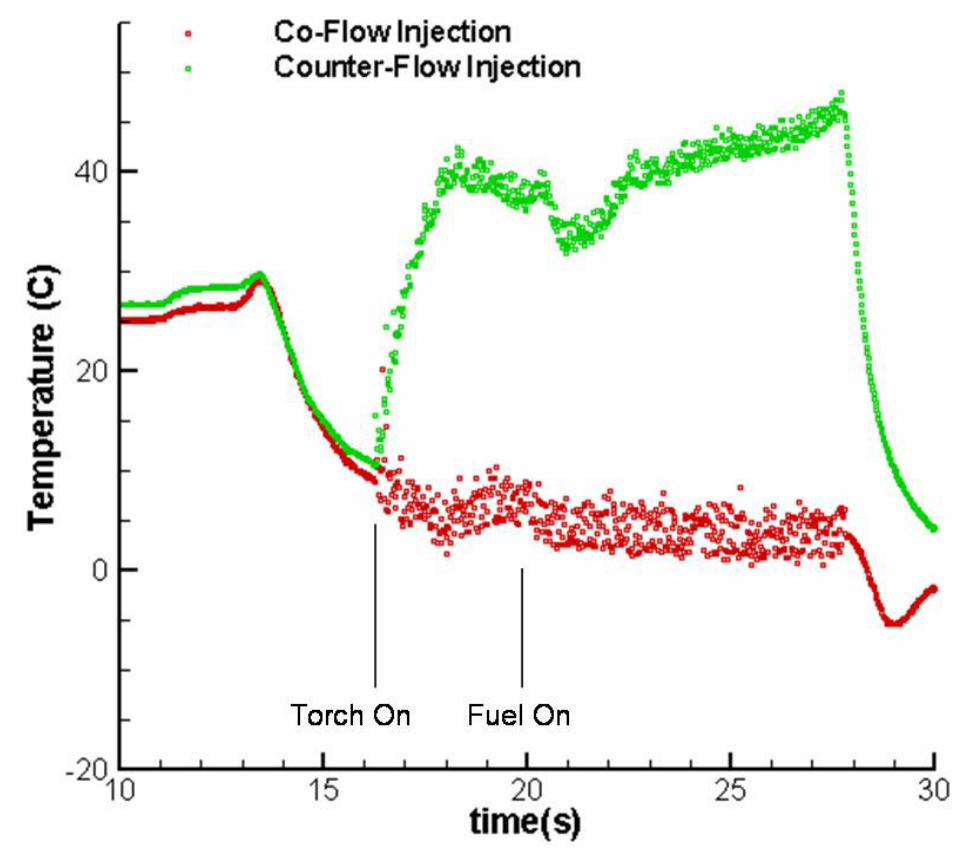

Figure 5.9: Temperature Response to Fuel Flow for Co- and Counter-Flow Injection

Throughout the experimental testing, the temperature behavior varied greatly with time. Experiments were conducted to determine the source of these temperature dynamics. Possible sources of temperature fluctuations included unsteady torch ignition, unsteady tunnel flow, defective temperature sensors, unsteady fuel flow, or a combination of these. Figure 5.10 shows magnified fuel pressure and downstream temperature data for a typical run. This figure is to illustrate the correlation between the two signals and thus the two physical processes. The voltage levels were too low for the similarity in signals to be caused by induced voltage. Therefore, a physical process seen by the pressure transducer measuring the fuel injection pressure is having an effect on the temperature measured by the thermocouple in the reacting flow. With a constant fuel supply pressure, the only explanation is unsteady fuel injection. This is most likely caused due to pockets of nitrogen or air being mixed with the injected fuel. As this non-homogeneous mixture flows through the fuel line, the pressure transducer produces a voltage signal that reflects the unsteady fuel flow. As the mixture is discharged and ignited, the 
heat release reflects the atomization and vaporization. The thermocouple response is not expected to fluctuate as the pressure fluctuates; there is a delay period, indicated on the figure, as the fuel is discharged, penetrates into the flow, and ignites. The relationship between fuel pressure and downstream temperature was witnessed in several cases, and therefore it is reasonable to conclude that the temperature fluctuations observed in the data are due to unsteady fuel flow rate.

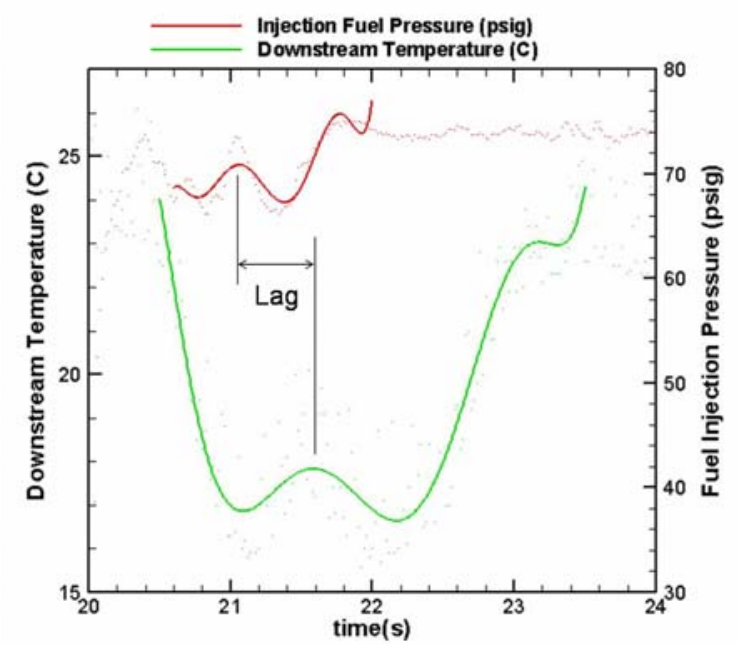

Figure 5.10: Correlation Between Fuel Injection Pressure and Downstream Temperature

\subsubsection{Time-Dependent Temperature Behavior}

Three distinct stages were observed during supersonic kerosene combustion, which are most noticeable when observing combustion temperature against time. These regions are shown in Figure 5.12. The first noticeable feature of Figure 5.12 is the difference in measured temperature between the thermocouples. The temperature of thermocouple $1, \mathrm{~T} 1$, is greater than the others for the entire run, although it was not centrally located. This surprising result is explained by Figure 5.11, a close view of the anode following the experiments. The burned portion is clearly off-center, due to the electric arc stabilizing itself in this location for most of the test. This off-center arc attachment could be due to slight imperfections in the geometry of the anode. Another possibility is that the flow swirler is causing the feedstock gas and arc to 
emerge from the feedstock orifice with some tangential velocity, which carries the arc to a location away from the center. Regardless of the reason for the off-center arc attachment, the thermocouple downstream of the arc actually sensed a greater temperature increase than the centrally-located thermocouple.

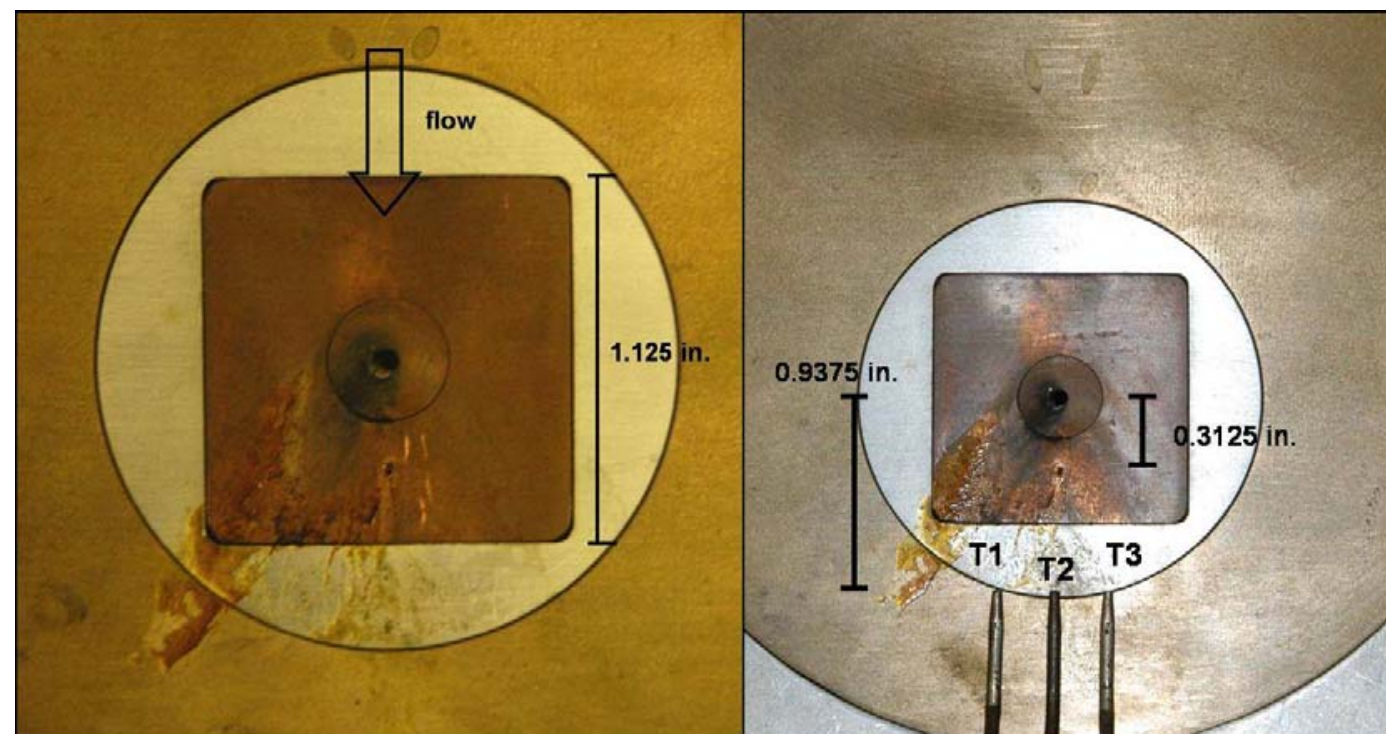

Figure 5.11: Effects of Off-Center Arc Attachment and Combustion on Supersonic Anode

Initially, a temperature rise is seen due to the plasma torch igniter. The maximum temperature reaches approximately $115^{\circ} \mathrm{C}$ around 19 sec., at which point the continuous fuel injection begins. The temperatures decrease slightly then remain fairly constant. It is likely that during this time combustion is still occurring, although the constant temperature would seem to indicate otherwise. If no chemical reaction were happening, one would expect to see a temperature profile such as that in Figure 5.13, which shows the temperature behavior for water injection with the plasma torch ignited. The temperature drops immediately as the water is injected, reaching a steady-state temperature around $20^{\circ} \mathrm{C}$. The kerosene case in Figure 5.12, however, reaches a steady-state temperature of around $100^{\circ} \mathrm{C}$, which indicates that combustion is still occurring, and the hot products are mixing with the unheated air to yield the global temperature indicated. At around $24 \mathrm{sec}$., the fuel injection becomes effervescent as the driver 
gas mixes internally with the remaining fuel in the system, pressurizing it and promoting atomization, thereby encouraging a suitable fuel-air mixture to burn. An increase in temperature is witnessed by $\mathrm{T} 1$. As shown, the temperature reaches a maximum of about $230^{\circ} \mathrm{C}$ and is continuing to increase as the igniter is turned off. There is no doubt that the actual flame temperature was much greater than this, given the rapid mixing of unheated tunnel air with the combustion products. Unfortunately, the diagnostics needed to accurately measure the temperature within the flame were unavailable, and the thermocouples downstream of the reaction zone serve as the best possible measurement.

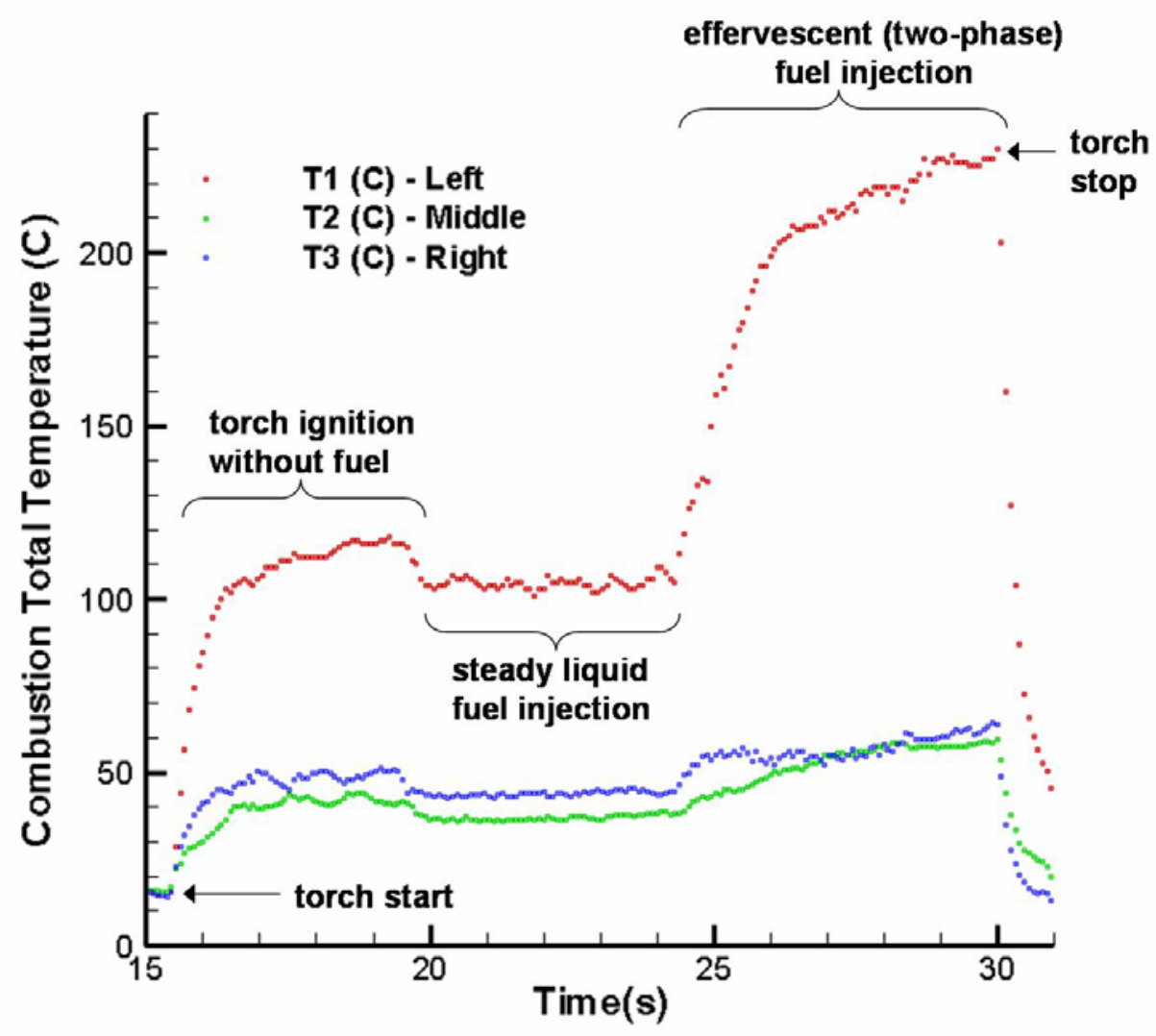

Figure 5.12: Supersonic Total Temperature Measurements: Time-Dependent Behavior 


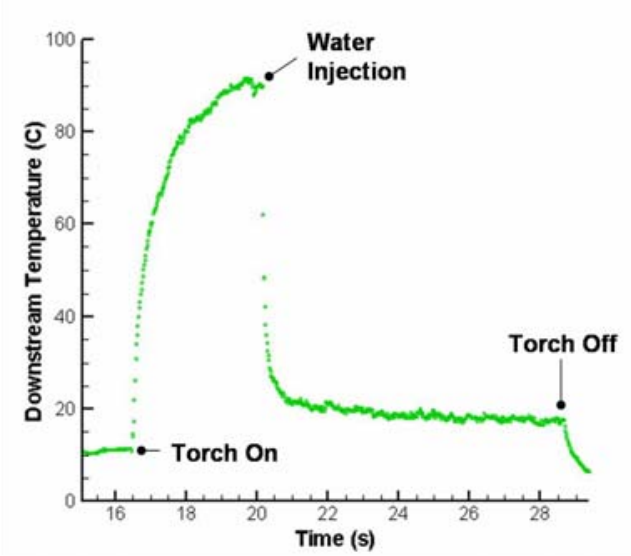

Figure 5.13: Water Injection Temperature Profile with Torch Ignited

\subsubsection{Total Temperature Profiles}

The temperatures discussed in Section 5.4.2 were measured at a location very close to the wind tunnel floor. It was desired to examine the temperature rise moving away from the floor as well since ultimately, uniform heat release throughout the cross-section of the combustor is desired. Example results of this spatial temperature analysis are given in Figure 5.14 and Figure 5.15 for continuous liquid injection and effervescent injection, respectively. A scale of the measurement region, showing actual distances, is provided in Figure 5.17. The normalizing distance for all axes was the diameter of the fuel injection orifice, 0.020 ", so the actual distance away from the wall of the maximum measured temperatures was 0.386 in. The Y-direction is vertical, in the direction away from the wall. The Z-direction is spanwise. So the temperature profiles can be seen as a cross section of the flow at the streamwise distance of the thermocouple junctions. Contour labels are provided so that small differences in measured temperature may be scrutinized. Several key observations can immediately be made regarding these results. First, effervescent atomization causes a global increase in total temperature. Second, there is a significant temperature rise at all locations when compared with water injection, the temperature profile of which is provided in Figure 5.16. Notably, a temperature increase of about $15^{\circ} \mathrm{C}$ is 
seen $0.386 \mathrm{in}$. away from the tunnel floor. While this may seem insignificant from a combustion perspective, it should be remembered that even in the short distance from the flame to the thermocouple location, mixing with the unheated wind tunnel air has occurred, so that the actual flame temperature is certainly greater than the temperature shown. The greatest temperature in all three cases occurs in the lower left corner, due to the arc and therefore the primary ignition location being off-center as discussed in Section 5.4.2. It is also interesting to note the relatively high temperature region near the center of the kerosene combustion cases. This is likely caused by a combination of the reacting fuel-air mixture and the sensible heat of the fuel itself. Figure 5.4 indicates that at the downstream location of the thermocouples $\left(Z / d_{o}=46.9\right)$, the core of the injected fuel will be at a $Y / d_{o}$ value of between 10 and 15 , which is precisely where the high temperature regions in the center appear in Figure 5.14 and Figure 5.15. A similar pattern is weakly observed in the water injection case, probably due to its lower specific heat and therefore lower temperature as it issues from the injector. The most important conclusion drawn from these figures is that the torch ignition itself is causing a negligible amount of temperature rise (Figure 5.16), while the combustion reaction is significantly increasing the local and global temperatures downstream (Figure 5.14 and Figure 5.15). 


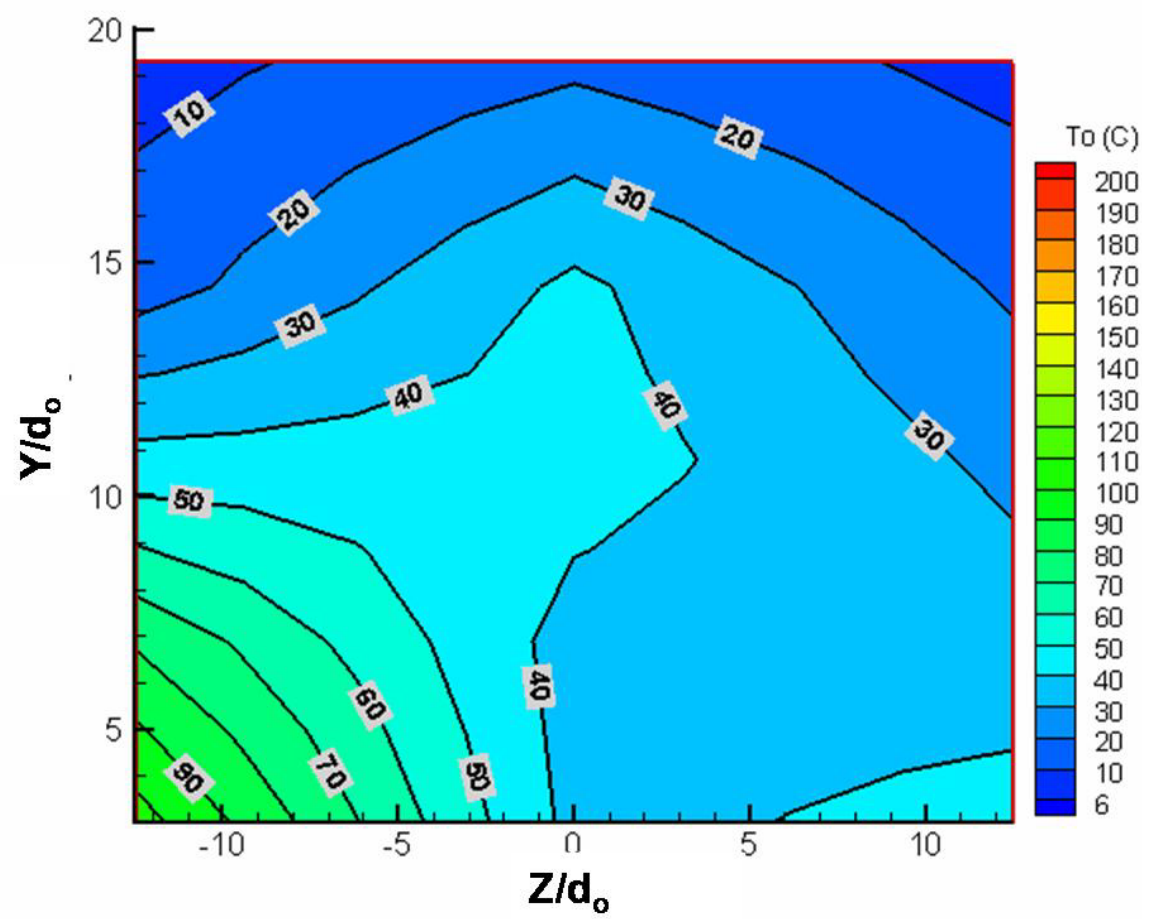

Figure 5.14: Continuous Injection Total Temperatures for Normalized Locations

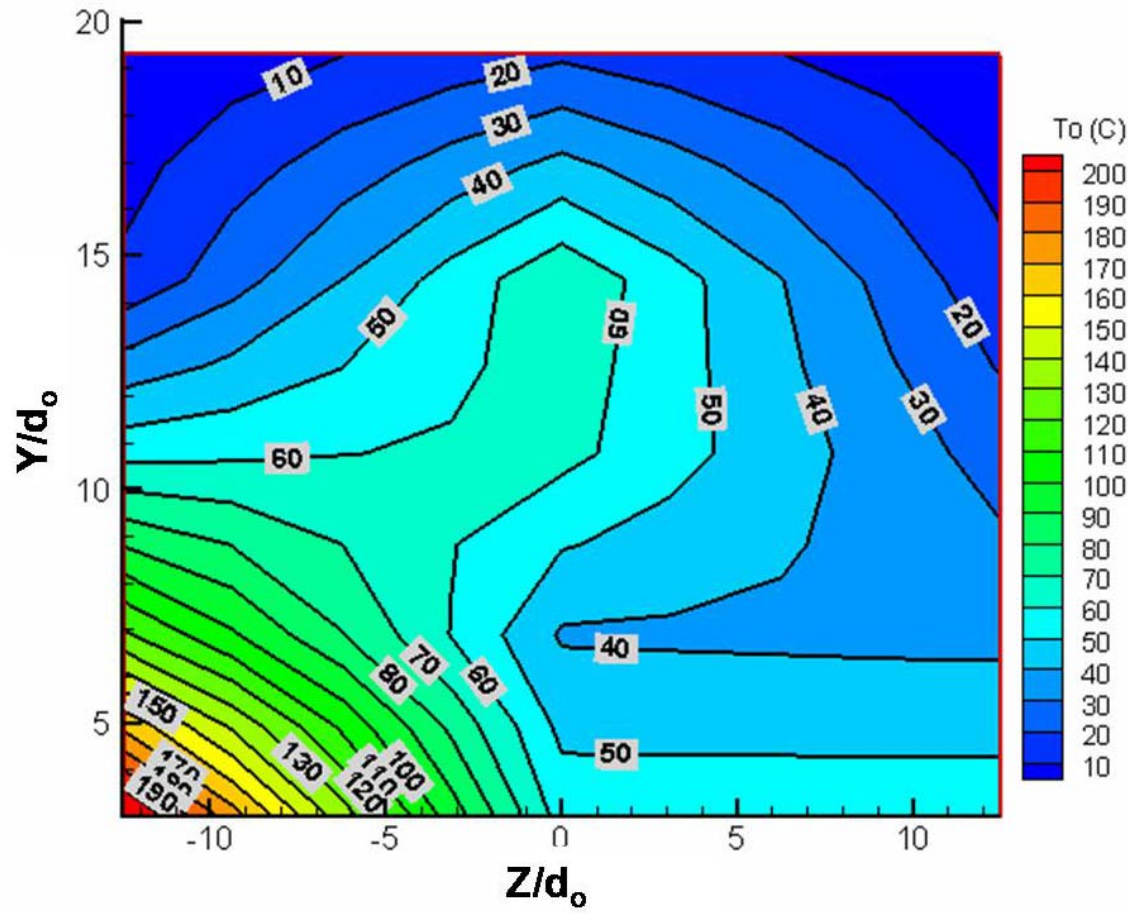

Figure 5.15: Effervescent Injection Total Temperatures for Normalized Locations 


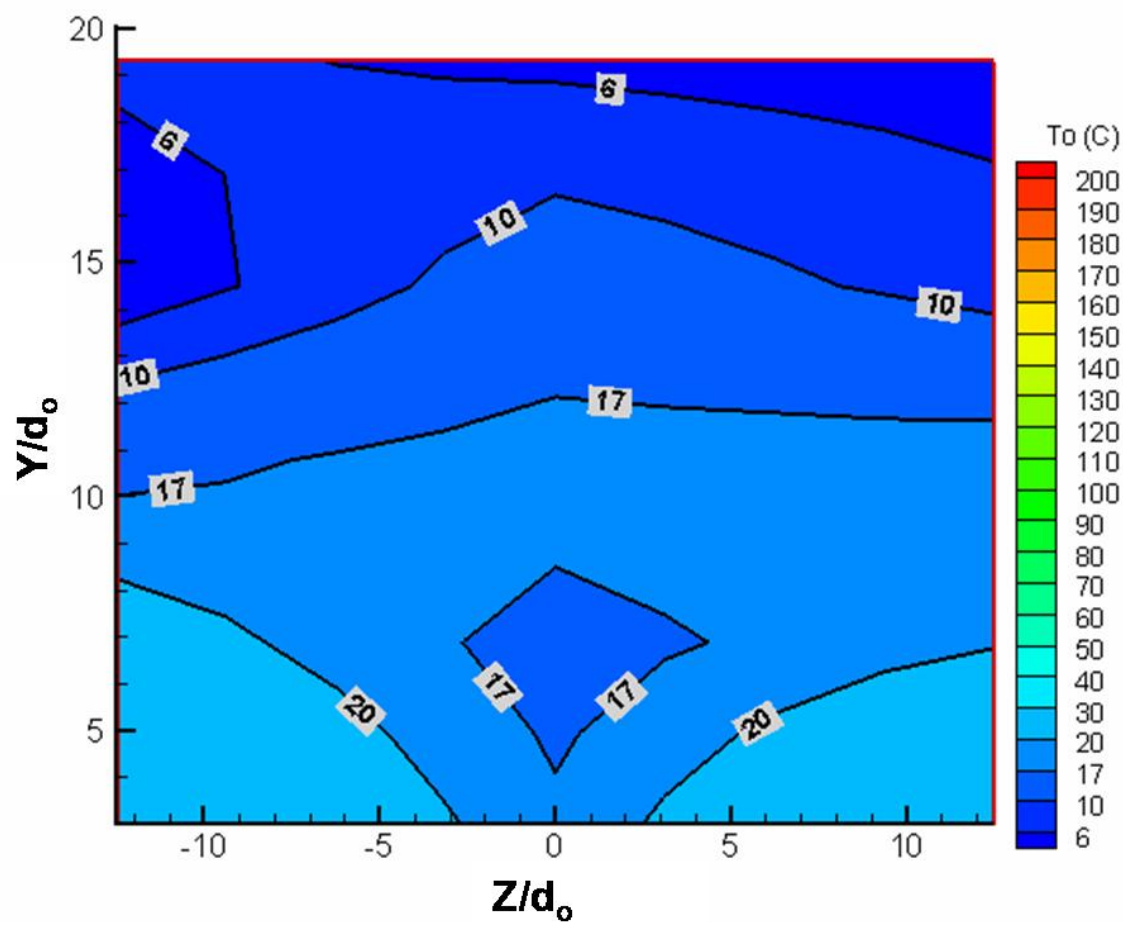

Figure 5.16: Water Injection with Torch: Total Temperature Profile

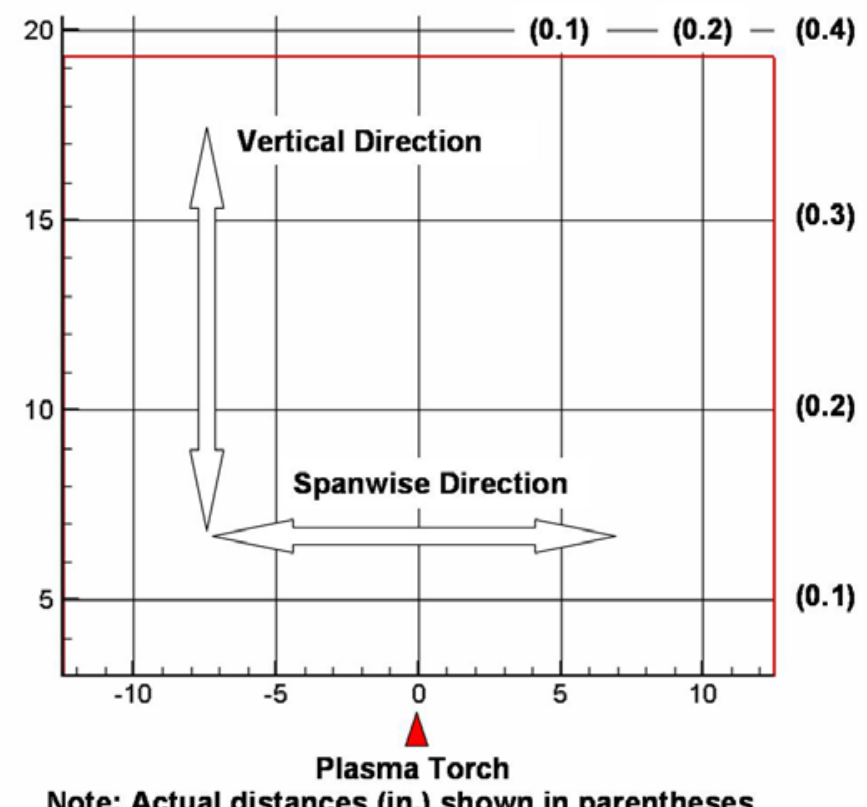

Figure 5.17: Total Temperature Profile Scale

\subsubsection{Effect of Injection Pressure on Total Temperature}

Tests were conducted to examine the influence of fuel injection pressure on combustion, either in terms of reaction location or temperature rise. It was originally thought that penetration 
would be increased for a higher fuel injection pressure due to the greater momentum flux of the fuel stream, and also that combustion temperature would increase due to the proximity of the fuel to the ignition location. The temperature profiles for (a) $50 \mathrm{psi}$ and (b) $70 \mathrm{psi}$ are provided in Figure 5.18. It is clear that although a greater fuel injection pressure does have a positive effect on the global total temperature, the absolute maximum total temperature, which occurs in the lower left corner, is actually less for the greater injection pressure. It may be concluded that the amount of heat release accompanied by the reaction is sensitive to the location of the fuel with respect to the igniter and to the local equivalence ratio. Additionally, although increasing the injection pressure had a detrimental effect on the maximum total temperature for the locations measured, the global temperature reached $30-40^{\circ} \mathrm{C}$ at a location $0.285 \mathrm{in}$. above the tunnel floor.

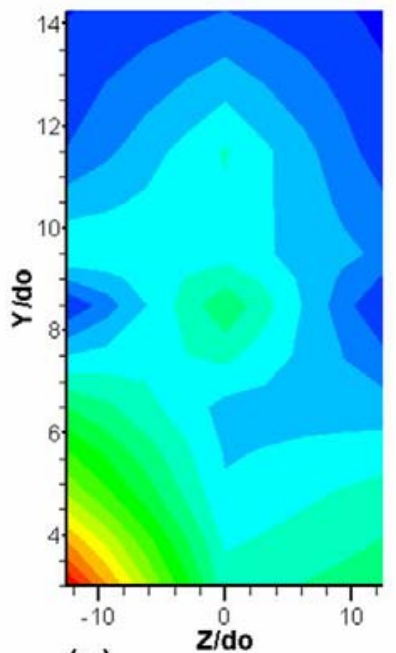

(a)

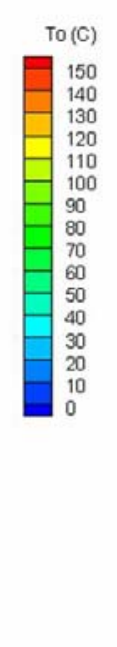

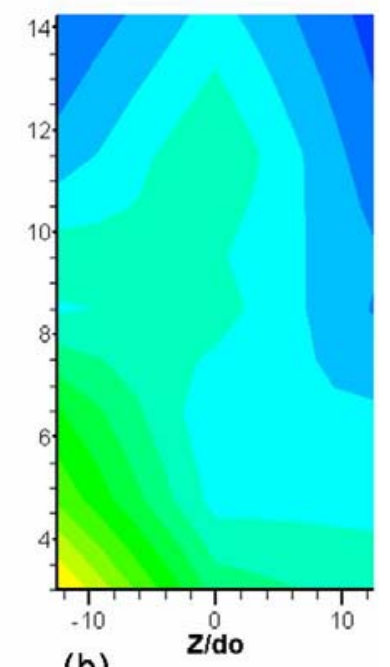

(b)

Figure 5.18: Effect of Fuel Injection Pressure on Downstream Total Temperature

Another representation of the effect of injection pressure on total temperature is given in

Figure 5.19 and Figure 5.20. These plots show the measured total temperature for three probes normalized by the freestream normal temperature, in this case approximately $292 \mathrm{~K}$. The values are given for varying normalized vertical distances above the floor, and $\mathrm{d}_{\text {eff }}$ is the diameter of the feedstock orifice. In this case, $\mathrm{d}_{\text {eff }}$ (torch feedstock throat diameter) was used instead of $d_{o}$ so that 
comparisons with existing data could be made. Figure 5.21 shows the maximum normalized total temperatures obtained by Gallimore [43] and Cross [42]. The present work resulted in a similar maximum total temperature ratio than Gallimore with approximately one-third of the power consumption. This is surprising given that the gaseous hydrocarbon feedstock was passing directly through the ignition region in Gallimore's work, while in the current work a liquid hydrocarbon was injected externally, vaporized, mixed, and combusted. The maximum total temperature ratio in the present work is almost 1.6 and occurs near the tunnel floor, while Cross's data shows a maximum of 1.3, which occurs well above the tunnel floor. A reasonable explanation for this discrepancy is that the effervescent injection and atomization resulted in a flame closer to the tunnel floor than the steady liquid stream (See Figure 5.6). Another difference is the power levels used. The present design used a power level approximately one-fifth of the power level used by Cross to obtain a higher total temperature ratio.

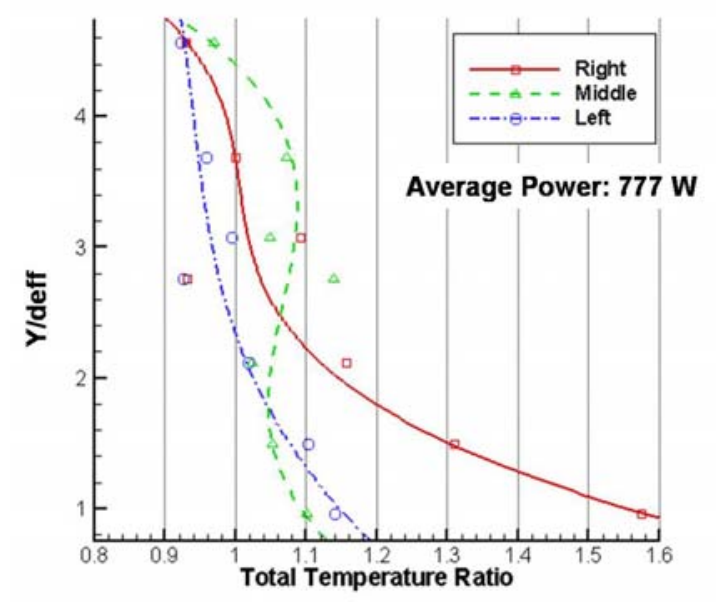

Figure 5.19: Normalized Total Temperature for 50 psi Injection Pressure 


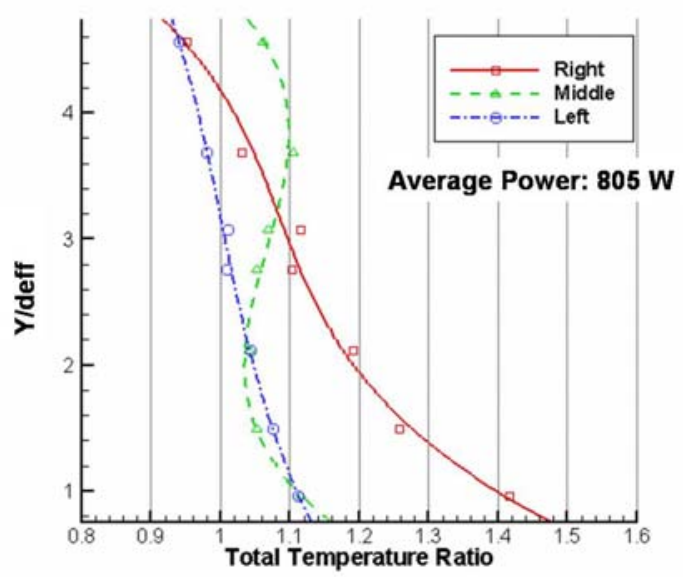

Figure 5.20: Normalized Total Temperature for 70 psi Injection Pressure

Finally, the total temperature characteristics of the right and middle thermocouples should be analyzed. Both Figure 5.19 and Figure 5.20 show the third degree polynomial trend lines for the right and middle thermocouples crossing. This indicates that close to the tunnel floor, the combustion is dominating and causing a greater total temperature ratio. Moving away from the tunnel floor, there is very little combustible fuel (See Figure 5.4), so the total temperature at this location is influenced by the hot plasma gases. With an increase in fuel injection pressure, enhanced penetration occurs, and so the combustion causes the total temperature at this greater Y-location to increase, as seen in Figure 5.20.
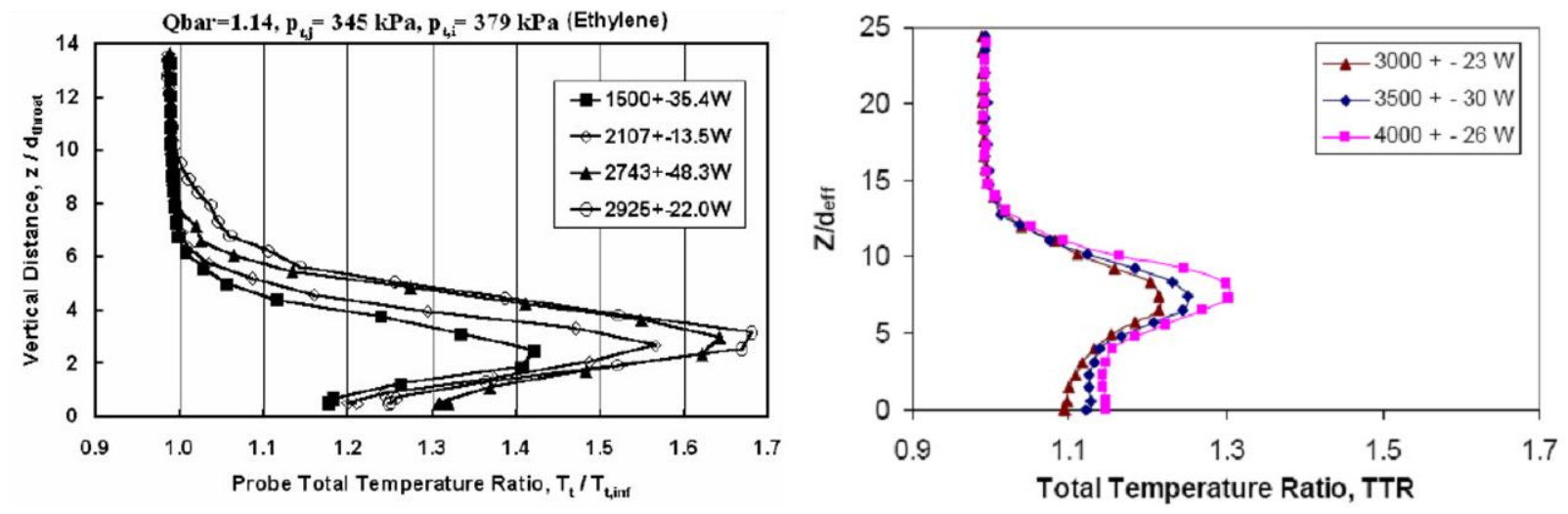

Figure 5.21: Normalized Total Temperatures Obtained by Gallimore [43] and Cross [42] 


\subsection{Chemical Species Analysis}

Hundreds of different chemical species may occur in any given higher hydrocarbon flame. They occur as stable combustion intermediates, electronically excited molecules, free radicals, and decomposition products of parent straight-chain or cyclic paraffins, aromatics, and naphthenes. If a non-intrusive method were developed to simultaneously measure absolute concentrations of many of these, particularly products of combustion and key intermediates, a reacting system could be accurately modeled. However, even systems monitoring just a few species simultaneously are costly, can be impractical in an existing experimental setup, and often require technical expertise. The current experiments, therefore, relied on readily available and relatively inexpensive optical techniques: filtered photography and UV-visible spectroscopy.

\subsubsection{Filtered Photography}

Filtered photography provided a qualitative indication of certain chemical species present in the system. In order to draw conclusions, a reference intensity was needed that would be close to constant in all cases. The torch operation without fuel ignition was chosen for this reference. The procedure for filtered photography included finding a combination of shutter speeds and aperture settings so that the light from the torch just saturated the detector in the camera. By doing this, gradients in the pictures were visible as opposed to large saturated regions. In some cases, this allowed the geometry of the system to be seen. The camera settings were not changed from torch-only operation to torch operating with fuel, so that a direct comparison between the light intensities could be made. This is shown in Figure 5.22 for OH. The three pictures represent three stages in a typical test progression: torch operation, continuous liquid fuel injection, and an unsteady, sputtering fuel injection as the driver gas purges the fuel system. As stated previously, the torch light covers a wide spectrum, which explains the visibility of this particular wavelength 
in (a). A bright location is shown in (b) between the igniter and the fuel. In (c), the fuel appears to be igniting in the stagnation region. Notice also that a tail of $\mathrm{OH}$ is seen extending downstream in (c), but not in (a) or (b). These figures show the presence of $\mathrm{OH}$ in the region of combustion.

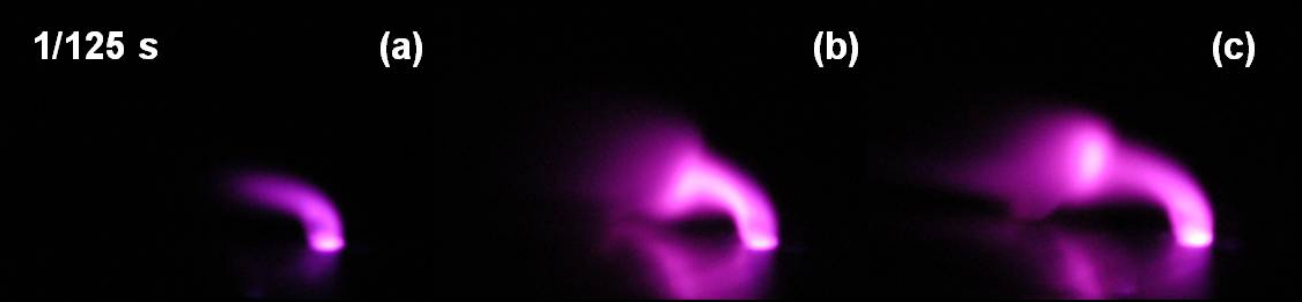

\section{Figure 5.22: OH Filtered Photographs: Torch Only; Continuous Fuel; Effervescent Fuel}

It was also realized that using air as a feedstock would promote combustion since it contains oxygen. This would lead to a greater variety of ionized atoms and molecules in the plasma. However, torch operation with air as opposed to nitrogen as the feedstock causes severe anode erosion, so nitrogen was used for most of the testing. Figure 5.23 gives a comparison of nitrogen (top three frames) and air (bottom three frames) feedstock on the intensity of $\mathrm{C}_{2}$ emission. Similar trends are seen in (a), (b), and (c) that are observed in Figure 5.22, although there appears to be more extensive presence of $\mathrm{C}_{2}$ than $\mathrm{OH}$, as seen by the long, trailing tail continuing downstream. Frame (c) indicates that the fuel is igniting in the stagnation region, with a stronger presence of $\mathrm{C}_{2}$ at this location than in the extremely bright torch itself. The difference in combustion with air feedstock is obvious when comparing the top three frames with the bottom three frames. For all operating conditions, the air feedstock is accompanied by a greater intensity, particularly in the continuous fuel injection case, (e). One interesting observation is that the nitrogen feedstock appears to penetrate farther into the flow than the air feedstock. Also, although the air feedstock produces a greater intensity (f) than the nitrogen, the downstream extent of the luminous region is not significantly different. Figure 5.22 and Figure 5.23 
effectively demonstrate the presence of certain key combustion species, comparing torch-only operation with fuel ignition.

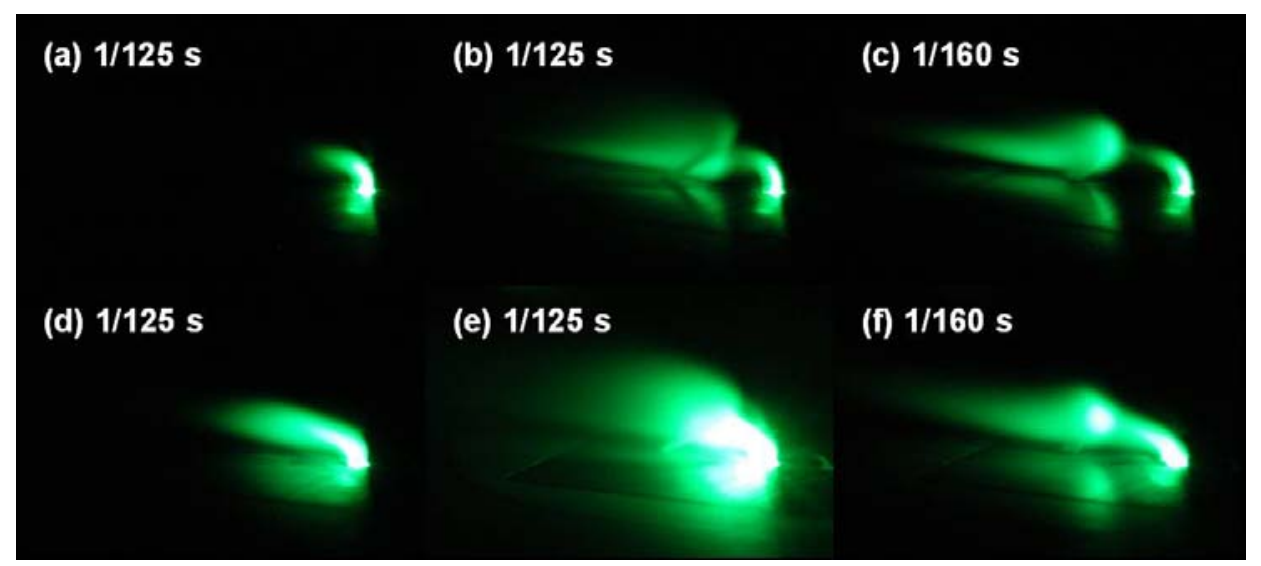

Figure 5.23: Effects of Feedstock Gas on $\mathrm{C}_{2}$ * Intensity for Typical Operating Conditions

A final comparison of filtered photographs was made between water and kerosene injection under similar torch operating conditions. As Anderson [39] noted, the possibility of scattered light reflecting from droplets could possibly make the reaction region appear larger than it actually is. To address this concern, water was injected with the torch ignited, and the resulting filtered photographs were compared to kerosene injection with similar torch operating conditions. The comparison is given in Figure 5.24. A very small region of $\mathrm{C}_{2}$ is seen for the water case. This is almost certainly due to remnants of kerosene in the fuel line being mixed with water and reacting in the torch region. The difference between these two photographs is apparent, and provides conclusive evidence that the light intensities witnessed by the photography as well as the spectroscopy are due to combustion fuel, and cannot be attributed to optical droplet scatter or reflection. On a slightly different note, Figure 5.24 (b) clearly shows the luminous region extending downstream on the far side of the fuel injection, but not on the near side. As previously stated, this is due to the arc attaching itself to the anode in an off-center location, which causes the ignition and combustion to occur on the far side. For example, observe the temperature rise profile in Figure 5.15 and the post-testing anode in Figure 5.11. 


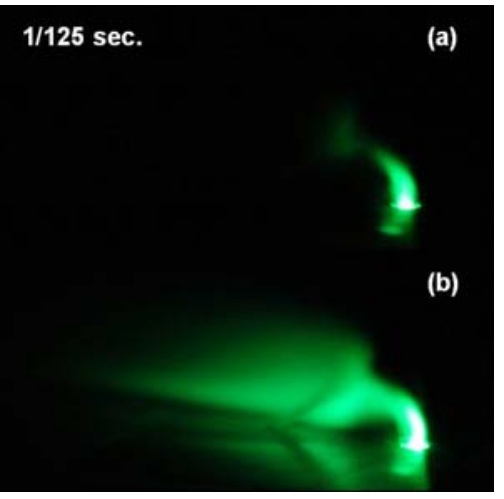

Figure 5.24: Comparison of Water and Kerosene Injection on $\mathrm{C}_{2}$ Emission Intensity

\subsubsection{Spectroscopy}

\subsubsection{General Discussion}

UV-visible emission spectroscopy of hydrocarbon flames provides a qualitative indication of the presence of combustion, although it is currently not used to deduce specific chemical parameters such as species concentration. Spectroscopy in this sense is most useful in obtaining information related to the chemiluminescence of a given process. Chemiluminescence is the light emitted by atoms or molecules as they transition from a more energetic state to a less energetic state. The wavelength of the emitted light is specific to both the chemical specie and the particular transition it is undergoing. For example, free radicals emit line spectra during electronic transitions, while molecules emit bands, often with distinct heads marking their occurrence. As transitions between various energy states occur during a reaction, light is emitted and can be focused, collected, and integrated to obtain an indication of the chemical kinetics present in the system. Ideally, the species most indicative of complete combustion would be those permanent constituents such as $\mathrm{CO}, \mathrm{CO}_{2}$, and $\mathrm{H}_{2} \mathrm{O}$. For example, Turns [24] notes that the presence of $\mathrm{CO}$ indicates the initial breakdown of the fuel, which is generally followed by the final oxidation of $\mathrm{CO}$ to $\mathrm{CO}_{2}$. However, flame temperatures are not normally adequate to produce visible excitation of such molecules. Free radicals, on the other hand, are an ideal 
candidate for UV-visible spectroscopy because relatively small amounts of energy are required for their transition from the ground state to the lowest electronic state. Haber [60] reviewed the experimental use of chemiluminescence, particularly in the study of three important electronically excited species: $\mathrm{OH}^{*}, \mathrm{CH}^{*}$, and $\mathrm{C}_{2}{ }^{*}$. These species are dominant in the $250-600$ $\mathrm{nm}$ region, and were the species of interest in a study conducted by Sandrowitz et al. [61] to determine the dependence of emission characteristics on equivalence ratio and total flow rate. A Bunsen burner flame chemiluminescence emission spectrum from Haber's testing is shown in Figure 5.25.

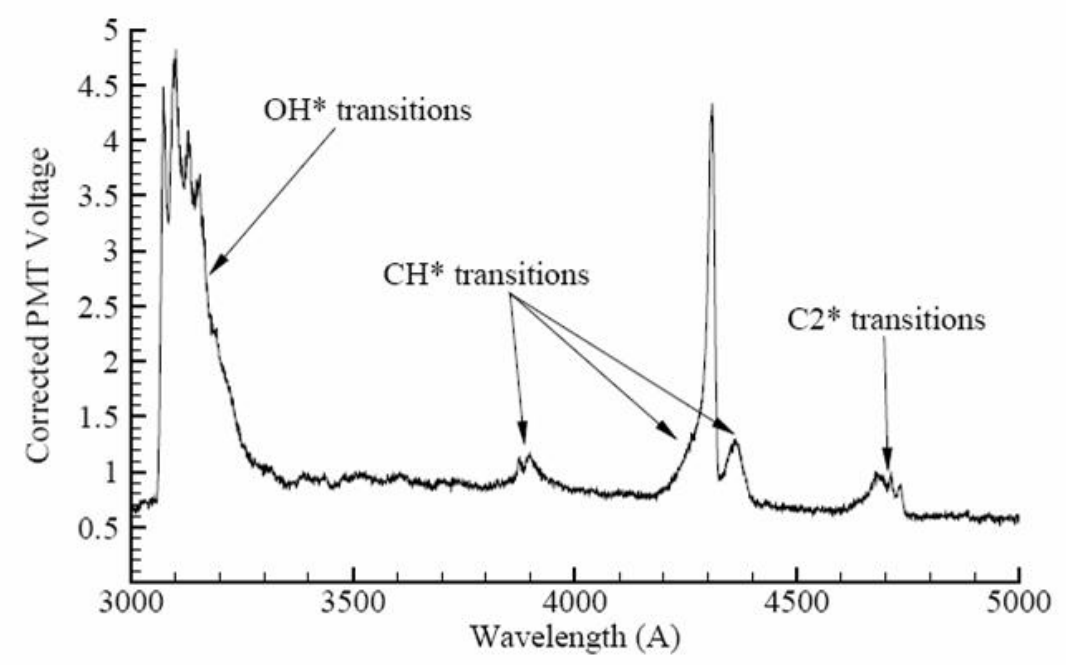

Figure 5.25: Bunsen Burner Flame Chemiluminescence Emission Spectrum [60]

\subsubsection{Emission Spectrum Characteristics}

As previously stated, atomic and molecular transitions are accompanied by light emission at wavelengths particular to the atom, molecule, and transition. For a given spectrum of integrated intensity, conclusions can be drawn about the processes being monitored. A representative emission spectrum is shown in Figure 5.26. The scale is the same for each graph to show the difference between the plasma torch (a) and fuel ignition (b). The torch operating power was identical, as the emission snapshots were taken within seconds of each other. Without 
further analysis, it is evident from these graphs that significant chemical activity is occurring. The specific molecules present can be examined by magnifying relevant portions of the spectrum.
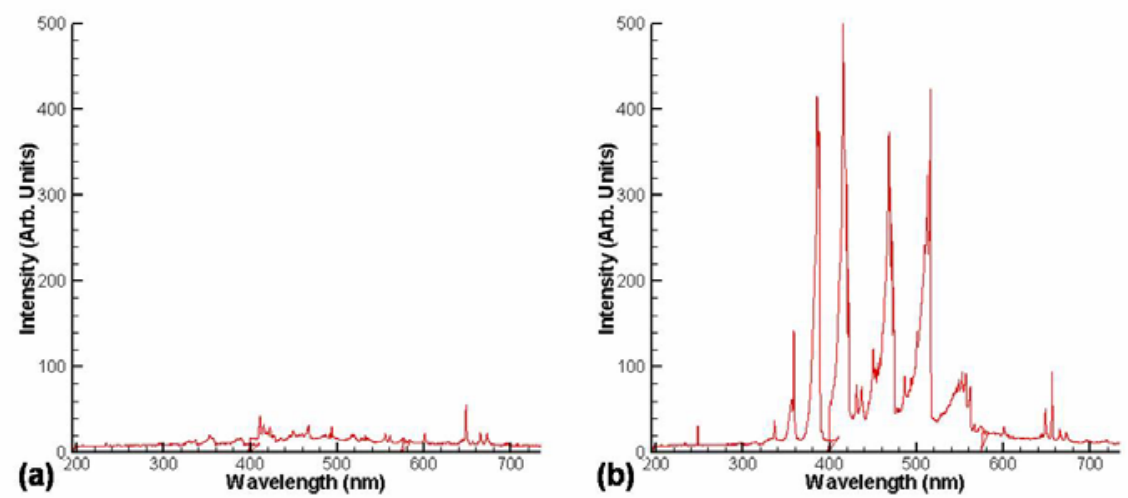

Figure 5.26: Plasma Torch Igniter (a) and Kerosene Combustion (b) Emission Spectra

Gaydon [62] has thoroughly tabulated emission band spectra commonly found in hydrocarbon flames, and much of the following discussion is based on his book. Additionally, Gilbert's [63] commentary and graphical emission spectra allowed for convenient comparison in many cases. Pearse and Gaydon's [64] comprehensive review of transition phenomena for thousands of molecules was also a helpful reference. The $\mathrm{CN}$ molecule represents some of the most distinctive peaks visible in Figure 5.26 (b), and at least four identifiable occurrences were seen in the spectrograph. They are shown individually in Figure 5.27. These bands are all part of the CN Violet System and occur in hot organic flames containing nitrogen. Nitrogen in various forms was readily available since it was the feedstock gas used in the experiments. The lower right graph demonstrates a difficulty encountered with emission spectroscopy: masking. This occurs when transitions between molecules emit light at similar wavelengths to other transitions happening simultaneously. In this case, $\mathrm{CN}$ and $\mathrm{CH}$ emissions overlap, but as Gaydon notes, the leftmost band, at $386 \mathrm{~nm}$, dominates the group when $\mathrm{CH}$ masking happens. 


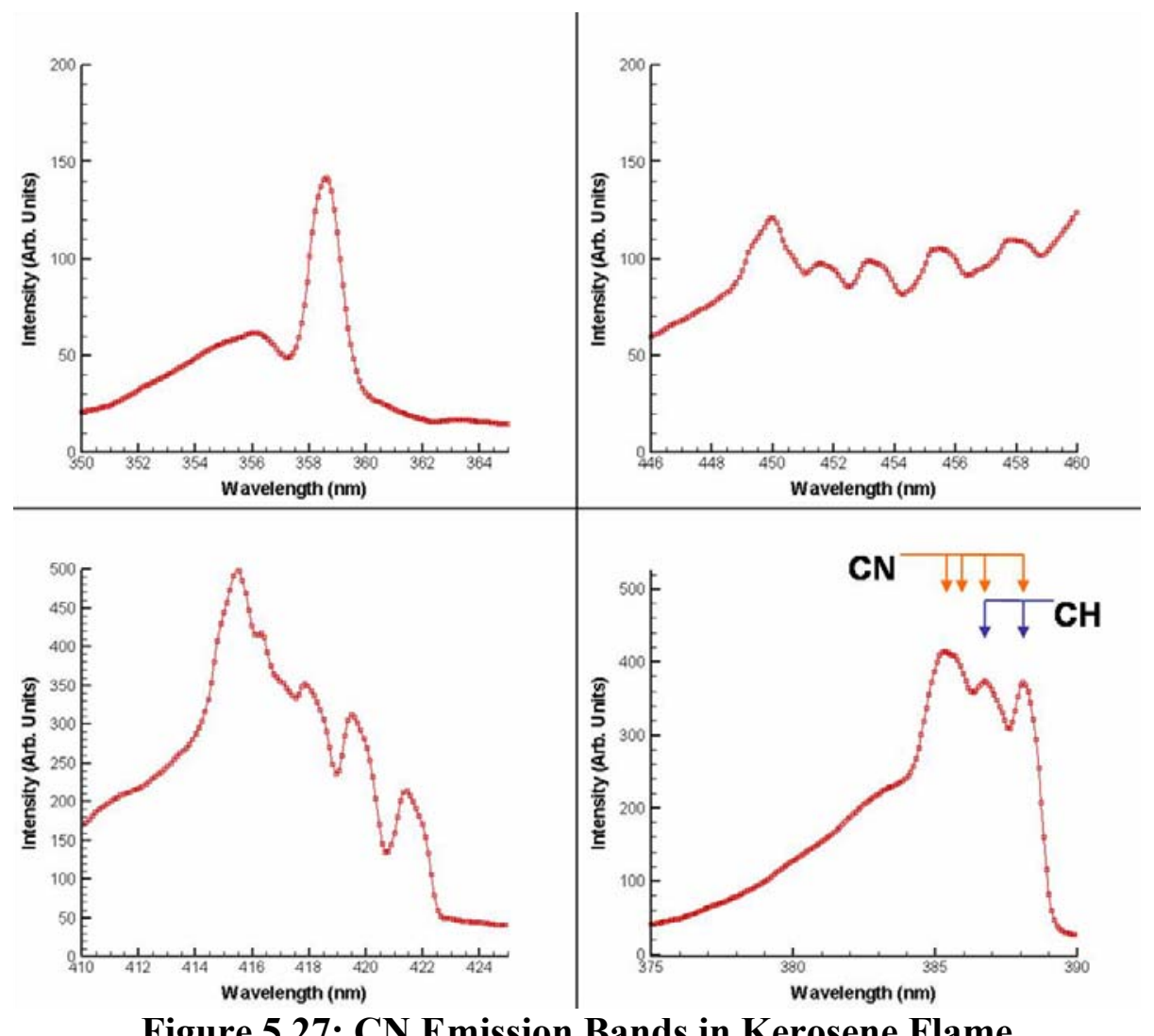

Figure 5.27: CN Emission Bands in Kerosene Flame

In addition to the $\mathrm{CH}$ bands near $388 \mathrm{~nm}$, a strong band occurs at $431 \mathrm{~nm}$, which is shown in the upper left graph of Figure 5.28 along with a weak portion of the $\mathrm{C}_{2}$ Swan band system. Additionally, a weak $\mathrm{CH}$ band was seen near $314 \mathrm{~nm}$, but is not shown. The other three graphs in Figure 5.28 are portions of the $\mathrm{C}_{2}$ Swan band system, a common and easily recognizable feature in most hydrocarbon flames. It is evident from the presence of $\mathrm{C}_{2}$, as well as $\mathrm{CH}$ and $\mathrm{CN}$, that reaction is occurring. As previously stated, visible emission spectroscopy provides a qualitative indication of electronic transitions associated with combustion processes, but is not suitable to give a quantitative analysis of the ultimate combustion products themselves. 

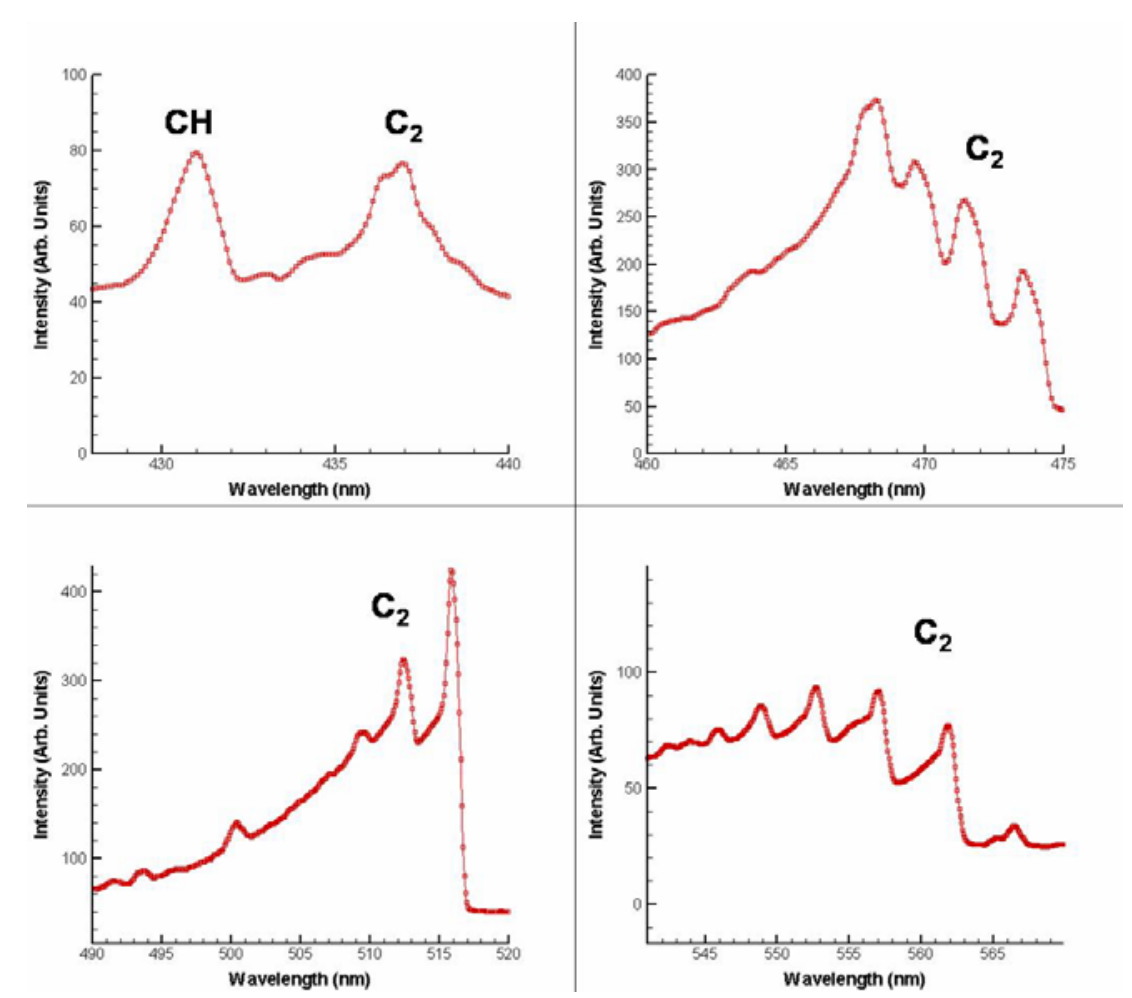

Figure 5.28: $\mathrm{CH}$ and $\mathrm{C}_{2}$ Swan Emission Bands in Kerosene Flame

A peculiar feature regarding the radiation spectra is the apparent absence of $\mathrm{OH}$, which is usually one of the most dominant features in hydrocarbon flames. Compare, for example, Figure 5.25 with Figure 5.26(b). One would expect to see strong $\mathrm{OH}$ bands, particularly $\mathrm{OH}^{*}$ chemiluminescence at $305.4 \mathrm{~nm}$ due to the ${ }^{2} \Sigma^{+}-{ }^{2} \Pi$ transition from the first electronically excited state to the ground state. A possible explanation for the lack of visible $\mathrm{OH}$ emission could be a low equivalence ratio in the region of radiation. Dandy and Vosen [65] developed numerically and verified experimentally an exponential relationship between the amount of total $\mathrm{OH}^{*}$ intensity and the fuel-air equivalence ratio. They found that for low equivalence ratios, $\mathrm{OH}^{*}$ emission was drastically reduced. However, even if this were the case and low $\mathrm{OH}^{*}$ chemiluminescence was expected, the bands from ground state $\mathrm{OH}$ would be visible in the spectrum. Another possibility is simply that $\mathrm{CH}^{*}$ and $\mathrm{C} 2 *$ were formed, as demonstrated by Figure 5.27 and Figure 5.28, in the radiation area since the reactants needed to form them, 
namely hydrocarbon fuel and nitrogen feedstock, were readily available. The formation of $\mathrm{OH}$ and $\mathrm{OH}^{*}$, however, depend on atmospheric oxygen as shown by the following formation reactions:

$$
\begin{aligned}
& \mathrm{H}+\mathrm{O}_{2} \leftrightarrow \mathrm{O}+\mathrm{OH} \\
& \mathrm{CH}+\mathrm{O}_{2} \leftrightarrow \mathrm{CO}+\mathrm{OH}^{*}
\end{aligned}
$$

Therefore, if the plasma igniter is acting as a blockage to the freestream flow, sufficient oxygen is not available in the reaction zone to form appreciable quantities of $\mathrm{OH}$ or $\mathrm{OH}^{*}$. It is clear from the temperature results presented in Section 5.4 that heat release due to combustion is occurring, but the results shown indicate that a key ingredient in the combustion reaction, $\mathrm{OH}$, is absent at this location in the flow ( $2 \mathrm{~mm}$ downstream of feedstock orifice, $4 \mathrm{~mm}$ above tunnel floor). As air is entrained and mixed around the sides and top of the igniter, $\mathrm{OH}$ is produced and subsequently consumed in chain reactions.

A most important result of the spectroscopic analysis is portrayed in Figure 5.29. The emission intensities for operation of plasma torch only and plasma torch with fuel injection are compared. Two important spectral features are present: an $\mathrm{N}_{2}$ band of the first positive neutral nitrogen molecule and the $\mathrm{H}_{\alpha}$ atomic hydrogen line at $656 \mathrm{~nm}$ [64]. The spectrometer location for these measurements was $4 \mathrm{~mm}$ above the tunnel floor and $2 \mathrm{~mm}$ downstream of the torch feedstock orifice, so the presence of atomic hydrogen indicates that the fuel is penetrating farther upstream than originally thought. Furthermore, these results are encouraging from a chemical kinetics point of view, since $\mathrm{H}$ atom abstraction from the parent fuel is widely accepted as a key factor in the combustion of heavy saturated hydrocarbons [29]. Finally, the occurrence of hydrogen is beneficial from an ignition standpoint, as it has been shown that the presence of 
hydrogen atoms in a reacting system may be as or more beneficial than the incorporation of currently-used pyrophoric additives (See Section 1.3) [38].

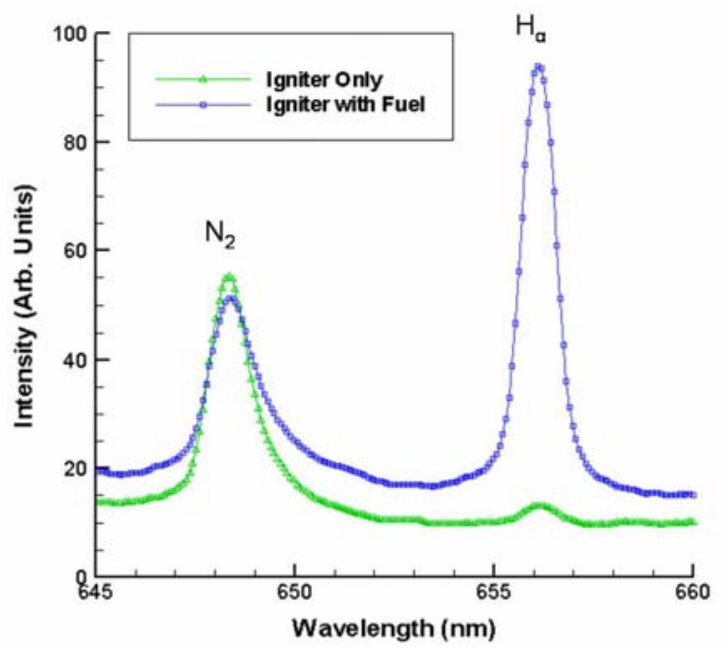

Figure 5.29: Comparison of $\mathbf{H}_{\alpha}$ Emission Intensities for Torch Only and Torch with Fuel

\subsubsection{Chemiluminescence Profiles}

Chemical species are now examined on a spatial scale. To obtain these results, the spectral data presented briefly in Section 5.5.2.2 were processed by identifying wavelengths and corresponding indices of specific molecules, and plotting these intensities on a normalized scale of Y-direction (vertical distance above tunnel floor) and X-direction (downstream direction; direction of tunnel flow). Again, $d_{o}$ is the fuel injection orifice diameter, a convenient normalizing parameter, equal to 0.020 ". A dominant emission peak of cyanogen $(\mathrm{CN}), 415 \mathrm{~nm}$ in Figure 5.27, was processed in this way and is presented in Figure 5.30. The positions of the plasma torch discharge orifice (Igniter) and the fuel injection orifice (Injector) are indicated. The profile on the left corresponds to a spectroscopic measurement of the torch only operating; the right is with the torch operating while liquid fuel is being injected. Similar scales were used to allow for direct comparison. The figure indicates minimal $\mathrm{CN}$ for the torch-only case. With fuel injection, however, a relatively large amount of light is emitted, indicating qualitatively the presence of $\mathrm{CN}$ undergoing this transition. 

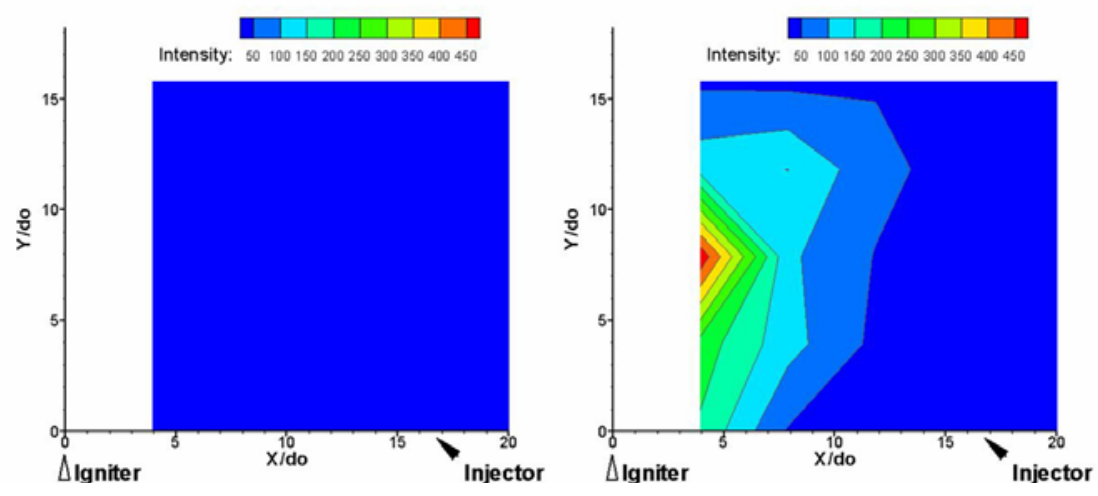

Figure 5.30: CN (415 nm) Emission Intensity for Igniter with and without Fuel Injection

Similar profiles for two important chemiluminescent species, $\mathrm{CH}^{*}$ and $\mathrm{C} 2 *$, are given in Figure 5.31 and Figure 5.32, respectively. The most obvious conclusion drawn from these profiles is that during fuel injection and combustion, much greater intensity levels are seen that for plasma torch operation without fuel injection. This indicates the presence of these species in the combustion region. Although this appears trivial, given that the fuel is the only carbon source available, the location of the maximum intensity values is significant. For all species shown, it occurs $2 \mathrm{~mm}$ downstream of the torch and $4 \mathrm{~mm}$ above the tunnel floor. Normally, a high intensity at this location would be attributed to the light emitted from the plasma torch itself, which is believed to possess a broadband emission spectrum with individual peaks corresponding to the type of feedstock used. However, as the figures on the left-hand side indicate, very small intensities may be attributed to the plasma torch itself, leaving the only possible source for the presence of these species as the combustion (chemical reaction) of the hydrocarbon. 

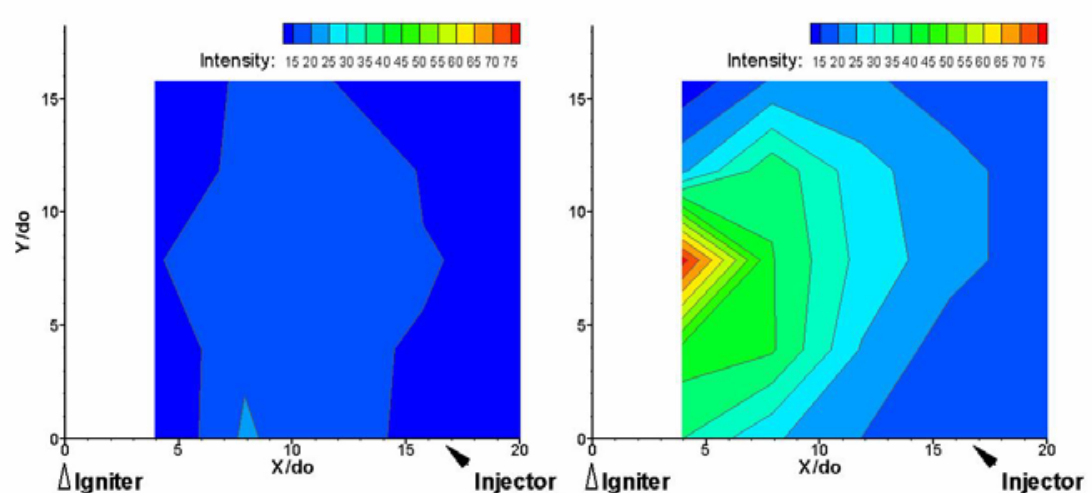

Figure 5.31: $\mathrm{CH}^{*}(431 \mathrm{~nm})$ Emission Intensity for Igniter with and without Fuel Injection
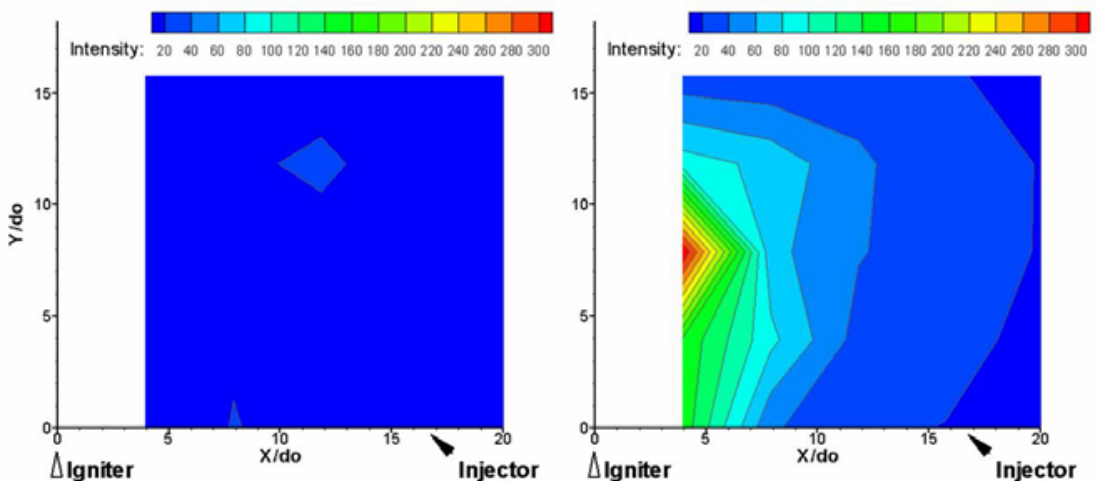

Figure 5.32: $\mathrm{C}_{2}{ }^{*}(513 \mathrm{~nm})$ Emission Intensity for Igniter with and without Fuel Injection

Additionally, it is noteworthy to consider the degree of upstream penetration witnessed by these results. Again, the maximum intensity values are obtained at a location closer to the plasma torch that the injector. Since this is not evident from Figure 5.3 and Figure 5.6, it is clear that there remain processes at work which were not captured photographically. Specifically, fuel entrainment in a counter-rotating vortex is likely drawing injected fuel vapor upstream into the region of ignition. The swirling flow is effectively acting as a flameholder, with relatively low velocities encountered and behavior similar to the combustion in an annular gas turbine burner. This type of opposing-jet flameholder has been shown to successfully stabilize hydrocarbon flames, although to the author's knowledge, this has been restricted to subsonic flow with afterburner applications in mind. Lefebvre [66] discussed research related to opposing-jet 
flameholders. The flame stabilization method in the current work differs from common designs only in that it relies on the low-velocity wake of the feedstock injection and the upstream-angled fuel injection, rather than a physical protrusion into the flow.

\subsection{Boundary Layer Considerations}

Finally, in an effort to investigate the species and temperature rise locations within the flow, measurements were made to estimate the thickness of the boundary layer. With this knowledge, it is possible to categorize the combustion reaction as main flow combustion, supersonic boundary layer combustion, or subsonic boundary layer combustion, or a combination of the three. Typical measurements based on a series of traverse stations are given in Figure 5.33. Three probes (total temperature, total pressure, static pressure) were traversed vertically into the flow to gather the data shown by the red, green, and blue lines in the figure. They are normalized by the upstream plenum temperature and total pressure. Also shown is the behavior of the plenum total pressure over time. Time elapses as the traverse moves, and so traverse position could also be interpreted as time. Clearly, the plenum pressure is constant initially, then begins to decrease toward the end of the run. This could be due to a low supply tank pressure, and could explain why the Mach number, calculated from the total and static pressure values, appears to reach only around 1.8 as opposed to the $\mathrm{M}=2.4$ design condition. The downstream normalized total pressure would be expected to reach the value of the upstream plenum pressure once the traverse is outside the boundary layer. Clearly, though, substantial total pressure losses occur between the plenum and the traverse, possibly due to shocks. The static pressure remains essentially constant moving upward from the tunnel floor. The total temperature decreases. The boundary layer is the region near the wall where viscous forces due

to the no-slip condition at the wall are important. In this region, the flow velocity is somewhat 
lower than the freestream flow velocity. Moving upward from the wall, there occurs a location where the velocity no longer changes, and is equal to the freestream velocity. At this point, the second term on the right-hand side of

$$
P_{o}=P+\frac{\rho V^{2}}{2}
$$

is constant, i.e., the total pressure $P_{o}$ is no longer changing given a static pressure $P$. Based on the measurements, this location occurs in between 0.5 and 0.6 in. above the tunnel floor. Additionally, the Mach number calculation shows that the boundary layer consists primarily of supersonic flow, with only a thin (0.1") region very close to the wall being subsonic. Comparing these results to Figure 5.15, it is seen that the most intense region of heat release occurs within 0.1 " of the floor, on the verge of the subsonic and supersonic boundary layer regions. However, Figure 5.18 shows that an increase in fuel injection pressure from 50 psi to 70 psi causes an upward shift in the $60^{\circ}$ total temperature region from $\mathrm{Y} / \mathrm{d}_{\mathrm{o}}=9\left(0.18^{\prime \prime}\right)$ to $\mathrm{Y} / \mathrm{d}_{\mathrm{o}}=13\left(0.26^{\prime \prime}\right)$, clearly into the supersonic boundary layer. Additionally, significant temperature rise was measured as far as $\mathrm{Y} / \mathrm{d}_{\mathrm{o}}=17(0.34$ ") above the floor, a region within the supersonic boundary layer (Figure 5.15). Similarly with species profiles, the most intense region of chemical activity appears to be approximately $\mathrm{Y} / \mathrm{d}_{\mathrm{o}}=7.5\left(0.15^{\prime \prime}\right)$, according to Figure 5.31 , for example. This indicates that combustion is occurring in the supersonic regime. 


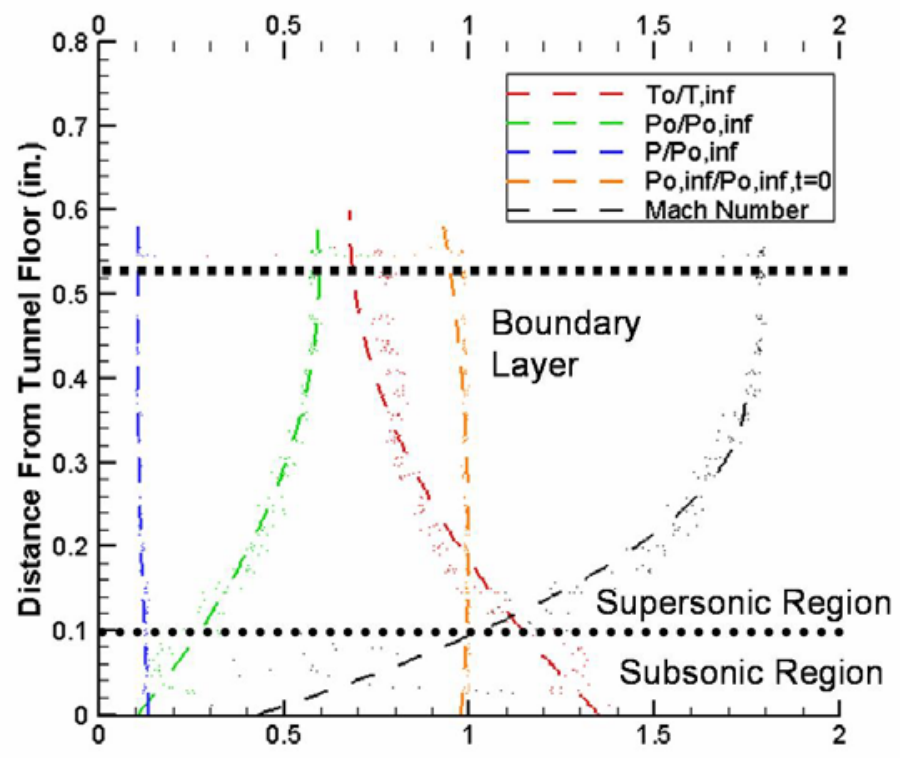

Figure 5.33: Supersonic Boundary Layer Measurements 


\section{Conclusions and Recommendations}

\subsection{Summary of Quiescent Testing Conclusions}

\subsubsection{Validity of Design}

A novel design was built and tested in quiescent and supersonic environments. The unique features of the design include its capability for regenerative fuel heating and its method of atomization. In preliminary testing, it was found that anode life was significantly increased due to torch operation with regenerative heat exchange. The heat exchanger was redesigned for subsequent quiescent tests, and was found to be $65 \%$ more effective than the original design in heating the fuel.

\subsubsection{Atomization}

Given the sensitivity of the combustion reaction to effective atomization, care was taken to characterize the methods of atomization present with the design. To the author's knowledge, the atomization scheme employed by the injector is unique: liquid fuel is injected cylindrically at an external location; following the onset of jet disintegration, the fuel is impinged upon by a sonic cylindrical gas stream, shattering it into a polydisperse spray (In the supersonic environment, another method of atomization occurs as the high-velocity air stream meets the fuel as it proceeds into the supersonic boundary layer). It was discovered that finer atomization occurred during the effervescent injection of the liquid, i.e. as the driver gas mixed internally with the liquid. To characterize the mode of jet disintegration, the Reynolds Number and Ohnesorge Number were calculated and plotted, with the result that the jet breakup fell in the second wind-induced regime. This result was consistent with magnified photographs. Using a correlation from the literature for external-mixing air-assist atomizers, the Sauter Mean Diameter of the quiescent spray was calculated to be $35 \mu \mathrm{m}$. 


\subsubsection{Combustion}

Quiescent combustion of kerosene and JP-7 was achieved. Torch power was not found to have a great influence on combustion performance, with powers as low as $850 \mathrm{~W}$ igniting the mixture. Flame formation of kerosene and JP-7 was examined, with the kerosene flame fully formed approximately $30 \mathrm{~ms}$ before the JP-7 flame. The flame itself consisted of a turbulent premixed flame superimposed on a turbulent diffusion flame. The non-homogeneity of the flame structure was attributed to the wide variety of initial atomized drop sizes.

\subsection{Summary of Supersonic Testing Conclusions}

\subsubsection{Injection, Penetration, and Atomization}

In the supersonic environment, it was determined that fuel injection in the direction opposite to the main flow resulted in better penetration and was accompanied by significant heat release, while fuel injection in the direction of the main flow yielded no noticeable heat release and poor penetration. The penetration into the main flow was measured and normalized, and results indicate that much better penetration is seen for the case of upstream feedstock injection in cooperation with counter-flow fuel injection than for previous injection which consisted of the fuel injector alone. Penetration heights as much as 0.32 in. were measured at a location 0.8 in. downstream of the fuel injection orifice. This was achieved with a relatively low fuel injection pressure, 50 psig.

\subsubsection{Visible Evidence of Combustion}

Supersonic combustion was witnessed as a blue-green flame extending downstream. The ignition location varied according to the fuel injection method (continuous or effervescent), but was often seen close to the stagnation point of the injected fuel. At this location, the plasma torch ignition region was bent toward the fuel by the supersonic flow, providing a high temperature 
source of ions. Water and fuel were compared visually, and the results clearly indicate combustion occurring in the case of fuel injection. The method of flame stabilization is essentially an opposed-jet flameholder, with the incoming fuel stagnating and turbulently mixing in a region close to the plasma torch igniter.

\subsubsection{Chemical Species}

Further evidence of combustion was found by the presence of several key indicators of hydrocarbon combustion, including $\mathrm{CH}^{*}, \mathrm{OH}^{*}$ and $\mathrm{C}_{2}{ }^{*}$. This was accomplished through filtered photography and ultraviolet-visible emission spectroscopy. The results were compared with similar measurements taken with only the torch operating, and differences between the spectra are obvious. The presence of atomic hydrogen was also found to drastically increase upon injection and combustion of fuel. $\mathrm{OH}^{*}$ was not found in the spectroscopic signal, but was present in the filtered photographs. $\mathrm{CN}$ was dominant in the spectral emissions. The most active region of chemical activity, i.e. combustion, was discovered to be $2 \mathrm{~mm}$ downstream of the feedstock orifice and $4 \mathrm{~mm}$ above the tunnel floor based on spectroscopic intensity locations.

\subsubsection{Temperature Measurements}

The distinct behavior of the ignition system as a result of the method of fuel injection (continuous or effervescent), was observed in the total temperature measurements, just as in the filtered, Schlieren, and direct photography. During this portion of the tests, significantly greater temperatures were measured. A temperature of as much as $230^{\circ} \mathrm{C}$ was witnessed by the total temperature probes, with the corresponding temperature due to the torch alone just above $100^{\circ} \mathrm{C}$. This type of heat release was encountered with fuel injection, while water injection resulted in almost no temperature rise, even with the plasma torch ignited. Increasing the fuel injection pressure from 50 psig to 70 psig resulted in an increase in the global total temperature, but a 
decrease in the maximum measured total temperature. A general upward shift of high temperature was witnessed. Although the hottest locations were in general on the verge between the subsonic and supersonic boundary layer regions, significant temperature increase was seen well into the supersonic boundary layer in many cases. The heat release seen in these results confirms the visible and spectroscopic evidence that supersonic ignition and combustion of a liquid hydrocarbon fuel by a flush-wall injector and igniter has been achieved.

\subsection{Recommendations for Further Research}

The combustion temperatures measured downstream did not correctly characterize the degree of combustion occurring due to the intense mixing with the cold wind tunnel air. The flame was certainly hotter than the temperatures measured. Since mixing is occurring primarily in the streamwise direction due to the low relative velocity between the combustion products and the freestream air, a study investigating the temperature in this direction should be conducted. A convenient normalization to avoid mistaking the plasma torch heat release with combustion heat release would be the plasma torch temperature itself. A floor plate could be easily designed to provide for translation in the streamwise direction, and temperature measurements could be taken each run for plasma torch only operation and plasma torch with fuel operation. In addition, better spanwise resolution is possible with the current total temperature probe rake. Finally, traversing the probe in the Y-direction (moving up from the tunnel floor) would complete a 3-D total temperature map.

It was somewhat surprising to witness unheated supersonic liquid hydrocarbon combustion without the use of vanes, struts, or cavities. The conditions in the tunnel (low temperature and low pressure) did not help. Testing this design in conditions more conducive to 
combustion would no doubt give a better idea of the potential of this device in an actual scramjet engine.

As previously stated, the concept was not designed to behave as an effervescent atomizer. This effect was discovered during the quiescent testing, and was found to produce different results than the continuous fuel injection. Similar differences were observed for the supersonic testing. However, the unsteady nature of the fuel injection system (see Figure 5.10) caused the direct comparison between continuous and effervescent to be difficult. Although the temperature evidence of Figure 5.12 would indicate better combustion for effervescent injection, certain photographs, such as those shown in Figure 5.7, suggest that the continuous fuel injection results in better combustion. To address these discrepancies, a controlled, effervescent atomization scheme should be designed and compared with a continuous liquid injection scheme. The steady liquid injector must be free of any gas that could potentially cause bubbles in the liquid; one such method would be an inverted syringe-type injector actuated by a computer-controlled piston cylinder.

Diagnostically, opportunities abound to characterize the combustion evidenced by the current design. For one, although filtered photography and spectroscopic chemiluminescence measurements provide a good qualitative indication of reaction, they are useless to describe in detail the chemistry occurring. The CARS (Coherent Anti-Stokes Raman Spectroscopy) method has been widely-accepted as a nonintrusive tool for measuring temperature [67] and species concentration [68] in scramjets for some time. Unfortunately, the abundance of possibilities are only possibilities given the resources to obtain them or the chance to work in conjunction with a facility who has them. 
Finally, as stated previously, an interesting and possibly rewarding project would be modeling the combustor as an altered plug-flow reactor (PFR). The governing equations would need slight modifications as discussed in Section 2.6.2. If this were accomplished and coupled with a reaction mechanism such as that developed by Mulholland et al. [28], a 2-D model including concentration, temperature, and pressure variations could be compared with experimental results. Early on in the current work, the governing conservation equations for a PFR were derived as the most basic step toward this end. They are provided in Appendix B. 


\section{References}

1. Nicholls, J.A., Dabora, E.K., and Gealer, R.L., "Studies in Connection With Stabilized Detonation Waves," in Proceedings of the Seventh Symposium (International) on Combustion, London and Oxford, 1958. Butterworths Scientific Publications, pp. 766-772.

2. Weber, R.J. and MacKay, J.S., "An Analysis of Ramjet Engines Using Supersonic Combustion," NACA Technical Note 4386, 1958.

3. Williams, S., Midey, A.J., Arnold, S.T., Miller, T., Bench, P.M., Dressler, R.A., Chiu, Y.-H., Levandier, D.J., Viggiano, A.A., Morris, R.A., Berman, M.R., Maurice, L.Q., and Carter, C.D., "Progress on the Investigation of the Effects of Ionization on Hydrocarbon/Air Combustion Chemistry: Kinetics and Thermodynamics of C6-C10 Hydrocarbon Ions," (AIAA) 2001-2873 in 4th Weakly Ionized Gases Workshop, Anaheim, CA, 2001.

4. Marshall, L.A., Bahm, C., Corpening, G.P., and Sherrill, R., "Overview With Results and Lessons Learned of the X-43A Mach 10 Flight," (AIAA) 2005-3336 in AIAA/CIRA 13th International Space Planes and Hypersonics Systems and Technologies Conference, Capua, Italy, 2005.

5. Waltrup, P.J., "Liquid-Fueled Supersonic Combustion Ramjets: A Research Perspective," Journal of Propulsion and Power, Vol. 3, Issue 6, 1987. pp. 515-524.

6. Anderson, G.Y., McClinton, C.R., and Weidner, J.P., Scramjet Performance, in Scramjet Propulsion, E.T. Curran and S.N.B. Murthy, Editors. Progress in Astronautics and Aeronautics. 2001, AIAA: Washington, D.C. p. 369-446.

7. Curran, E.T., "Scramjet Engines: The First Forty Years," Journal of Propulsion and Power, Vol. 17, Issue 6, 2001. pp. 1138-1148.

8. Townend, L.H., "Domain of the Scramjet," Journal of Propulsion and Power, Vol. 17, Issue 6, 2001. pp. 1205-1213.

9. Mercier, R.A. and Ronald, T.M.F., "Hypersonic Technology (HyTech) Program Overview," (AIAA) 1998-1566 in AIAA 8th International Space Planes and Hypersonic Systems and Technologies Conference, Norfolk, VA, 1998.

10. Marren, D., Lewis, M., and Maurice, L.Q., "Experimentation, Test, and Evaluation Requirements for Future Airbreathing Hypersonic Systems," Journal of Propulsion and Power, Vol. 17, Issue 6, 2001. pp. 1361-1365.

11. Voland, R. and Rock, K., "NASP Concept Demonstration Engine and Subscale Parametric Engine Tests," (AIAA) 1995-6055 in AIAA 6th International Aerospace Planes and Hypersonics Technologies Conference, Chattanooga, TN, 1995.

12. Lewis, M.J., "Significance of Fuel Selection for Hypersonic Vehicle Range," Journal of Propulsion and Power, Vol. 17, Issue 6, 2001. pp. 1214-1221. 
13. Baurle, R.A., Mather, T., Gruber, M.R., and Jackson, K.R., "A Numerical and Experimental Investigation of a Scramjet Combustor for Hypersonic Missile Applications," (AIAA) 19983121 in AIAA/ASME/SAE/ASEE 34th Joint Propulsion Conference and Exhibit, Cleveland, $\mathrm{OH}, 1998$.

14. Waltrup, P.J., "Upper Bounds on the Flight Speed of Hydrocarbon-Fueled ScramjetPowered Vehicles," Journal of Propulsion and Power, Vol. 17, Issue 6, 2001. pp. 11991204.

15. Maurice, L.Q., Liquid Hydrocarbon Fuels for Hypersonic Propulsion, in Scramjet Propulsion, E.T. Curran and S.N.B. Murthy, Editors. Progress in Astronautics and Aeronautics. 2001. p. 757-822.

16. Yu, G., Li, J.G., Chang, X.Y., Chen, L.H., and Sung, C.J., "Fuel Injection and Flame Stabilization in a Liquid-Kerosene-Fueled Supersonic Combustor," Journal of Propulsion and Power, Vol. 19, Issue 5, 2003. pp. 885-893.

17. Lefebvre, A.H., Atomization and Sprays. Combustion: An International Series, ed. N. Chigier. 1989: Taylor \& Francis. 421.

18. Sirignano, W.A. and Mehring, C., "Review of Theory of Distortion and Disintegration of Liquid Streams," Progress in Energy and Combustion Science, Vol. 26, 2000. pp. 609-655.

19. Weber, C., "On the Breakdown of a Fluid Jet," Zeitschrift für Angewandte Mathematik und Mechanik, Vol. 11, 1931.p. 136.

20. Sterling, A.M. and Sleicher, C.A., "The Instability of Capillary Jets," Journal of Fluid Mechanics, Vol. 68, Issue 3, 1975. pp. 477-495.

21. Ohnesorge, W., "Die Bildung von Tropfen an Dusen und die Auflosung Flussiger Strahlen (Formation of Drops by Nozzles and the Breakup of Liquid Jets," Zeitschrift für Angewandte Mathematik und Mechanik, Vol. 16, 1936. p. 355.

22. Reitz, R.D., Atomization and Other Breakup Regimes of a Liquid Jet, Ph.D. Thesis. Mechanical and Aerospace Engineering, Princeton University, 1978.

23. Lin, S.P. and Reitz, R.D., "Drop and Spray Formation From a Liquid Jet," Annual Review of Fluid Mechanics, Vol. 30, 1998. pp. 85-105.

24. Turns, S.R., An Introduction to Combustion. 2 ed. McGraw-Hill Series in Mechanical Engineering, ed. J.P. Holman and J. Lloyd. 2000: McGraw-Hill. 676.

25. Chin, J.S. and Lefebvre, A.H., "The Role of the Heat-up Period in Fuel Drop Evaporation," (AIAA) 1983-0068 in 21st Aerospace Sciences Meeting, Reno, NV, 1983.

26. Kuo, K.K., Principles of Combustion. 2 ed. 2005: John Wiley \& Sons. 732. 
27. Westbrook, C.K., "Chemical Kinetics of Hydrocarbon Ignition in Practical Combustion Systems," in 28th (International) Symposium on Combustion, Edinburgh, United Kingdom, 2000. The Combustion Institute, pp. 1563-1577.

28. Mulholland, J.A., Sarofim, A.F., and Beer, J.M., "On the Derivation of Global Ignition Kinetics from a Detailed Mechanism for Simple Hydrocarbon Oxidation," Combustion Science and Technology, Vol. 87, 1992. pp. 139-156.

29. Lindstedt, R.P. and Maurice, L.Q., "Detailed Chemical-Kinetic Model for Aviation Fuels," Journal of Propulsion and Power, Vol. 16, Issue 2, 2000. pp. 187-195.

30. Simmie, J.M., "Detailed Chemical Kinetic Models for the Combustion of Hydrocarbon Fuels," Progress in Energy and Combustion Science, Vol. 29, 2003. pp. 599-634.

31. Warnatz, J., "Chemistry of High-Temperature Combustion of Alkanes up to Octane," in 20th Symposium (International) on Combustion: 1984. The Combustion Institute, p. 369.

32. Jones, W.P. and Lindstedt, R.P., "Global Reaction Schemes for Hydrocarbon Combustion," Combustion and Flame, Vol. 73, 1988. pp. 233-249.

33. Held, T.J., Marchese, A.J., and Dryer, F.L., "A Semi-Empirical Reaction Mechanism for nHeptane Oxidation and Pyrolysis," Combustion Science and Technology, Vol. 123, 1997. pp. 107-146.

34. Faeth, G.M., "Spray Atomization and Combustion," (AIAA) 1986-0136 in 24th Aerospace Sciences Meeting, Reno, NV, 1986.

35. Ballal, D.R. and Lefebvre, A.H., "Flame Propagation in Heterogeneous Mixtures of Fuel Droplets, Fuel Vapor and Air," in 18th Symposium (International) on Combustion: 1981. The Combustion Institute, pp. 321-328.

36. Harrison, A.J. and Weinberg, F.J., "Flame Stabilization by Plasma Jets," Proceedings of the Royal Society of London Series A - Mathematical and Physical Sciences, Vol. 321, 1971. pp. 95-103.

37. Kimura, I., Aoki, H., and Kato, M., "The Use of a Plasma Jet for Flame Stabilization and Promotion of Combustion in Supersonic Air Flows," Combustion and Flame, Vol. 42, 1981. pp. 297-305.

38. Northam, G.B., McClinton, C.R., Wagner, T.C., and O'Brien, W.F., "Development and Evaluation of a Plasma Jet Flameholder for Scramjets," (AIAA) 1984-1408 in AIAA/SAE/ASME 20th Joint Propulsion Conference, Cincinnati, OH, 1984.

39. Anderson, C., Development and Testing of an Integrated Liquid-Fuel-Injector/PlasmaIgniter for Scramjets. Aerospace and Ocean Engineering, Virginia Tech, 2004.

40. Barbi, E., Uncooled Choked Plasma Torch for Ignition and Flameholding in Supersonic Combustion, M.S. Thesis. Mechanical Engineering, Virginia Tech, 1986. 
41. Bonanos, A., Sanders, D., Schetz, J.A., O'Brien, W.F., Goyne, C., and Krauss, R., "HotFlow Testing of an Integrated Aero-Ramp-Injector/Plasma-Igniter for Scramjets with Hydrocarbon Fuel," (AIAA) 2003-6987 in 12th AIAA International Space Planes and Hypersonic Systems and Technologies Conference, Norfolk, VA, 2003.

42. Cross, M.A., Operational Characteristics of a Plasma Torch for Supersonic Combustion Applications with Simulated Cracked JP-7 Feedstock, M.S. Thesis. Mechanical Engineering, Virginia Tech, 2004.

43. Gallimore, S.D., A Study of Plasma Ignition Enhancement for Aeroramp Injectors in Supersonic Combustion Applications, Ph.D. Thesis. Mechanical Engineering, Virginia Tech, 2001.

44. Jacobsen, L.S., An Integrated Aerodynamic-Ramp-Injector/Plasma-Torch-Igniter for Supersonic Combustion Applications with Hydrocarbon Fuels, Ph.D. Thesis. Aerospace Engineering, Virginia Tech, 2001.

45. Mozingo, J.A., Evaluation of a Strut-Plasma Torch Combination as a Supersonic IgniterFlameholder, M.S. Thesis. Mechanical Engineering, Virginia Tech, 2004.

46. Sanders, D.D., An Investigation of Controlled Oscillations in a Plasma Torch for Combustion Enhancement, M.S. Thesis. Mechanical Engineering, Virginia Tech, 2005.

47. Stouffer, S.D., The Development and Operating Characteristics of an Improved Plasma Torch for Supersonic Combustion Applications, M.S. Thesis. Mechanical Engineering, Virginia Tech, 1989.

48. Wagner, T.C., Ignition and Flameholding in Supersonic Flow by Injection of Dissociated Hydrogen, Ph.D. Thesis. Mechanical Engineering, Virginia Tech, 1987.

49. Jacobsen, L.S., Carter, C.D., Jackson, T.A., and Baurle, R.A., "Toward Plasma-Assisted Ignition in Scramjets," (AIAA) 2002-0871 in 41st AIAA Aerospace Sciences Meeting and Exhibit Reno, NV, 2003.

50. Kitagawa, T., Moriwaki, A., Murakami, K., Takita, K., and Masuya, G., "Ignition Characteristics of Methane and Hydrogen Using a Plasma Torch in Supersonic Flow," Journal of Propulsion and Power, Vol. 19, Issue 5, 2003. pp. 853-858.

51. Takita, K., Murakami, K., Nakane, H., and Masuya, G., "A Novel Design of a Plasma Jet Torch Igniter in a Scramjet Combustor," in 30th (International) Symposium on Combustion: 2005. The Combustion Institute, pp. 2843-2849.

52. Arnold, S.T., Morris, R.A., and Viggiano, A.A., "Reactions of O- with Various Alkanes: Competition Between Hydrogen Abstraction and Reactive Detachment," Journal of Physical Chemistry, Vol. 102, 1998. pp. 1345-1348. 
53. Arnold, S.T., Viggiano, A.A., and Morris, R.A., "Rate Constants and Branching Ratios for the Reactions of Selected Atmospheric Primary Cations with n-Octane and Isooctane (2,2,4Trimethylpentane)," Journal of Physical Chemistry, Vol. 101, 1997. pp. 9351-9358.

54. Williams, S., Midey, A.J., Arnold, S.T., Bench, P.M., Viggiano, A.A., Morris, R.A., Maurice, L.Q., and Carter, C.D., "Progress on the Investigation of the Effects of Ionization on Hydrocarbon/Air Combustion Chemistry," (AIAA) 1999-4907 in 9th International Space Planes and Hypersonic Systems and Technologies Conference, Norfolk, VA, 1999.

55. Suyari, M. and Lefebvre, A.H., "Drop-Size Measurements in Air-Assist Swirl Atomizer Sprays," (The Combustion Institute) in Central States Combustion Institute Meeting, NASALewis, Cleveland, OH, 1986.

56. Elkotb, M.M., Mahdy, M.A.E.-S., and Montaser, M.E., "Investigation of External Mixing Air Blast Atomizers," in 2nd International Conference on Liquid Atomization and Spray Systems (ICLASS), Madison, WI, 1982. pp. 107-115.

57. Harstad, K. and Bellan, J., "Modelling Evaporation of Jet-A, JP-7, and RP-1 Drops at 1 to 15 Bars," Combustion and Flame, Vol. 137, 2004. pp. 163-177.

58. Hawthorne, W.R., Weddell, D.S., and Hottel, H.C., "Mixing and Combustion in Turbulent Gas Jets," in Third Symposium on Combustion, Flame and Explosion Phenomena: 1949.

59. Baranovsky, S.I. and Schetz, J.A., "Effect of Injection Angle on Liquid Injection," AIAA Journal, Vol. 18, Issue 6, 1980. pp. 625-629.

60. Haber, L.C., An Investigation Into the Origin, Measurement and Application of Chemiluminescent Light Emissions from Premixed Flames, M.S. Thesis. Mechanical Engineering, Virginia Tech, 2000.

61. Sandrowitz, A.K., Cooke, J.M., and Glumac, N.G., "Flame Emission Spectroscopy for Equivalence Ratio Monitoring," Applied Spectroscopy, Vol. 52, Issue 5, 1998. pp. 658-662.

62. Gaydon, A.G., The Spectroscopy of Flames. 2 ed. 1974, London: Chapman and Hall. 412.

63. Gilbert, P.T., Nonmetals, in Analytical Flame Spectroscopy, R. Mavrodineanu, Editor. 1970, MacMillan. p. 772.

64. Pearse, R.W.B. and Gaydon, A.G., The Identification of Molecular Spectra. 4 ed. 1976, London: Champman and Hall. 407.

65. Dandy, D.S. and Vosen, S.R., "Numerical and Experimental Studies of Hydroxyl Radical Chemiluminescence in Methane-Air Flames," Combustion Science and Technology, Vol. 82, 1992. pp. 131-150.

66. Lefebvre, A.W., Gas Turbine Combustion. McGraw-Hill Series in Energy, Combustion, and Environment, ed. N. Chigier. 1983: Hemisphere Pub. Corp. 531. 
67. Smith, M.W., Jarrett, O., Antcliff, R.R., Northam, G.B., Cutler, A.D., and Taylor, D.J., "Coherent Anti-Stokes Raman Spectroscopy Temperature Measurements in a HydrogenFueled Supersonic Combuster," Journal of Propulsion and Power, Vol. 9, Issue 2, 1993. pp. 163-168.

68. Tedder, S.A., O'Byrne, S., Danehy, P.M., and Cutler, A.D., "CARS Temperature and Species Concentration Measurements in a Supersonic Combustor with Normal Injection," (AIAA) 2005-616 in 43rd AIAA Aerospace Sciences Meeting and Exhibit, Reno, NV, 2005. 


\section{Appendix A: \\ Photographic Techniques Used in Supersonic Testing}

\section{Direct Shadowgraph}

Comments: The direct or spark shadowgraph as described schematically in Figure A. 1 was used initially as an indicator of penetration and atomization of the liquid fuel. No spark (instantaneous) shadowgraph results were included in the body of the report, although Figure 5.3 shows a time-averaged direct shadowgraph. An example of a direct shadowgraph image is shown in Figure A. 2. The direct shadowgraph was obtained by completely darkening the testing area (lights turned off; LED's covered with black tape; cracks covered, etc.), starting the experimental sequence as usual, and emitting a short "spark" of light from the nanopulser (light source) at the time of interest. The spark exposed the film, with a visible shadow remaining. The shadow was caused by the droplets and other strong changes in density, such as the shocks seen in the upperright corner. The boundary layer and a bow shock in front of the feedstock discharge are also visible.

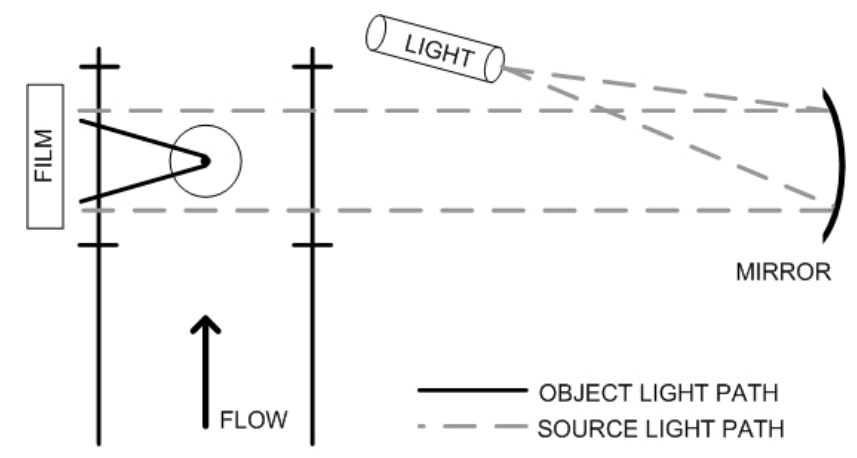

Figure A. 1: Direct Shadowgraph Experimental Setup 


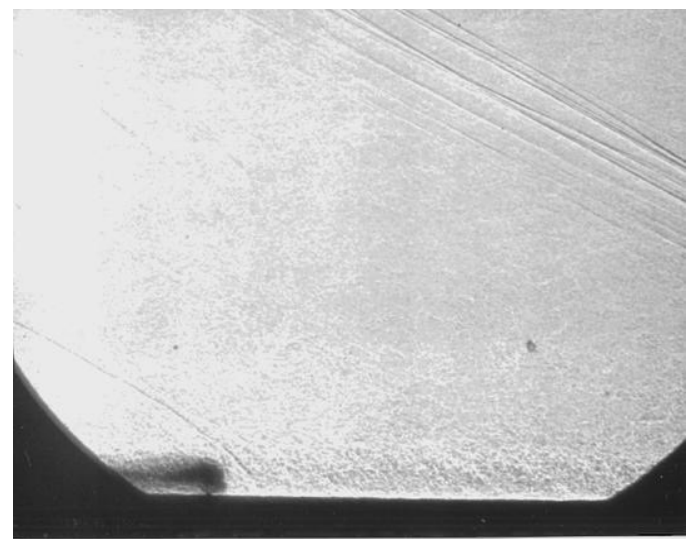

Figure A. 2: Direct Shadowgraph of Kerosene Injection

\section{Focused Shadowgraph}

Comments: The focused shadowgraph was used to obtain magnified views of the liquid injection. It is shown schematically in Figure A. 3, and examples are seen in Figure 5.2. The light source and film exposure method are the same as the direct shadowgraph. Focused shadowgraph images were typically darker than direct shadowgraph images, as the source spark travels a greater distance before reaching the film and is therefore diffused.

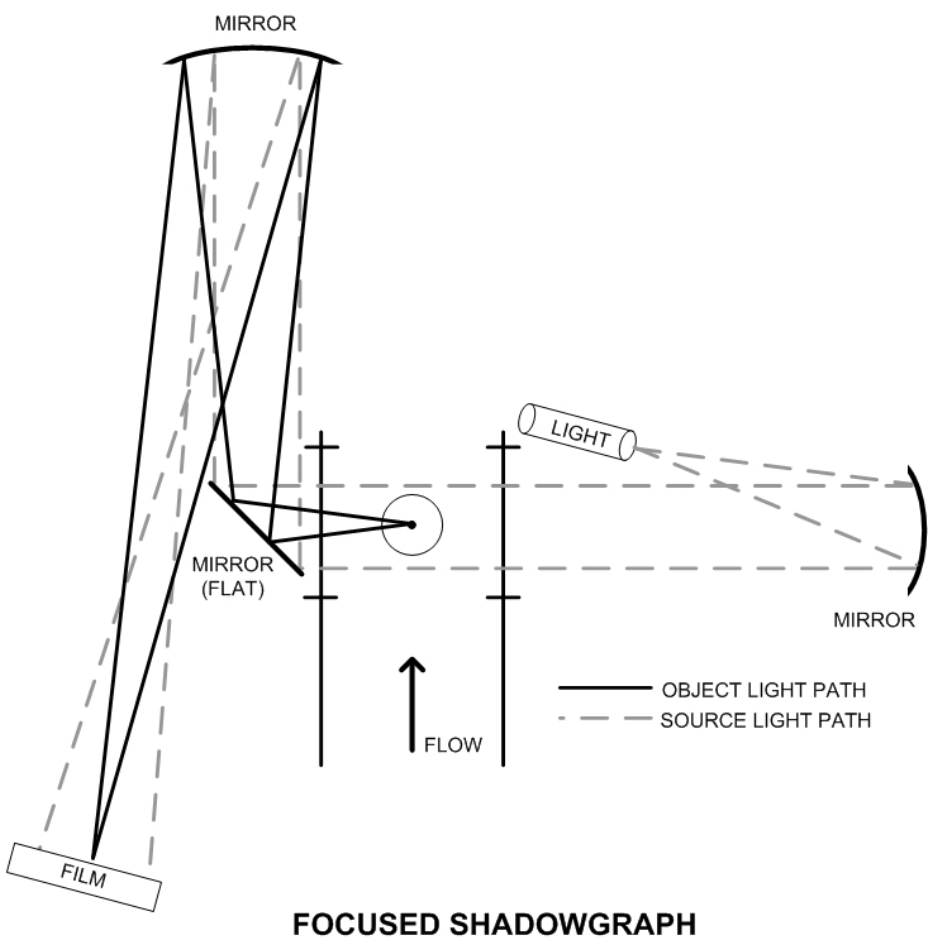

Figure A. 3: Focused Shadowgraph Experimental Setup 


\section{Schlieren (with virtual image of plasma torch superimposed)}

Comments: Schlieren photography is a method used to visualize sensitive variations in the flow field. The primary difference between Focused Shadowgraph and Schlieren images is the implementation of a knife-edge or light cutter, seen in the schematic view shown in Figure A. 4. However, for the images seen in Figure 5.7, for example, noticeable changes are seen in the experimental setup. First, a camera lens is used to focus the virtual image located behind the parabolic mirror, as opposed to the shadowgraph, which used film but not a focusing lens. Also, instead of a nanopulser, a continuous filament light source was used. The filament was oriented horizontally, and an obstruction of similar shape and direction (razor blade) was used to cut the light at its focal point. The camera must be placed behind the knife edge to capture the Schlieren effects. The camera lens focuses on the virtual image, the perceived distance of which is a function of the focal length of the parabolic mirror and the object distance (distance from the mirror to the plasma torch). Therefore, magnification is not achieved by moving further away from the light source focal point. In fact, placing the camera close behind the light source focal point provided a background light source which did not mask the light from the plasma torch. However, moving away from the focal point with the camera, the light source image was sharpened and intensified, eventually too bright to be of use. By increasing the aperture, the depth of field was narrowed, and the camera was focused on the object image, not the light source image. The ability of the Schlieren system to capture direct intensity as well as density

effects in the flow is well-illustrated in Figure A. 5. Shocks are crisp and clearly-seen, and the light emission from the plasma torch and column of water are also visible. 


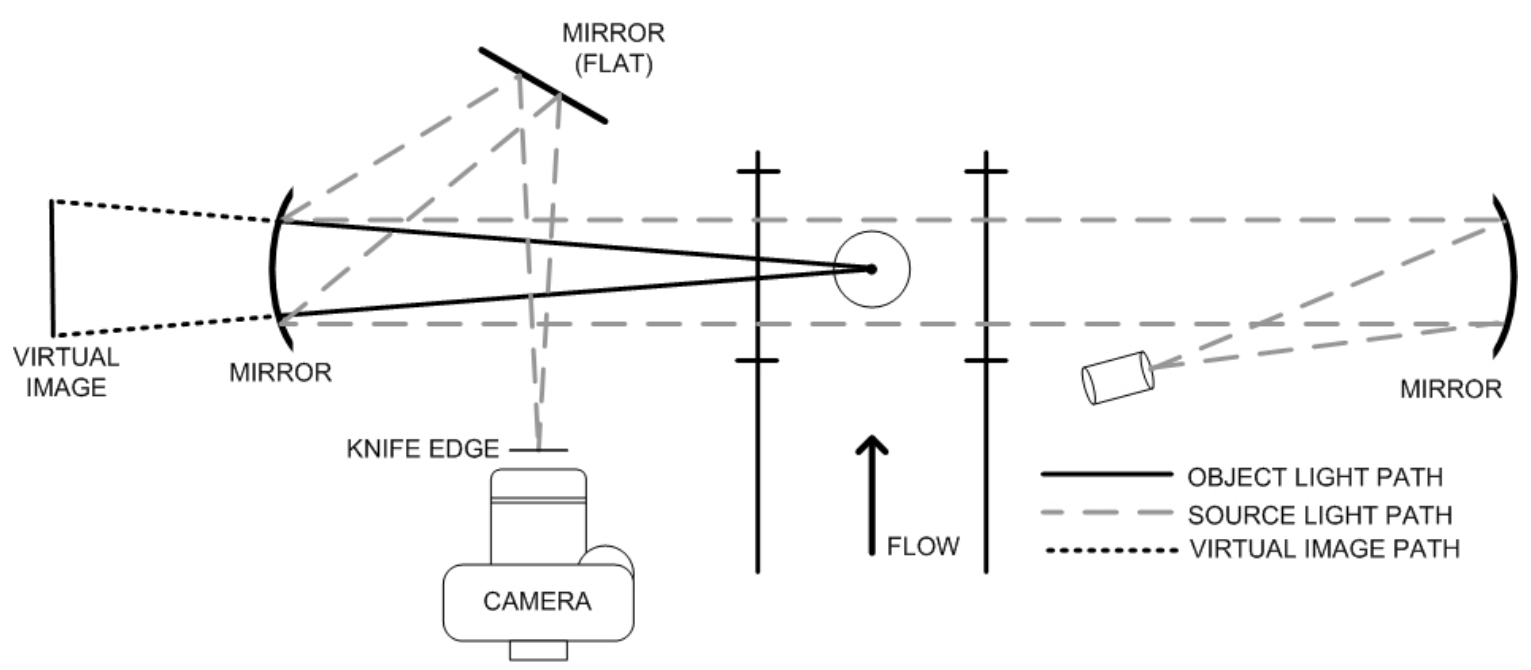

Figure A. 4: Schlieren Experimental Setup

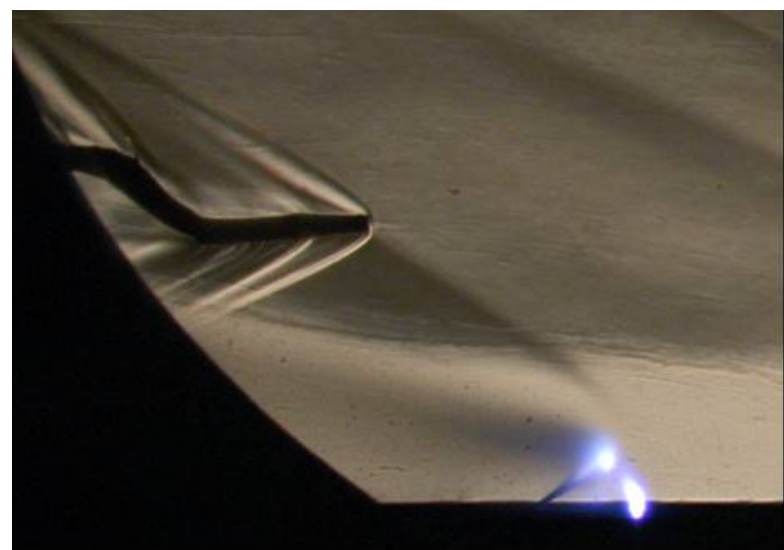

Figure A. 5: Schlieren Photograph Capturing Water Injection with Torch Operation 


\section{Appendix B: \\ Derivation of Conservation Equations for Plug-Flow Reactor (PFR)}

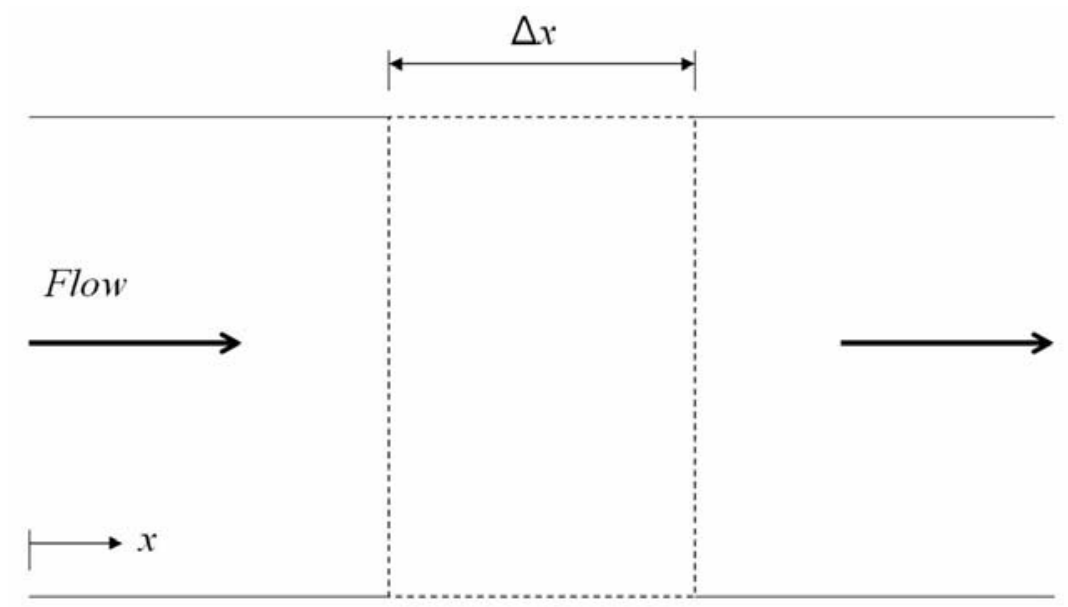

Figure B. 1: PFR Control Volume

\section{Mass Conservation}

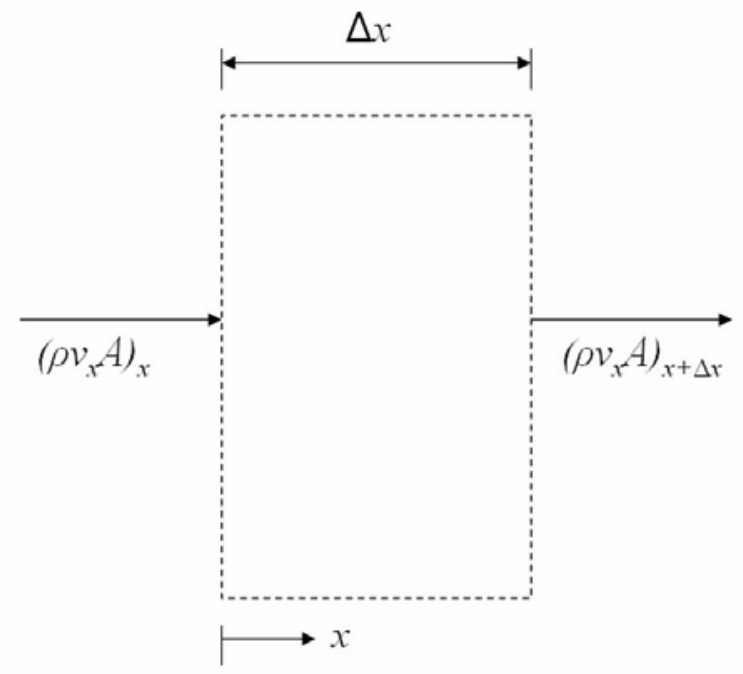

Figure B. 2: PFR Mass Conservation

$$
\begin{array}{ll}
\left(\rho v_{x} A\right)_{x}=\left(\rho v_{x} A\right)_{x+\Delta x} & \text { or } \\
\left(\rho v_{x} A\right)_{x}=\left(\rho v_{x} A\right)_{x}+\frac{d\left(\rho v_{x} A\right)}{d x} \Delta x & \text { so that }
\end{array}
$$




$$
\frac{d\left(\rho v_{x} A\right)}{d x}=0
$$

Also:

$$
\frac{d\left(\rho v_{x} A\right)}{d x}=A \frac{d\left(\rho v_{x}\right)}{d x}+\rho v_{x} \frac{d(A)}{d x}=A\left(\rho \frac{d\left(v_{x}\right)}{d x}+v_{x} \frac{d(\rho)}{d x}\right)+\rho v_{x} \frac{d(A)}{d x}=0
$$

or

$$
\begin{aligned}
& A \rho \frac{d\left(v_{x}\right)}{d x}+A v_{x} \frac{d(\rho)}{d x}+\rho v_{x} \frac{d(A)}{d x}=0 \quad \text { so } \\
& \frac{1}{v} \frac{d\left(v_{x}\right)}{d x}+\frac{1}{\rho} \frac{d(\rho)}{d x}+\frac{1}{A} \frac{d(A)}{d x}=0
\end{aligned}
$$

\section{x-Momentum Conservation}

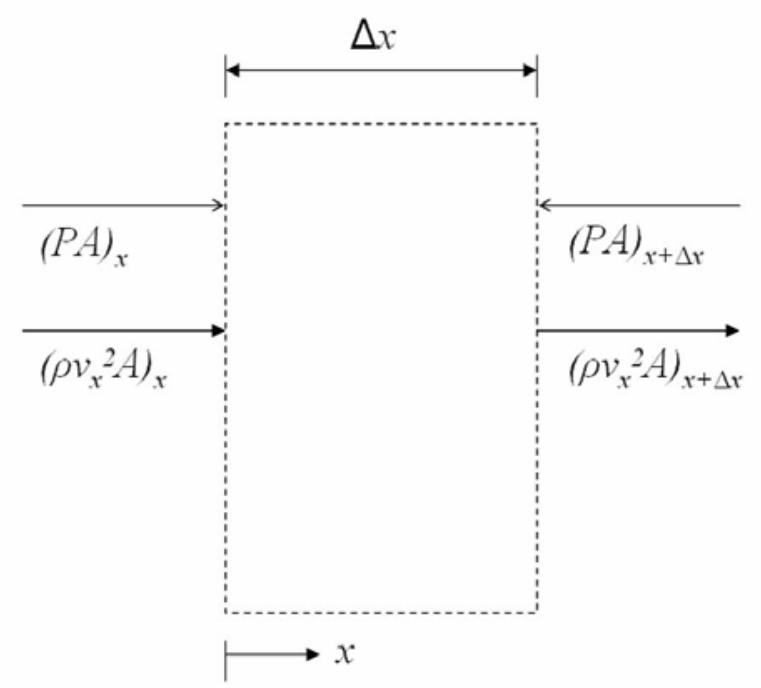

Figure B. 3: PFR x-Momentum Conservation

$$
\begin{aligned}
& (P A)_{x}-(P A)_{x+\Delta x}=\left(\rho v_{x}^{2} A\right)_{x+\Delta x}-\left(\rho v_{x}^{2} A\right)_{x} \quad \text { or } \\
& (P A)_{x}-(P A)_{x}-\frac{d(P A)}{d x} \Delta x=\left(\rho v_{x}^{2} A\right)_{x}+\frac{d\left(\rho v_{x}^{2} A\right)}{d x} \Delta x-\left(\rho v_{x}^{2} A\right)_{x}
\end{aligned}
$$

or

$$
-\frac{d(P A)}{d x} \Delta x=\frac{d\left(\rho v_{x}^{2} A\right)}{d x} \Delta x
$$




$$
\begin{aligned}
& \frac{d(P A)}{d x} \Delta x+\frac{d\left(\rho v_{x}^{2} A\right)}{d x} \Delta x=0 \\
& \frac{d(P A)}{d x}+\frac{d\left(\rho v_{x}^{2} A\right)}{d x}=0 \\
& A \frac{d(P)}{d x}+P \frac{d(A)}{d x}+A \frac{d\left(\rho v_{x}^{2}\right)}{d x}+\rho v_{x}^{2} \frac{d(A)}{d x}=0 \\
& \text { for } \frac{d A}{d x}=0 \text { : } \\
& A \frac{d(P)}{d x}+A \frac{d\left(\rho v_{x}^{2}\right)}{d x}=0 \\
& \frac{d(P)}{d x}+\frac{d\left(\rho v_{x}^{2}\right)}{d x}=0 \\
& \frac{d(P)}{d x}+\rho v_{x} \frac{d\left(v_{x}\right)}{d x}+v_{x} \frac{d\left(\rho v_{x}\right)}{d x}=0 \\
& \frac{d\left(\rho v_{x} A\right)}{d x}=A \frac{d\left(\rho v_{x}\right)}{d x}+\rho v_{x} \frac{d(A)}{d x}=A \frac{d\left(\rho v_{x}\right)}{d x}=0 \\
& \text { expanding: } \\
& \text { or } \\
& \text { expanding: }
\end{aligned}
$$

so that

$$
\begin{aligned}
& \frac{d\left(\rho v_{x}\right)}{d x}=0 \\
& \frac{d(P)}{d x}+\rho v_{x} \frac{d\left(v_{x}\right)}{d x}=0
\end{aligned}
$$

\section{Energy Conservation}




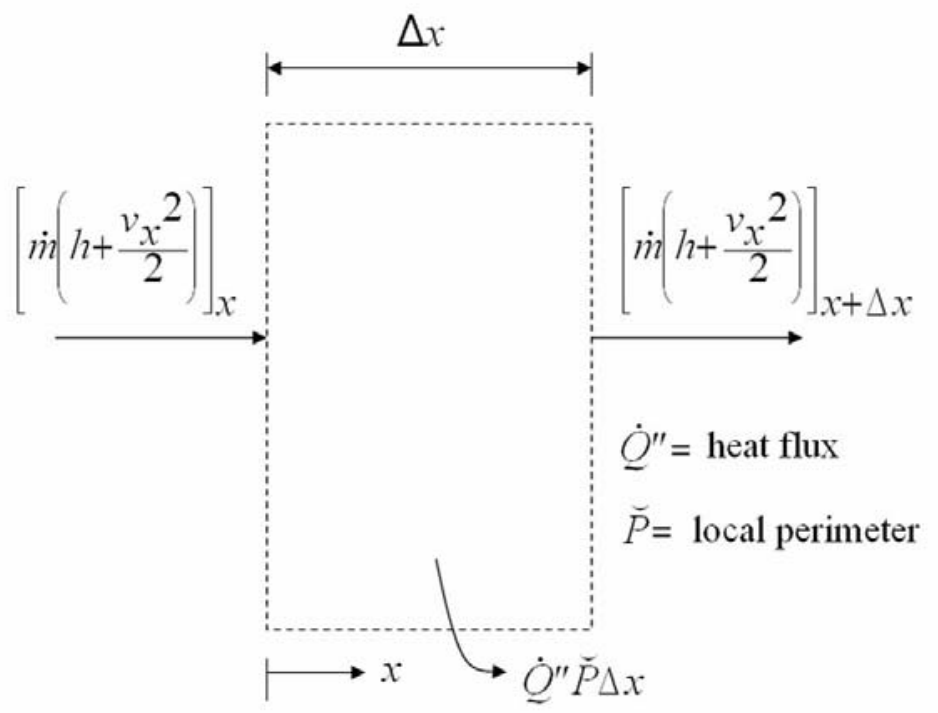

Figure B. 4: PFR Energy Conservation

$$
\begin{aligned}
& \dot{Q}_{c v}-\dot{W}_{c v}=\dot{m}\left[\left(h_{o}-h_{i}\right)+\frac{1}{2}\left(v_{o}{ }^{2}-v_{i}^{2}\right)\right] \quad \text { or } \\
& -\dot{Q}^{\prime \prime} \breve{P} \Delta x=\left[\dot{m}\left(h+\frac{v_{x}^{2}}{2}\right)\right]_{x+\Delta x}-\left[\dot{m}\left(h+\frac{v_{x}^{2}}{2}\right)\right]_{x} \quad \text { or } \\
& -\dot{Q}^{\prime \prime} \breve{P} \Delta x=\left[\dot{m}\left(h+\frac{v_{x}^{2}}{2}\right)\right]_{x}+\frac{d\left(\dot{m}\left[\left(h+\frac{v_{x}^{2}}{2}\right)\right]\right)}{d x} \Delta x-\left[\dot{m}\left(h+\frac{v_{x}^{2}}{2}\right)\right]_{x}
\end{aligned}
$$

or

- $\dot{Q}^{\prime \prime} \breve{P} \Delta x=\frac{d\left(\dot{m}\left[\left(h+\frac{v_{x}^{2}}{2}\right)\right]\right)}{d x} \Delta x \quad$ or

$-\dot{Q}^{\prime \prime} \breve{P}=\frac{d\left(\dot{m}\left[\left(h+\frac{v_{x}^{2}}{2}\right)\right]\right)}{d x} \quad$ or

$-\dot{Q}^{\prime \prime} \breve{P}=\dot{m} \frac{d\left(h+\frac{v_{x}^{2}}{2}\right)}{d x}+\left(h+\frac{v_{x}^{2}}{2}\right) \frac{d \dot{m}}{d x}=\dot{m} \frac{d\left(h+\frac{v_{x}^{2}}{2}\right)}{d x}+\left(h+\frac{v_{x}^{2}}{2}\right) \frac{d\left(\rho v_{x} A\right)}{d x}$

from (1): $\quad \frac{d\left(\rho v_{x} A\right)}{d x}=0 \quad$ so 
$-\dot{Q}^{\prime \prime} \breve{P}=\dot{m} \frac{d\left(h+\frac{v_{x}{ }^{2}}{2}\right)}{d x}$
$\frac{\dot{Q}^{\prime \prime} \breve{P}}{\dot{m}}+\frac{d\left(h+\frac{v_{x}{ }^{2}}{2}\right)}{d x}=0$

or

But

$$
\begin{array}{ll}
\frac{d\left(h+\frac{v_{x}^{2}}{2}\right)}{d x}=\frac{d(h)}{d x}+\frac{d\left(\frac{v_{x}^{2}}{2}\right)}{d x}=\frac{d(h)}{d x}+\frac{1}{2} \frac{d\left(v_{x}^{2}\right)}{d x} \text { and } \\
\frac{d\left(v_{x}^{2}\right)}{d x}=2 v_{x} \frac{d v_{x}}{d x} & \text { so } \\
\frac{\dot{Q}^{\prime \prime} \breve{P}}{\dot{m}}+\frac{d h}{d x}+v_{x} \frac{d v_{x}}{d x}=0 &
\end{array}
$$

\section{Species Conservation}

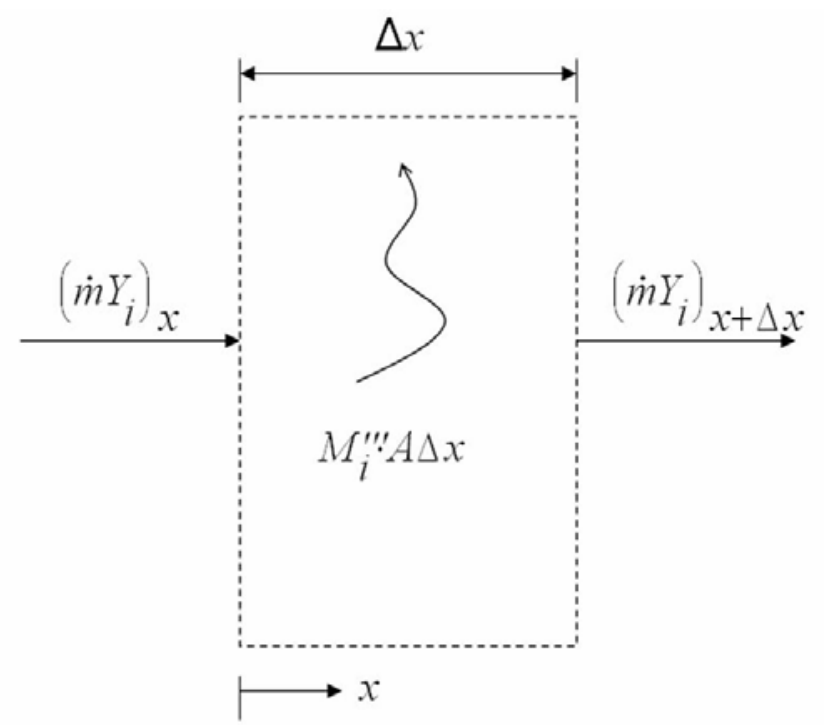

Figure B. 5: PFR Species Conservation

$$
\begin{array}{ll}
\left(\dot{m} Y_{i}\right)_{x+\Delta x}-M_{i}^{\prime \prime \prime} \cdot A \Delta x=\left(\dot{m} Y_{i}\right)_{x} & \text { or } \\
\left(\dot{m} Y_{i}\right)_{x}+\frac{d\left(\dot{m} Y_{i}\right)}{d x} \Delta x-M_{i}^{\prime \prime \prime} \cdot A \Delta x=\left(\dot{m} Y_{i}\right)_{x} & \text { or }
\end{array}
$$




$$
\begin{aligned}
& \frac{d\left(\dot{m} Y_{i}\right)}{d x} \Delta x=M_{i}^{\prime \prime \prime} \cdot A \Delta x \\
& \text { or } \\
& \frac{d\left(\dot{m} Y_{i}\right)}{d x}=M_{i}^{\prime \prime \prime} \cdot A \\
& \dot{m} \frac{d\left(Y_{i}\right)}{d x}+Y_{i} \frac{d(\dot{m})}{d x}=\dot{m} \frac{d\left(Y_{i}\right)}{d x}+Y_{i} \frac{d\left(\rho v_{x} A\right)}{d x}=M_{i}^{\prime \prime \prime} \cdot A \\
& \text { from (1): } \quad \frac{d\left(\rho v_{x} A\right)}{d x}=0 \\
& \dot{m} \frac{d\left(Y_{i}\right)}{d x}-M_{i}^{\prime \prime \prime} A=0 \\
& \frac{d\left(Y_{i}\right)}{d x}-\frac{M_{i}^{\prime \prime \prime} A}{\dot{m}}=0 \\
& \dot{\omega}_{i} M W_{i}=M_{i}^{\prime \prime \prime} \\
& \dot{m}=\rho v_{x} A \\
& \frac{d\left(Y_{i}\right)}{d x}-\frac{\dot{\omega}_{i} M W_{i} A}{\rho v_{x} A}=0 \\
& \frac{d\left(Y_{i}\right)}{d x}-\frac{\dot{\omega}_{i} M W_{i}}{\rho v_{x}}=0 \\
& \text { SO } \\
& \text { or } \\
& \text { Since } \\
& \text { and } \\
& \text { then } \\
& \text { or } \\
& \text { expanding: }
\end{aligned}
$$

r




\section{Vita}

Matthew Billingsley, the third of five children born to F. Owen and Margaret Billingsley, grew up in Lewistown, MT. After moving north, he graduated from Havre High School in 1998. He attended Montana Tech of the University of Montana in Butte, MT, initially majoring in Petroleum Engineering, then switching to General Engineering with a Mechanical option. Upon graduation in December 2002, he skied for the rest of the winter while pondering the next chapter in his educational or professional career. He decided to attend Virginia Tech and pursue his M.S. in Mechanical Engineering, due to the reputation of the school's aerospace propulsion program. Upon completion of his degree, he will begin work with the Combustion Group of the Aerophysics Branch, a division of the Air Force Research Lab's Space and Missile Propulsion Directorate, located at Edwards Air Force Base, CA. 